NASA Contractor Report 3548

\title{
An Assessment of Alternate Thermal Protection Systems for the Space Shuttle Orbiter
}

Volume I - Executive Summary

D. Hays 


\section{An Assessment of Alternate Thermal Protection Systems for the Space Shuttle Orbiter}

Volume I - Executive Summary

D. Hays

Rockwell International Corporation

Downey, California

Prepared for

Langley Research Center

under Contract NAS1-16302

\section{N/SN}

National Aeronautics

and Space Administration

Scientific and Technical

Information Branch 


\section{Page intentionally left blank}

Page intentionally left blank 


\section{FOREWORD}

This report describes the work performed between Ju1y 1980, and Ju1y 1981, under Contract NAS1-16302 for NASA Langley Research Center. The NASA study manager was J. E. Harris of the Langley Projects Directorate, and the technical monitor was H. N. Kelly, Aerothermal Loads Branch, Loads and Aeroelasticity Division, Structures Directorate.

The program was managed by E. M. Repic and D. Hays. Major contributions were made to the program by R. M. Hayes, J. P. King, D. U. McBride, I. A. Hunt, and R. L. Figard of Rockwell, and G. B. Whisenhunt and D. M. While of Vought Corporation. Contributions were also made by R. M. Martinez of Rohr Industries, E. L. Foster of Battelle Columbus Labs, and $\mathrm{H}$. Thibault of General Electric.

The report is submitted in two volumes:

$$
\begin{aligned}
& \text { Volume } 1 \text { - Executive Summary } \\
& \text { Volume } 2 \text { - Data Transmittal }
\end{aligned}
$$

Use of trade names or names of manufacturers in this report does not constitute an official endorsement of such products or manufacturers, either expressed or implied, by the National Aeronautics and Space Administration. 


\section{Page intentionally left blank}

Page intentionally left blank 
CONTENTS

Page

SUMMARY

INTRODUCTION

OBJECTIVE 1: CANDIDATE SYSTEMS DESIGN, EVALUATION, AND SELECTION • • 7

Design Environments • • • • • • • • • • • • • . • . 7

Design Criteria and Guidelines . . . . . . . . . . . . 17

Design Guidelines • • • • • • • • • • • • • • . 18

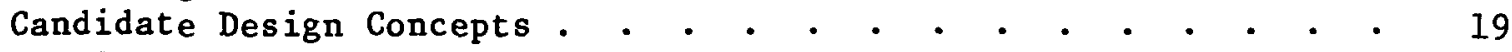

Prepackaged Concepts . . . . . . . . . . . . . . 421

Titanium Multiwall Concept . . . . . . . . . . . 21

Bimetallic Sandwich . • . . . . . . • • . . . 21

Stand-Off Concepts . . . • . • • • • . • . . . . 25

Superalloy Stand-Off Concepts . . • . . • . . . . 25

High Temperature Stand-Off Concepts . . . . . . . . 25

Manufacturing Considerations . • . • . • • . . • . 27

Candidate Systems Definition . - . . . • . • . . . . . 29

Orbiter Impacts • • • • • • • • • •

Merit Function Evaluation . • . . - . • . . . . . . . 32

System Selection. . . . . . . . . . . . . . . . . .

OBJECTIVE 2: TECHNOLOGY REQUIREMENTS - • • • • • • • • • • • . 43

Research and Development Recommendations . . . . . . . . . 45

Systems R\&D Recommendations . . . . . . . . . . . . 45

Concept Specific R\&D Recommendations • . • • • . • . . . 47

Priority Assignment of R\&D Recommendations . . . . . . . . 47

Orbiter Experiments (OEX) Applications . . . . . . . . . 48

OBJECTIVE 3: PROGRAM PLANS, COSTS, AND SCHEDULES • • • • • • • 49

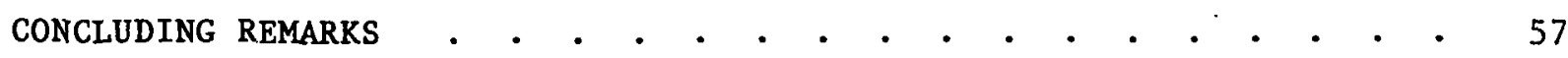

REFERENCES 
Page intentionally left blank

Page intentionally left blank 


\section{ILLUSTRATIONS}

Figure

Page

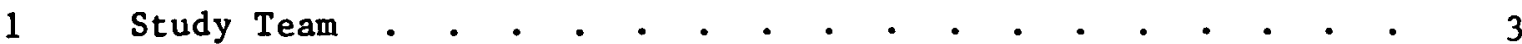

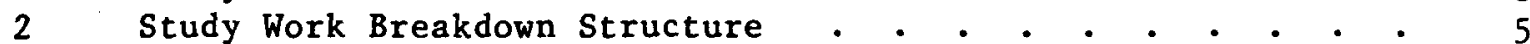

TPS Design Process

Orbiter Study Application Areas . . . . . . . . . . . 10

Orbiter Structural Design at Design Point I -

Wing (Upper) . . . . . . . . . . • . • . . . 10

Ascent Environment History - Design Point I . . . . . . 11

Entry Environment History - Design Point I

Orbiter Structural Design at Design Point II -

Aft Fuselage (Lower)

Ascent Environment History - Design Point II . . . . . . 12

Entry Environment History - Design Point II

Orbiter Structural Design at Design Point III -

Main Landing Gear Door

Ascent Environment History - Design Point III

Entry Environment History - Design Point III.

Orbiter Structural Design at Design Point IV -

Forward Fuselage . . . . . . . . . . . . . . 16

Ascent Environment History - Design Point IV . . . . . . 16

Entry Environment History - Design Point IV . . . . . . 17

Candidate Concepts . . . . . . . . . . . . . . . . . 20

Bayonet Attachment Scheme - Prepackaged Concepts . - . . 22

Titanium Multiwall . . . . . • . . • . . . . . 22

Temperature Histories - Titanium Multiwall . . . . . . 23

Superalloy Bimetallic Sandwich . . . . . . . . . . 23

Refractory Waffle Bimetallic Sandwich . . . . . . . . 24

Superalloy Isogrid Stand-Off . . . . . . . . . . . 26

Superalloy Honeycomb Stand-Off • • . . • . . • . . 26

Superalloy Corrugated Stand-Off . • • • • • • • • • 27

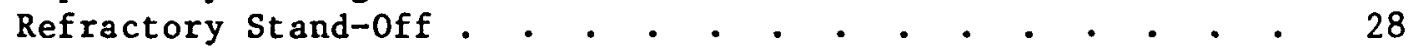

Carbon-Carbon Stand-off . . . . . . . . . . • . . 28 
37 Flow of Events Required to Qualify an Alternate TPS for the Orbiter . . . . . . . . . . . . . . . 43

38 Advanced TPS ROM Master Schedule . . . . . . . . . . 50

39 Program Funding Requirements - Best ATPS . . . . . . . 55

40 ATPS Only (No STS Valuation) ROM Total Cost, DDT\&E . . . . 55

\section{TABLES}

Table

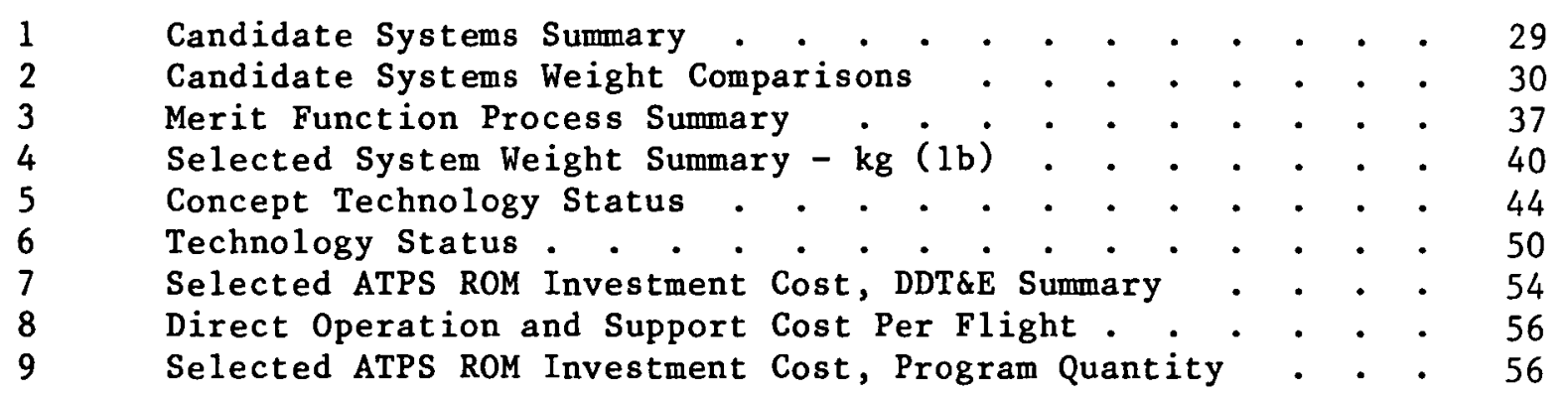




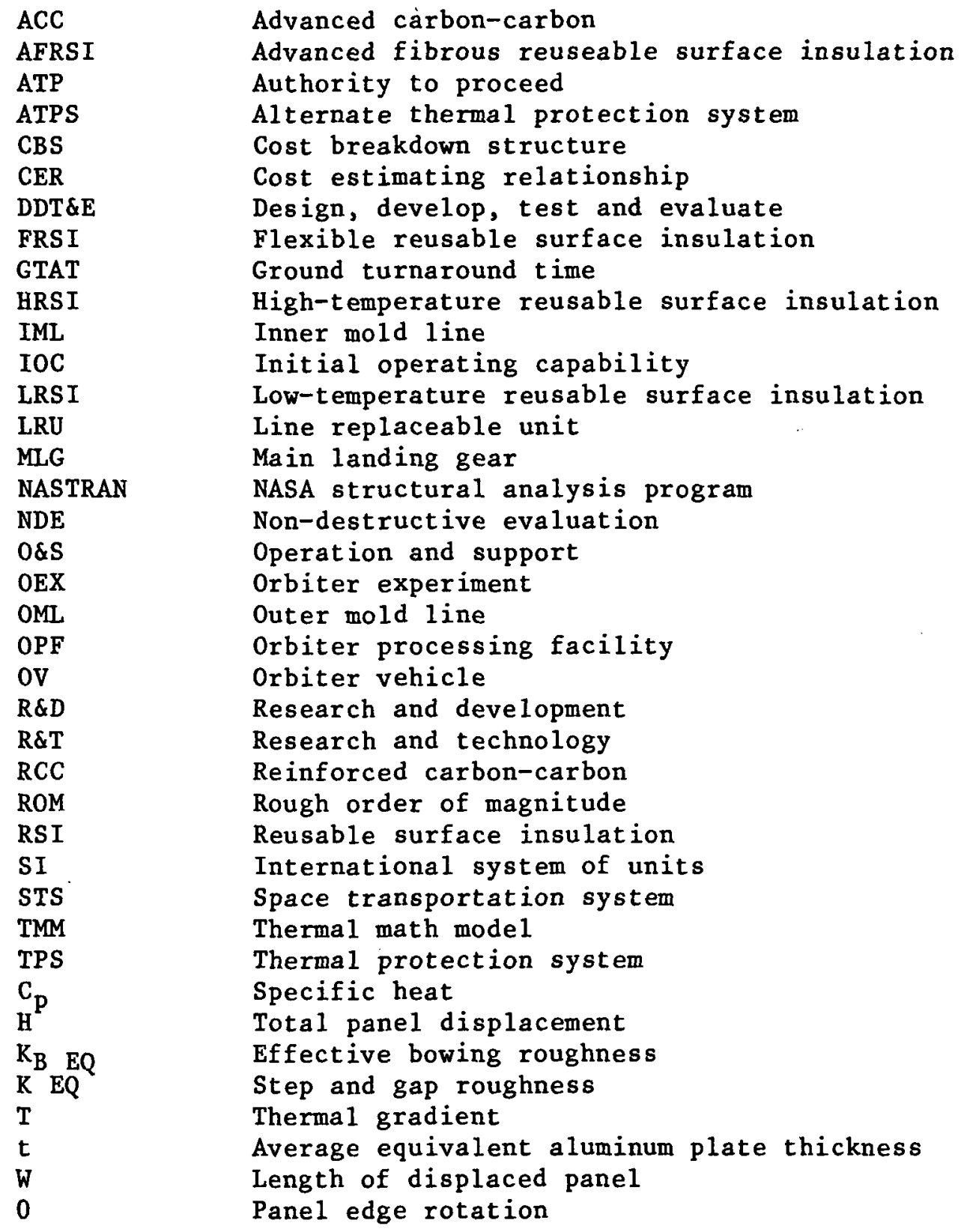




\section{SUMMARY}

The present space Shuttle orbiter represents a significant step towards achieving the long-range goal of low-cost, routine, near-Earth space operations. The ceramic reuseable surface insulation (RSI) thermal protection system (TPS) is a key element of the orbiter and was chosen in 1972 after an extensive evaluation of many competitive approaches. Alternate thermal protection system concepts have been studied since the initial selection of RSI, with the goals of reduced life cycle costs and improved operational characteristics.

A study was undertaken to assess the potential benefits of the application of those alternate TPS concepts to the Space Shuttle orbiter, accounting for the technology advances since the initial selection of RSI. In keeping with a study goal emphasizing improved TPS durability, only metallics, ablator, and carbon-carbon concepts were considered.

Integrated concept/orbiter point designs were generated and analyzed on the basis of Shuttle design environments and criteria. A merit function evaluation methodology based on mission impact, life cycle cost, and risk was developed to compare the candidate concepts and to identify the "best" alternate. Voids and deficiencies in the technology were identified, along with recommended activities to overcome them. Finally, programmatic plans, including RoM costs and schedules, were developed for all activities required to bring the selected alternate system up to operational readiness.

The "best" alternate thermal protection system considering metallics, ablators, and carbon-carbon concepts is a hybrid configuration consisting of prepackaged metallic concepts for application in the $589 \mathrm{~K}\left(700^{\circ} \mathrm{F}\right)$ to $1255^{\mathrm{K}}\left(1800^{\circ} \mathrm{F}\right)$ surface temperature areas, and a carbon-carbon stand-off concept for areas where temperatures are above $1255 \mathrm{~K}\left(1800^{\circ} \mathrm{F}\right)$. The estimated total installed investment cost for a fleet of five vehicles is approximately 425 million dollars. Detailed programmatic analyses reveal that the availability of this system is approximately five years from authority to proceed (ATP). 
Page intentionally left blank

Page intentionally left blank 


\section{IRTRODOCTIOR}

The basic objectives of this study are:

- To define the "best" alternate thermal protection system (ATPS) for application to the space shuttle orbiter, considering metallic, ablators, and carbon-carbon concepts.

- To define the technology requirements to bring the selected TPS up to operational readiness.

- To prepare plans, schedules, and cost estimates for the required research and development ( $R \& D)$, design, certification, fabrication, installation, and maintenance of the selected TPS.

The study was performed by an industry team (Figure 1) in order to ensure objective consideration of the latest advances in TPS technology. Rohr Industries (metallic concepts), Vought Corporation (carbon-carbon concepts), and General Electric (ablator concepts) provided concept designs; supporting analyses; and fabrication, schedule, and cost estimating data. Battelle Columbus Laboratories provided materials technology data and assisted Rockwell in developing merit functions for concept screening and selection.

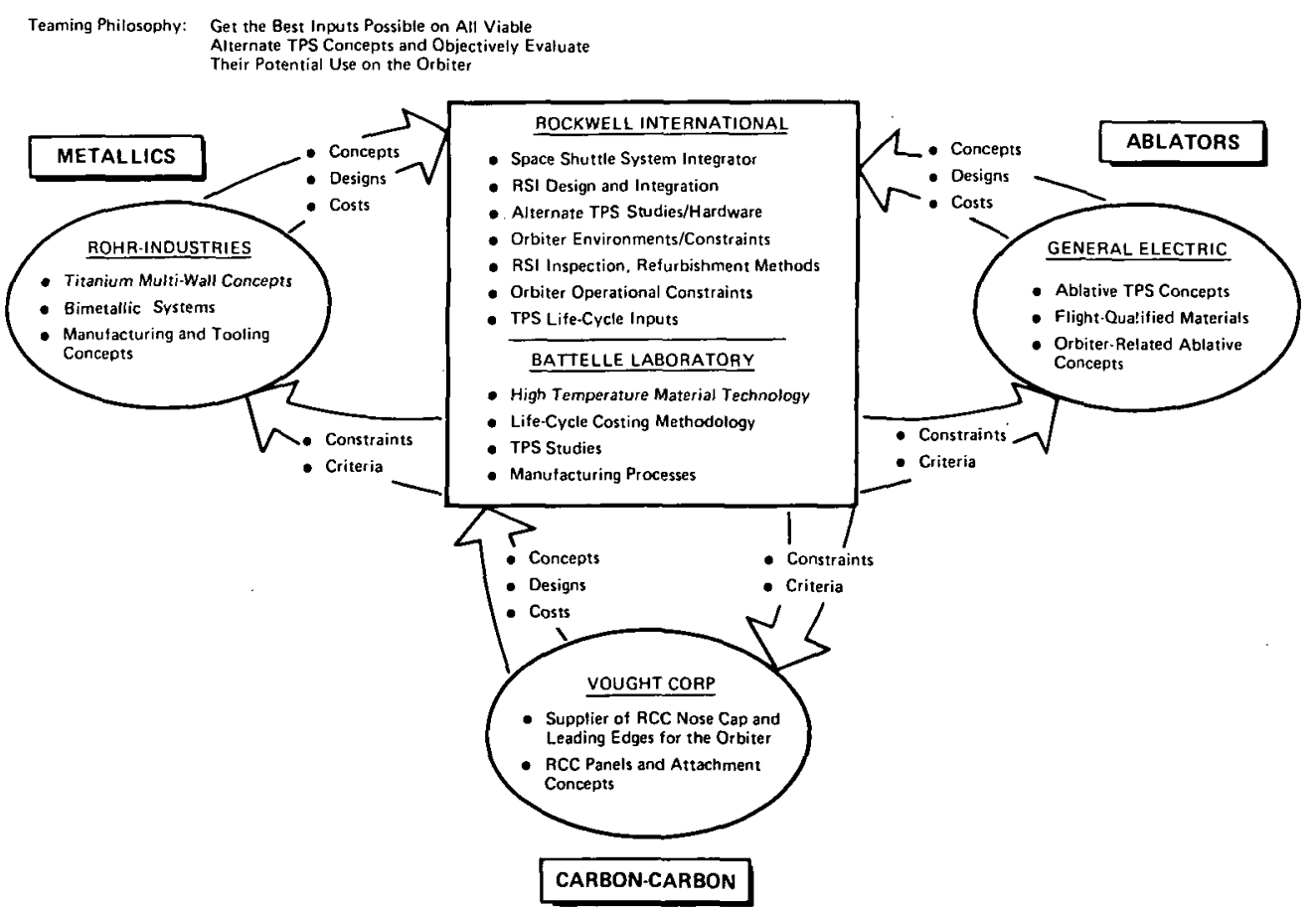

Figure 1. Study Team 
Several key issues are involved in meeting the three study objectives.

The first objective requires accumulation of a realistic data base and development of a methodology. A consistent set of design environments, design criteria, and operational constraints was established to be used for the engineering evaluation of all concepts. The metallic, ablator, and carbon-carbon concepts considered are selected from literature sources and the industry experience of the team. The concepts considered are not, for the most part, new designs; they had been studied previously for application as reentry vehicle TPS. Finally, meeting the first objective requires development of a set of merit functions by which the concepts/systems can be evaluated to define the "best" ATPS.

The second objective requires a definition of the technology status of the concepts and identification of required activities to overcome any voids or deficiencies in the technology.

The key issues in meeting the third objective relate to the validity of the manufacturing cost estimates and the methodology and data base by which they are parametrically expanded to obtain rough-order-magnitude (ROM) costs, schedules, and programmatic plans.

Only metallic, ablator, and carbon-carbon TPS concepts are considered.

This is consistent with a study goal of defining a more durable TPS for the orbiter. Applications of the concepts are limited to areas of the vehicle currently protected by ceramic tiles. Areas currently protected by blanket insulation, hot structure, leading edges, and nose cap are not considered. Advanced ceramic materials and blanket-type insulations currently being developed in direct support of the shuttle program were excluded from this study.

The study is divided into three major tasks. Figure 2 depicts the work breakdown structure of the study and summarizes the objectives of each task.

Task 1 involves selection of the study data base, identification of potential candidate concepts, identification of the critical technologies involved, and a preliminary screening to select several promising candidates for detailed evaluation in Task 2 .

Task 2 is centered around detailed evaluation of the concepts and systems. This includes engineering design and analyses, technology status definition, orbiter impacts definition, merit function development for evaluations, and selection of the best system or systems to be carried into Task 3 .

In Task 3, recommended $R \& D$ programs to overcome the voids and deficiencies in the critical technologies of the selected system are defined along with program plans, including ROM cost and schedule estimates, to bring the TPS to operational readiness.

Data reported herein are presented in both the International System of Units (SI) and customary units and are clearly marked. All computations were performed in customary units. 
The remainder of this report is organized by study objective: First, the Shuttle environments that form the study data base, the design criteria, the concept designs and analytical results, ATPS configurations, and merit function evaluation results leading to selection of the "best" ATPS are presented. Second, technology voids and deficiencies are identified along with recommended activities to bring the selected ATPS up to operational readiness. Final1y, programmatic plans, including cost and schedule estimates for the required activities, are identified.

TASK 1 - ESTABLISH STUDY DATA BASE AND BASELINE TPS CONCEPTS
TASK 2 - DETAILED EVALUATION OF ALTERNATE CONCEPTS
TASK 3 - RECOMMENDATIONS AND DOCUMENTATION
- Orbiter Environment/Constraints

- Definition of Critical Technology and Constraints

- Operational Constraints

- Design Criteria and Guidelines

- Metallic TPS Concepts

- Ablator TPS Concepts

- Carbon-Carbon TPS Concepts

- Selected Candidate Concepts
- Candidate Concept Designs

- Structural Layouts

- Aero-Thermal Analysis

- Orbiter Structural Impacts

- Orbiter Operational Impacts

- Technology Status

- Merit Function Development

- Concept/System Evaluations

- Selected "Best" System
- R\&D Planning

- OEX Program Plan

- Certification

- ROM Cost Estimates

- Program Planning

Figure 2. Study Work Breakdown Structure 


\section{Page intentionally left blank}

Page intentionally left blank 


\section{OBJECTIVE 1: CANDIDATE SYSTEMS DESIGN, BVALUATION, AND SELECTION}

\section{DESIGN ENVIRONMENTS}

The orbiter environment data used for al1 engineering analyses in the study come from the Shuttle Design Data Books listed below:

1. Orbiter Vehicle End Item Specification for the Space Shuttle System, Space Systems Group, Rockwe11 International Corporation, MJ070-0001-1B (January 15, 1976).

2. Orbiter Master Dimensions Specification, Space Systems Group, Rockwe11 International Corporation, MD-V70.

3. Ascent Aerodynamic Heating Data Book, Space Systems Group, Rockwel1 International Corporation, SD73-SH-0181 Rev B (October, 1978).

4. Entry Aerodynamic Heating Data Book, Space Systems Group, Rockwel1 International Corporation, SD73-SH-0184 Rev C (October, 1978).

5. Structura 1 Design Loads Data Book, Space Systems Group, Rockwe11 International Corporation, SD73-SH-0069 Vo1. 2D (May, 1979).

6. Acoustics and Shock Data Book, Space Systems Group, Rockwell International Corporation, SD74-SH-0082 Rev A (December, 1976) and Addendums 1 and 2 (October 15, 1977).

7. Environmental Requirements and Test Criteria for the Orbiter Vehicle, Space Systems Group, Rockwell International Corporation, MF0004-014 Rev C (March 15, 1978).

8. Airloads Design Data Book, Space Systems Group, Rockwell International Corporation, SD72-SH-0060-3G (March 2, 1979).

9. Thermodynamic Design Data Book, Space Systems Group, Rockwell International Corporation, SD73-SH-0226 Vo1. 2C, 3D, 5C.

10. Structural Design Loads Data Book--Orbiter TPS Loads, Space Systems Group, Rockwel1 International Corporation, SD73-SH-0069 Vo1.9 Chg. 14 (August, 1980) and Vol. 10 Rev C.

These documents contain the detailed design specifications, aerodynamic, heating, acoustic, and structural loads data for the orbiter TPS design mission (Trajectory 14414.1C). 
The orbiter entry environment is the major determinant of the TPS thermal design. The design evolves from the heating environments that determine the material/concept application areas and TPS insulation requirements (Figure 3 ). Concept structural requirements are determined by aerodynamic shocks and acoustic environments, which are generally most severe during lift-off and ascent.

Since detailed design of an ATPS for the entire orbiter was beyond the scope of this study, four areas were selected that were representative of much larger areas (acreage) having similar expected surface temperature ranges on the orbiter. Area $I$ is representative of acreage where surface temperatures are nominally $644 \mathrm{~K}$ to $811 \mathrm{~K}\left(700^{\circ} \mathrm{F}\right.$ to $\left.1000^{\circ} \mathrm{F}\right)$. Area II is representative of the range between $811 \mathrm{~K}$ and $1144 \mathrm{~K}\left(1000^{\circ} \mathrm{F}\right.$ to $\left.1600^{\circ} \mathrm{F}\right)$. Area III covers the range from $1144 \mathrm{~K}$ to $1366 \mathrm{~K}\left(1600^{\circ} \mathrm{F}\right.$ to $\left.2000^{\circ} \mathrm{F}\right)$, and Area IV covers $1366 \mathrm{~K}$ to $1755 \mathrm{~K}$ $\left(2000^{\circ} \mathrm{F}\right.$ to $\left.2700^{\circ} \mathrm{F}\right)$. Figure 4 depicts the orbiter and the point areas selected for concept design. Thermally defined body points were chosen as being the centroid of the area of interest, and orbiter baseline data were accumulated for those body points.

Area I (Figure 4) is located on the upper outboard wing surface, a zone subjected to only moderate heating, but crucial to aerodynamic characteristics, particularly at subsonic speeds. The primary structure is mildly contoured in Area I (Figure 5) and consists of thin sheet aluminum skin over stringers. This zone experiences re-entry surface temperatures approaching $811 \mathrm{~K}\left(1000^{\circ} \mathrm{F}\right)$, which is also characteristic of the mid and forward fuselage sides and portions of the vertical stabilizer.

The current orbiter baseline TPS design in this area utilizes low-temperature reusable surface insulation (LRSI) tiles, which are LI-900 ceramic material with a white ceramic oxide coating that provides low radiation absorption and high emissivity. Interfaces in Area I include flexible reusable surface insulation (FRSI) in the low temperature regime (under $644 \mathrm{~K}$ ) and candidate ATPS concepts for Area II.

The ascent environment for the body point in Area $I$ is shown in Figure 6 . Pressure loads on the TPS are moderate, with the peak acoustic loading immediately at lift-off, followed by coincident peaks in aero-acoustic shock pressure shortly after launch. The rate of surface temperature increase is moderate, caused by a combination of plume and aerodynamic heating.

Area I surface temperature profiles for the entry phase are shown in Figure 7 . Heating occurs from undersurface airflow spilling over the leading edge and tip of the wing. Shock pressure peaks late in the entry time profile, when the TPS is essentially cool.

Area II (Figure 4) is located on the lower surface of the aft fuselage, just forward of the body flap. Moderately high heating occurs in Area II, which is representative of transition zones on the sides of the forward and aft fuselage, portions of the upper wing surface, and parts of the vertical stabilizer. The primary structure moldline is nearly flat and consists of integrally stiffened waffle skins (Figure 8). 

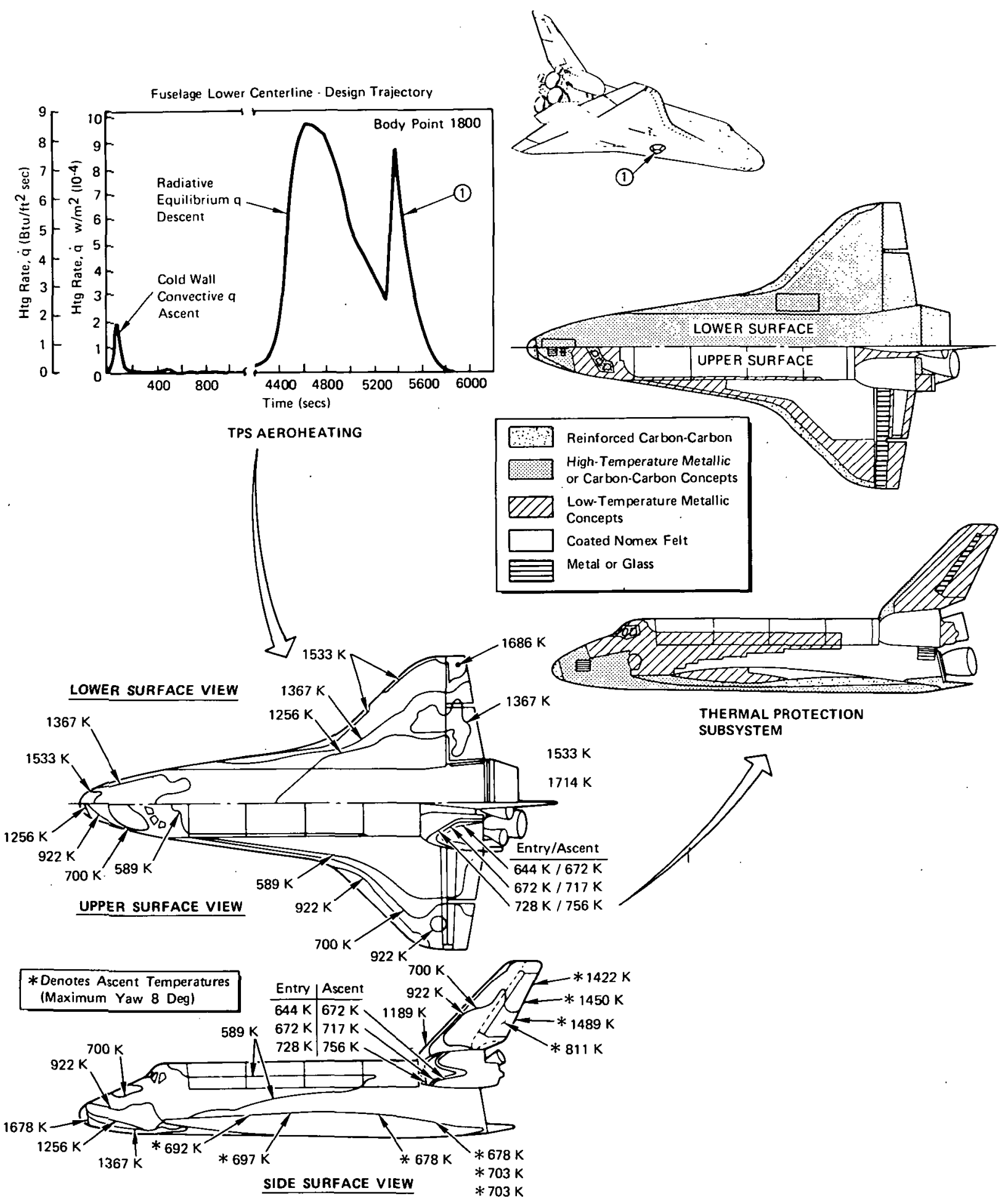

ORBITER ISOTHERMS

Figure 3. TPS Design Process 


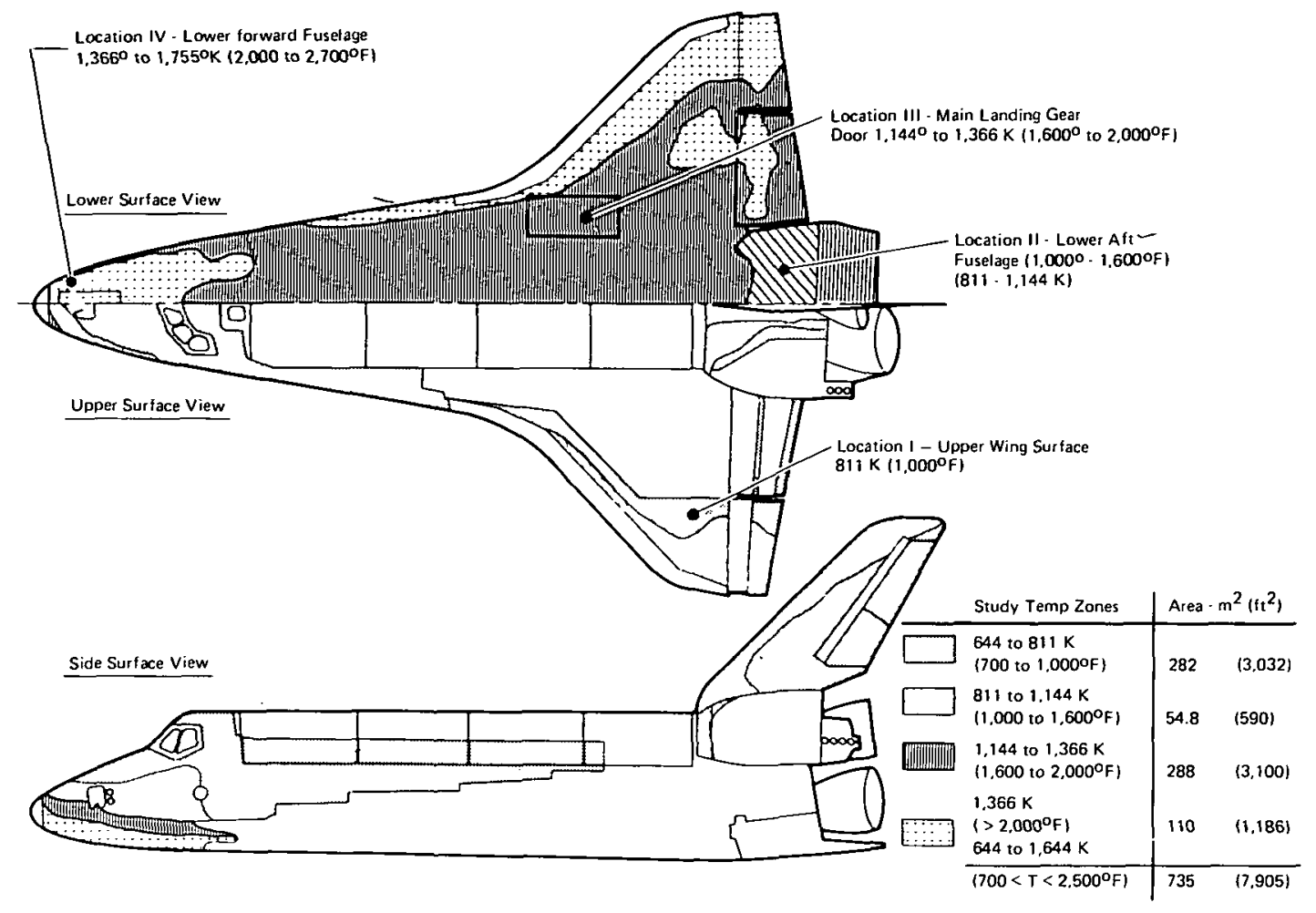

Figure 4. Orbiter Study Application Areas
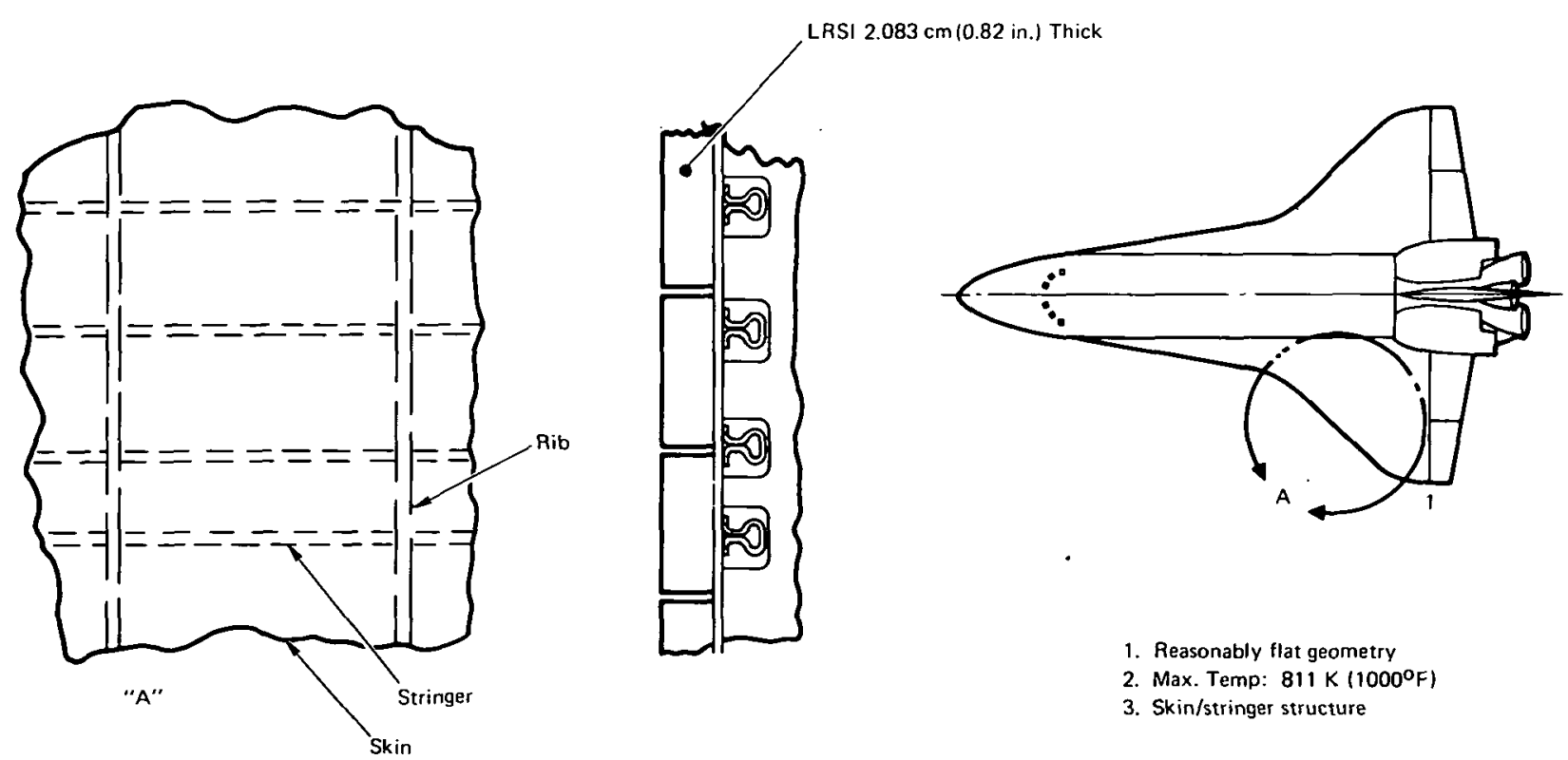

Figure 5. Orbiter Structural Design at Design Point I - Wing (Upper) 


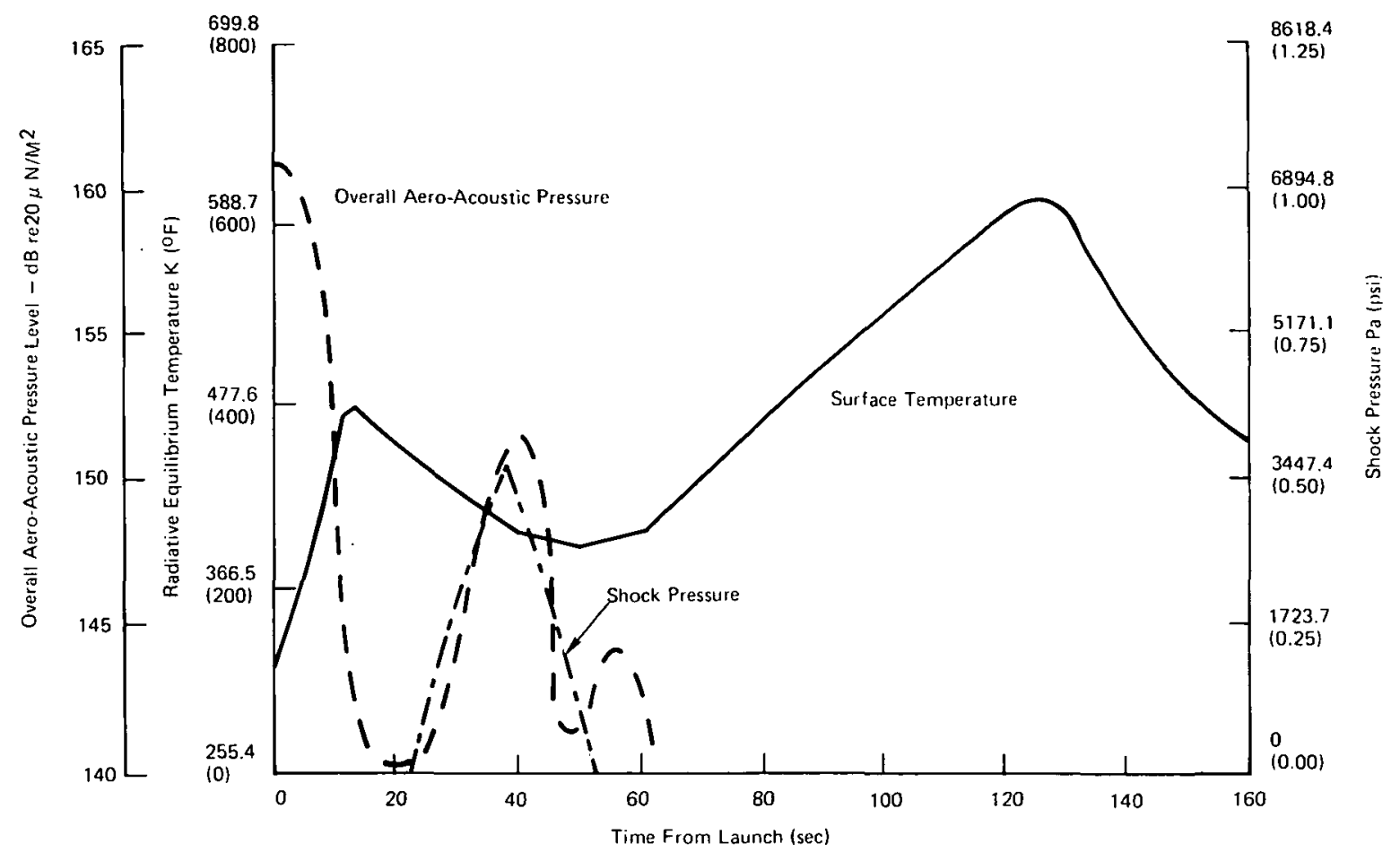

Figure 6. Ascent Environment History-Design Point I

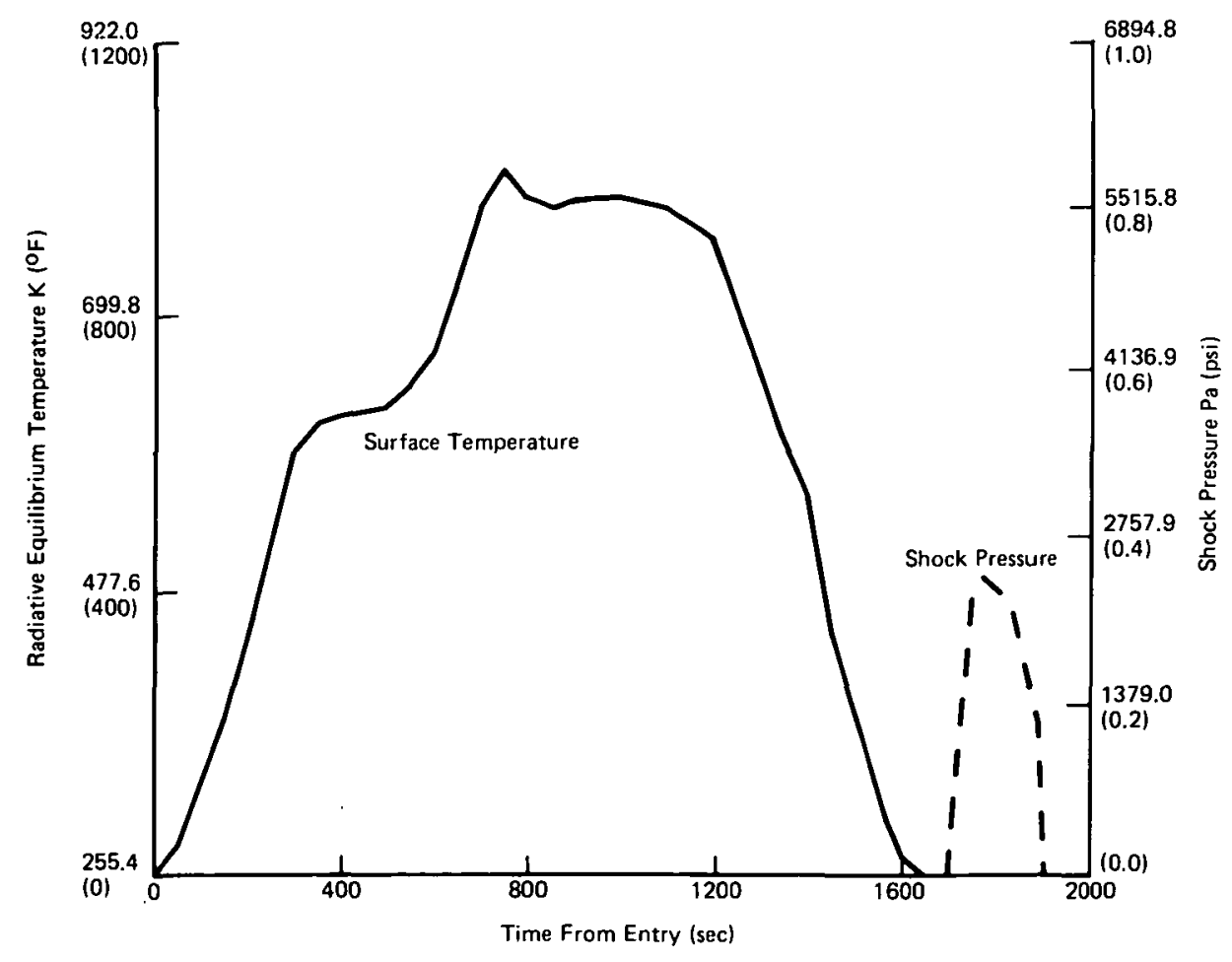

Figure 7. Entry Environment History - Design Point I 


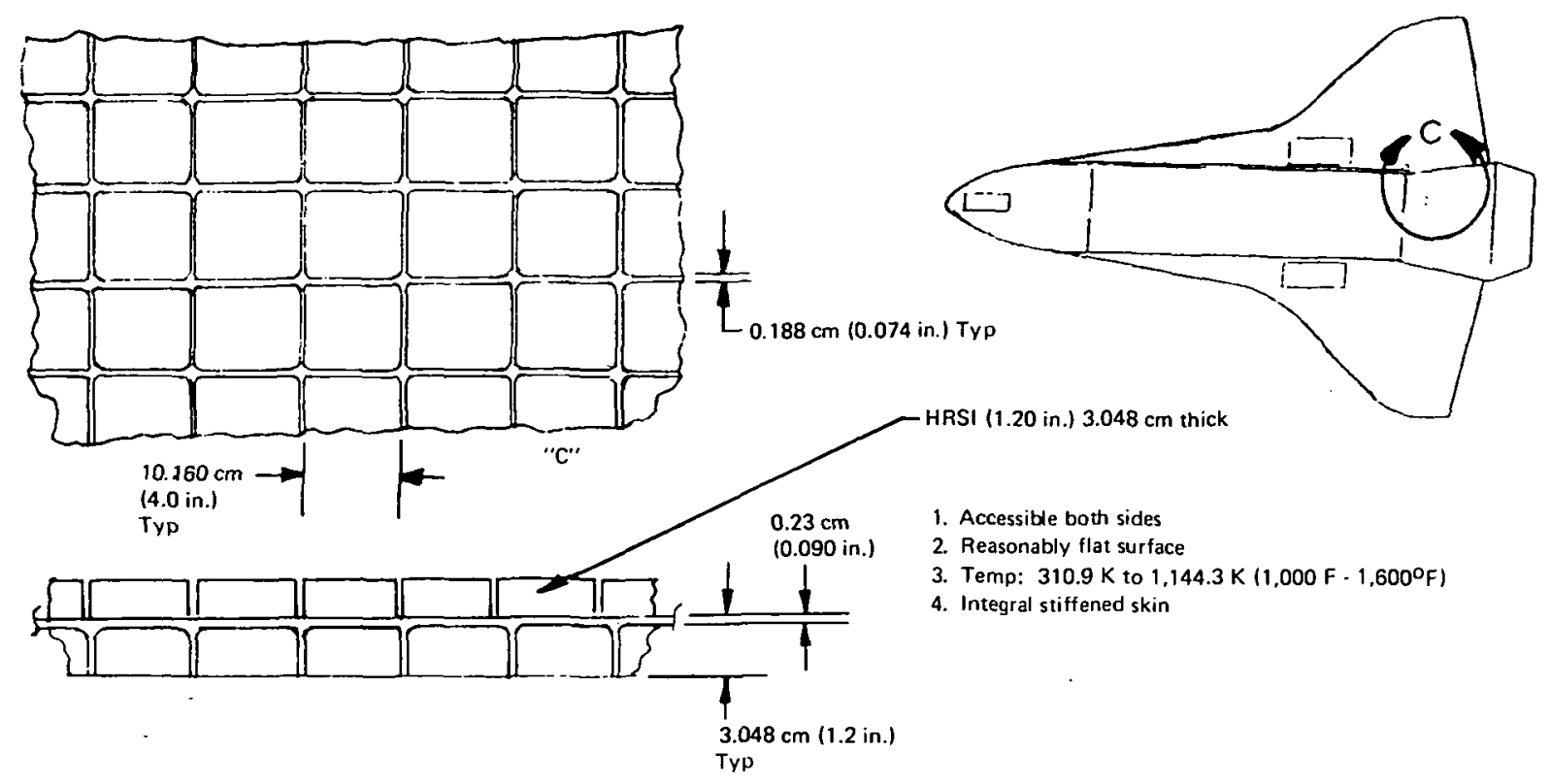

Figure 8. Orbiter Structural Design at Design Point II - Aft Fuselage (Lower)

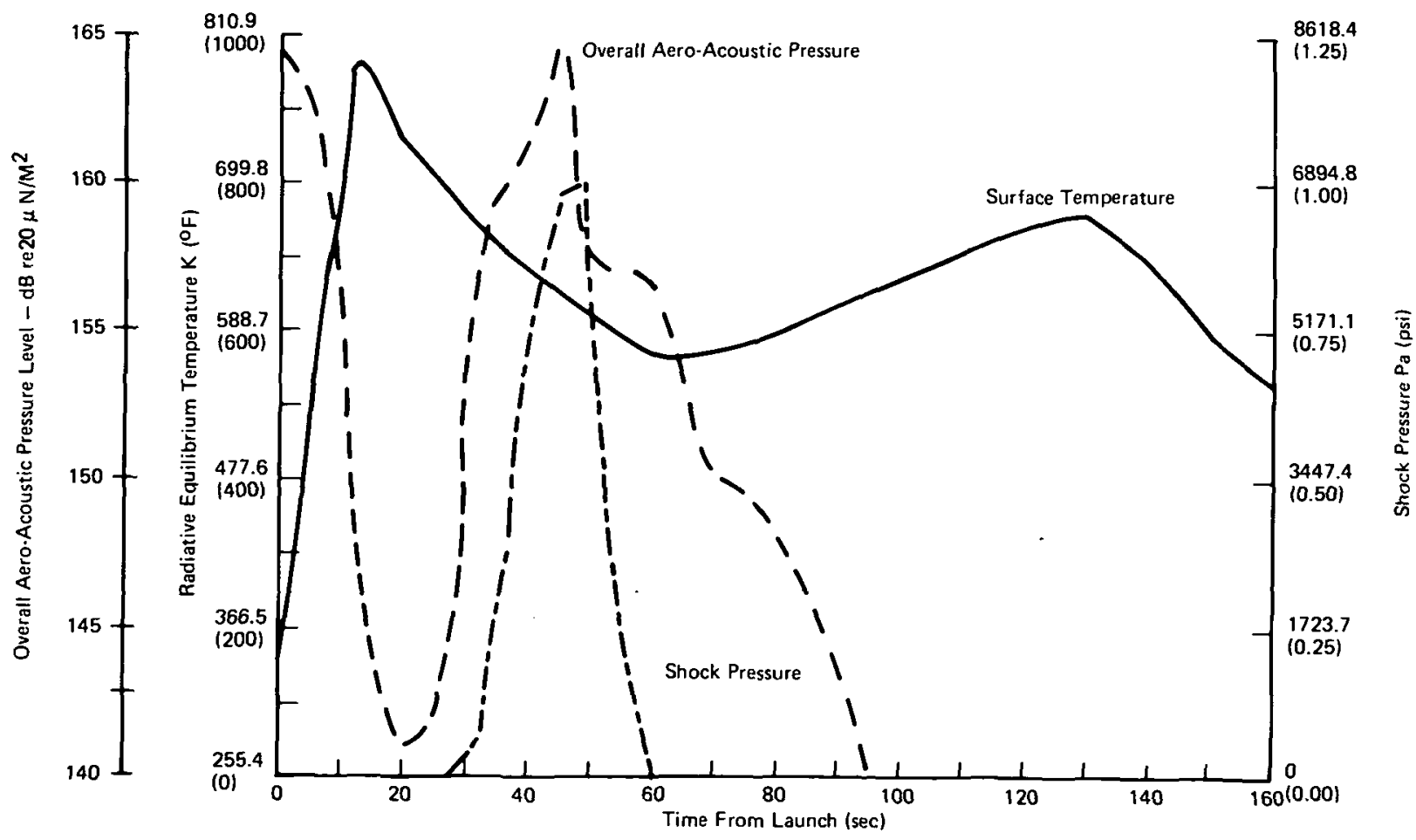

Figure 9. Ascent Environment History - Design Point II 
Ascent environment conditions for Area II are shown in Figure 9, and entry conditions are presented in Figure 10. Moderately high pressures and temperatures are experienced in this zone, with surface temperatures approaching $1144 \mathrm{~K}\left(1600^{\circ} \mathrm{F}\right)$. The current orbiter baseline TPS design in this area utilizes high-temperature reusable surface insulation (HRSI) tiles which are LI-900 ceramic material with a black ceramic oxide coating that provides high radiation absorption and emmisivity. Interfaces exist with Areas I, III and IV concepts, and a corner transition from the lower surface to the side fuselage is required.

The main landing gear ( $M L G$ ) door was selected for the point design for Area III. Moderately high heating occurs on the MLG door since it is reasonably close to the wing leading edge. Area III is representative of the majority of the lower surface of the orbiter (Figure 4). The primary structure is skin-stringer stiffened with a thin sheet, and the moldline has a very minor contour. Special features in Area III include an interface with surrounding structure, an opening door in flight, and a thermal/pressure seal dedicated structure at the door edge. Figure 11 depicts the features of the door. Baseline design uses HRSI (LI-900) tiles of added thickness due to fairing requirements created by very thick tiles near the leading edge.

Environmental conditions for Area III during ascent are presented in Figure 12, and entry data are contained in Figure 13. Moderate loads are experienced during ascent, and moderately high heat loads are present during entry, resulting in a surface temperature of just over $1144 \mathrm{~K}\left(1600^{\circ} \mathrm{F}\right)$. Nearby surfaces experience temperatures in excess of $1255 \mathrm{~K}\left(1800^{\circ} \mathrm{F}\right)$.

The most complex point design area selected for this study is Area IV, which is close to the nose cap and on the transition radius from the lower surface to the sidewall. Severe heating is encountered at this body point, and outer mold line (OML) smoothness is critical. Surface temperatures in this area approach $1561 \mathrm{~K}\left(2350^{\circ} \mathrm{F}\right)$, with temperatures dropping drastically as the OML moves around to the sidewal1. The baseline TPS in this area uses HRSI (LI-900) tiles. Primary structure is thin sheet stiffened with close-spaced hat sections, shown in Figure 14. The compound contour inner mold line (IML) is somewhat conical as the nose cone is approached.

Area IV is a representative of lower surfaces which extend from the forward fuselage to just aft of the wing leading edge. Also, similar heating profiles are seen on portions of the elevons and the lower surface of the body flap.

Area IV environmental conditions for ascent and entry are described in Figures 15 and 16 . Loading conditions are moderate during ascent, as is heating. Maximum surface temperatures occur on entry with both high heating rates and high total heat loads. Surface roughness has to be minimal in this area to avoid early transition to turbulent flow, which can cause excessive heating further aft on the lower surface.

Ground operations during turnaround expose the orbiter to environments that are considerably different from those of the flight regime. While ground environments do not generally determine the design of the TPS, they must be considered in the design criteria and merit functions in order to ensure compatibility between the system and the ground-operations exposure. 


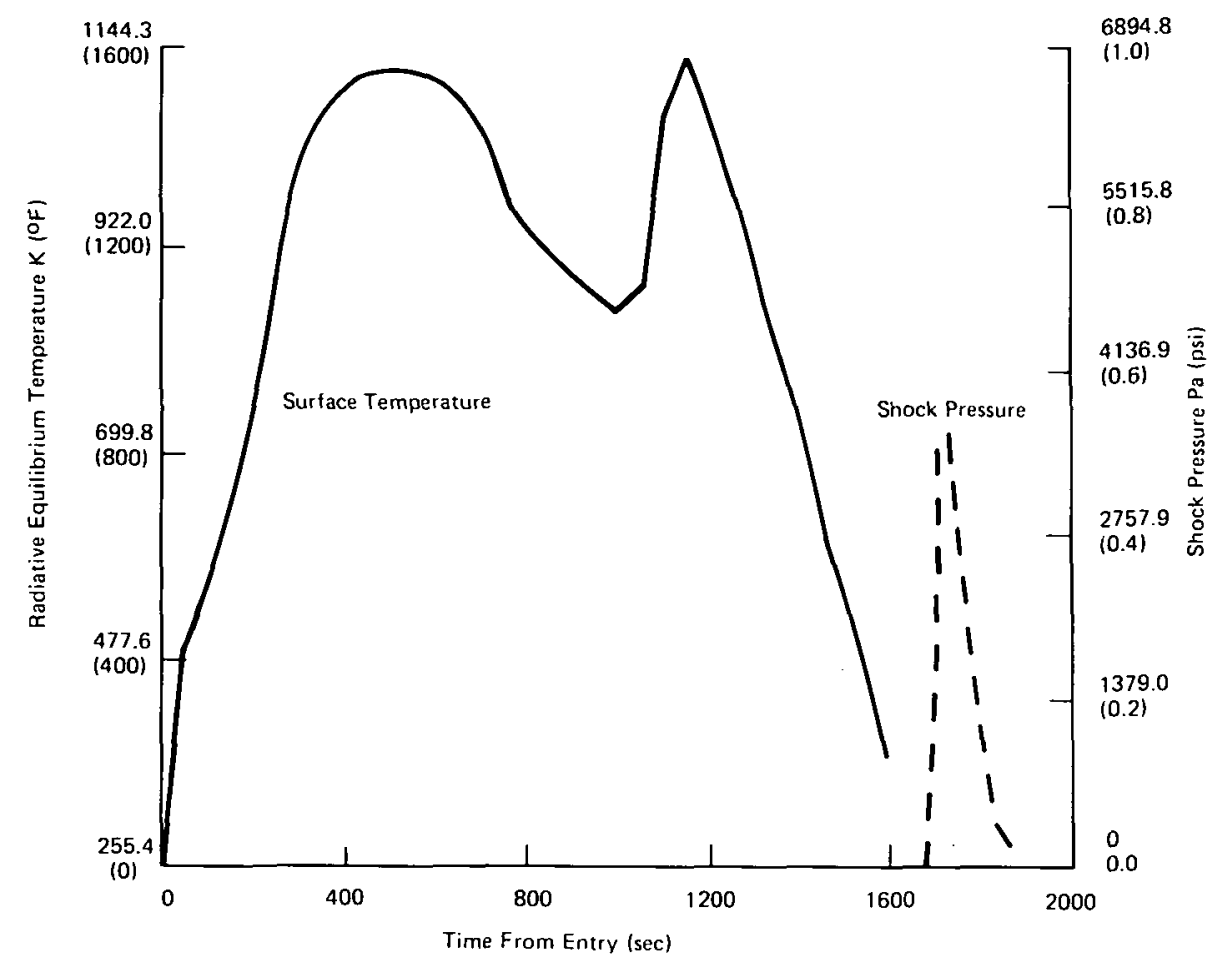

Figure 10. Entry Environment History - Design Point II
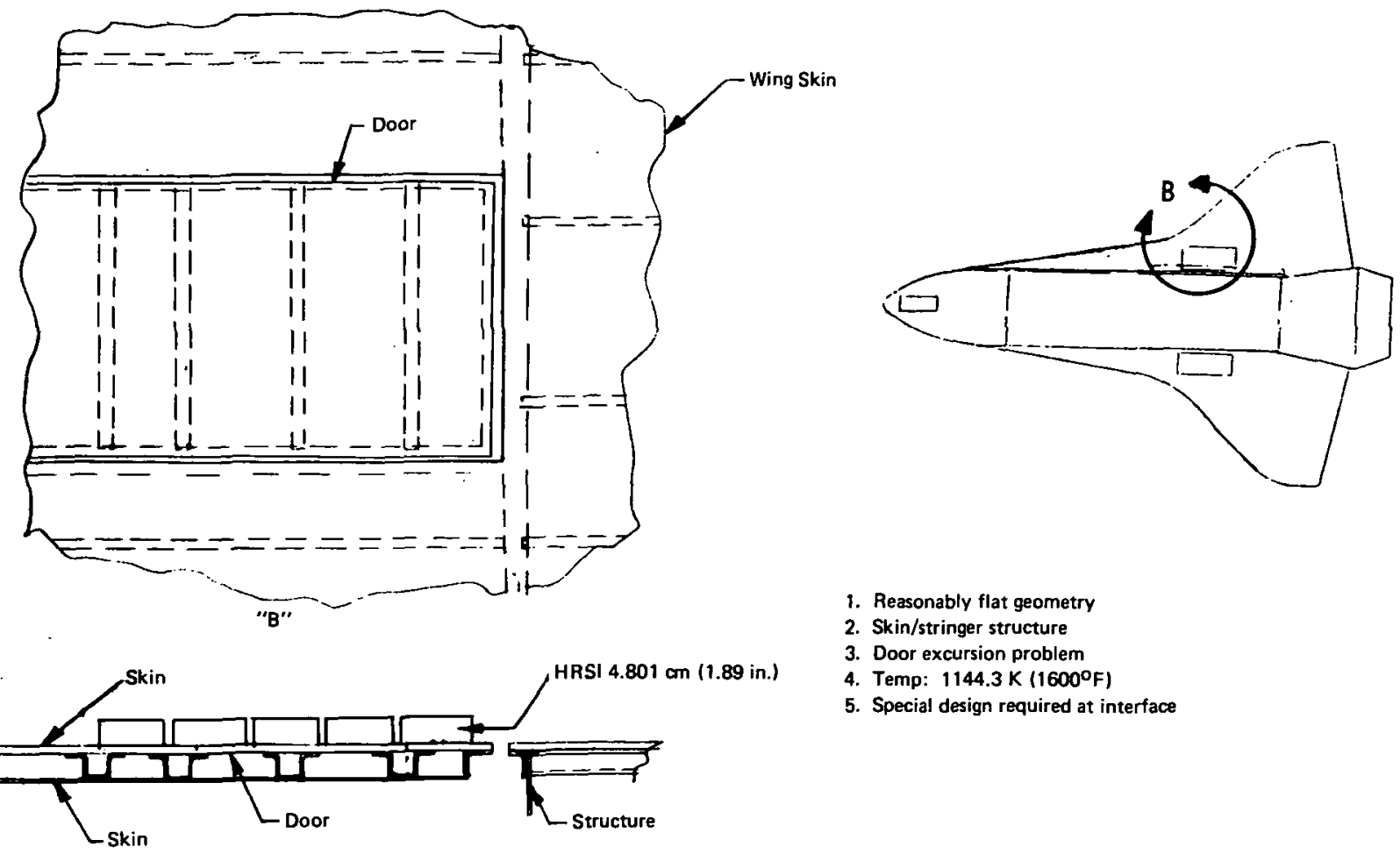

1. Reasonably flat geometry

2. Skin/stringer structure

3. Door excursion problem

4. Temp: $1144.3 \mathrm{~K}\left(1600^{\circ} \mathrm{F}\right)$

5. Special design required at interface

Figure 11. Orbiter Structural Design at Design Point III Main Landing Gear Door 


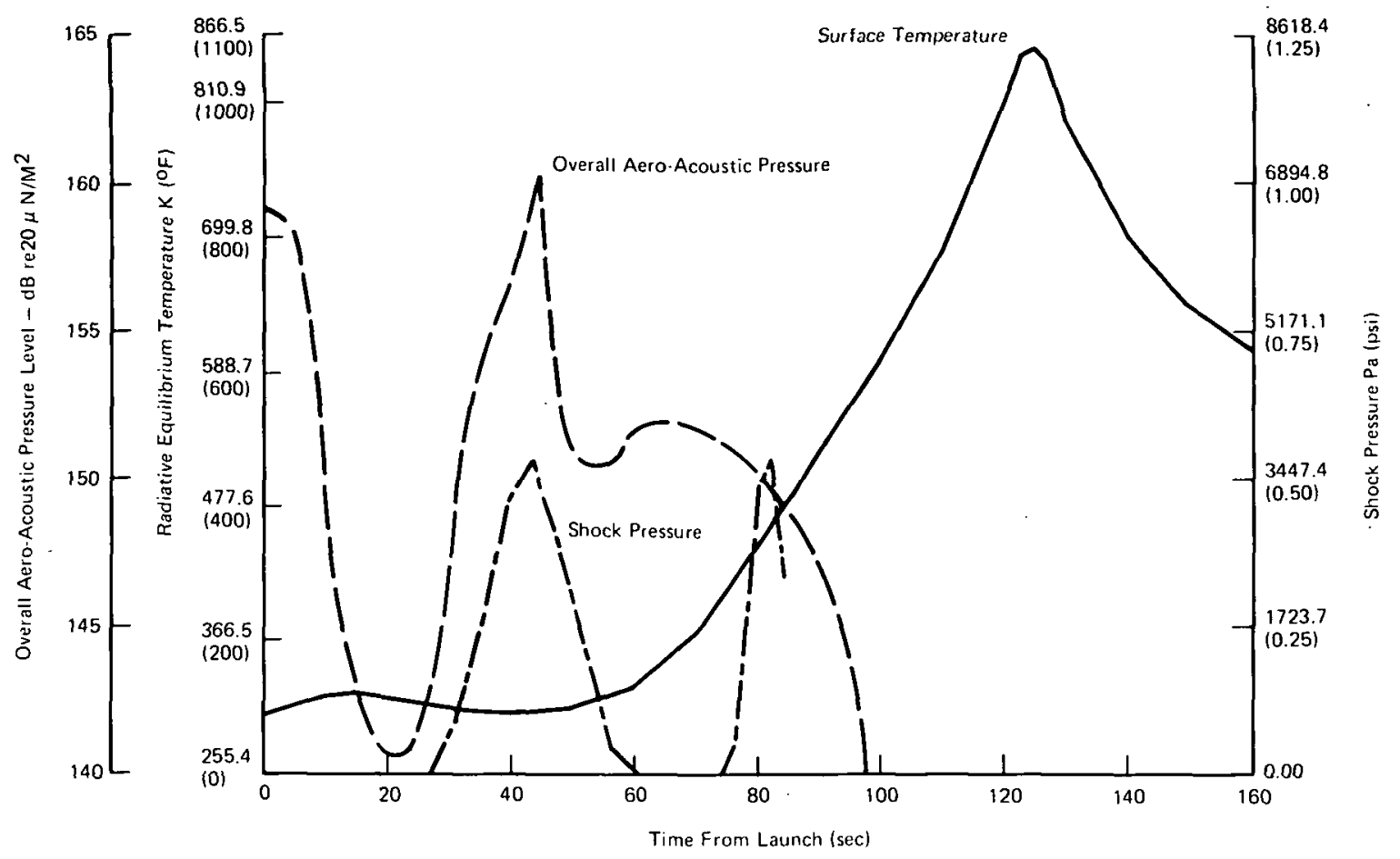

Figure 12. Ascent Environment History - Design Point III

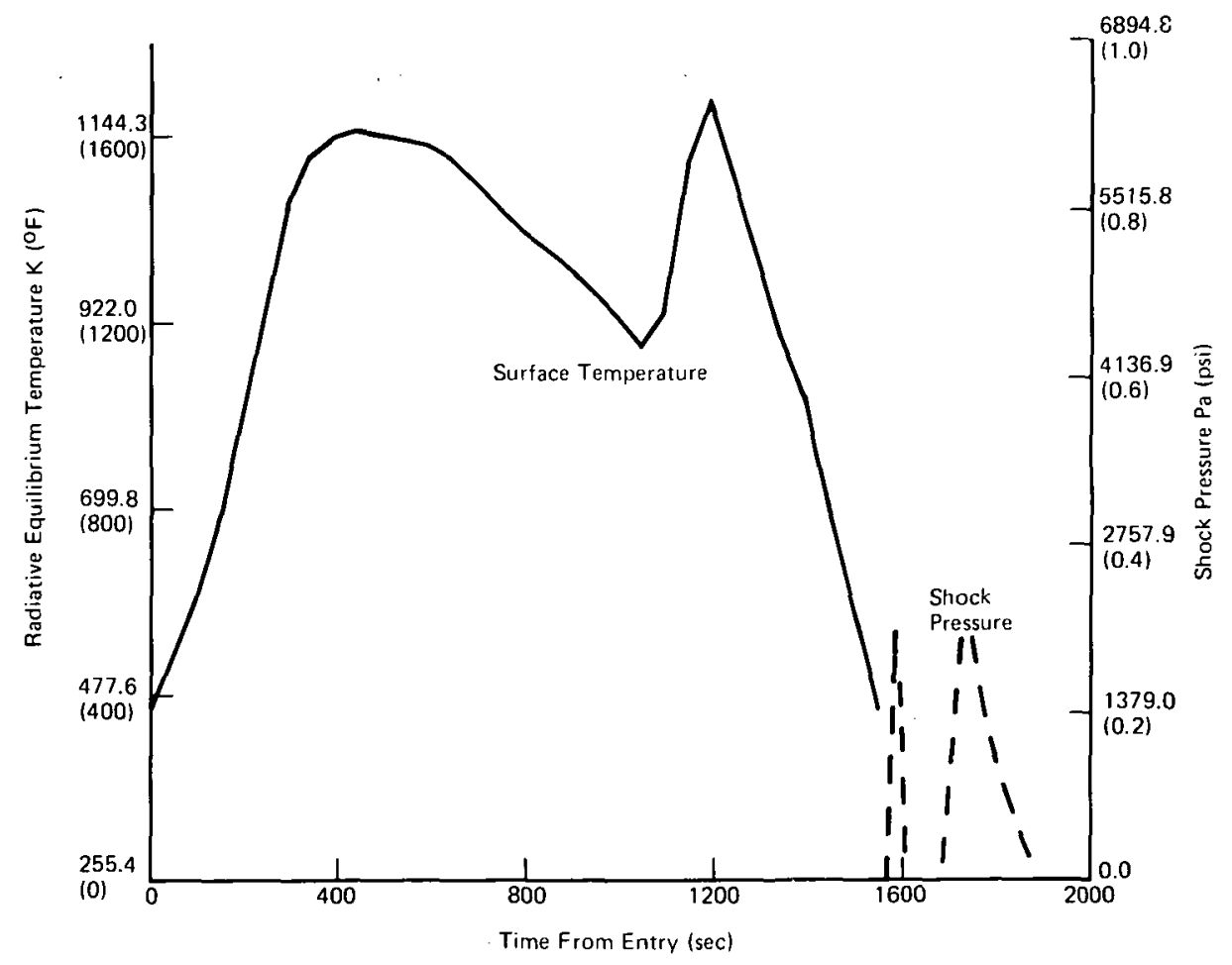

Figure 13. Entry Environment History - Design Point III 

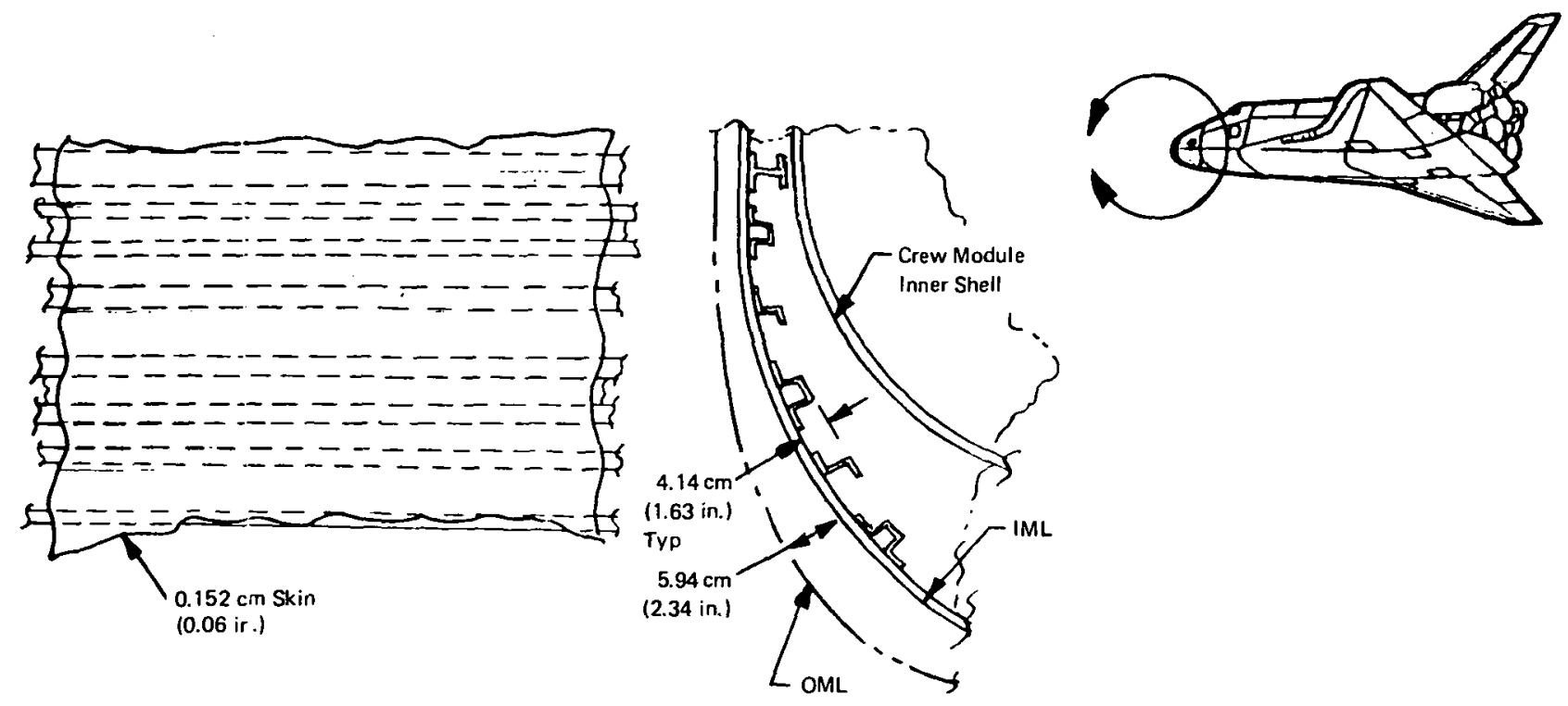

1. Inaccessible from inside

2. Nonconcentric IML/OML

3. Compound contour geometry

4. Temp: drastic changes, $<1255.4 \mathrm{~K}>1366.5 \mathrm{~K}\left(<1800^{\circ} \mathrm{F}>2000^{\circ} \mathrm{F}\right)$

5. Skin/stringer structure

6. Converging stringer, close spacing

Figure 14. Orbiter Structural Design at Design Point IV - Forward Fuselage

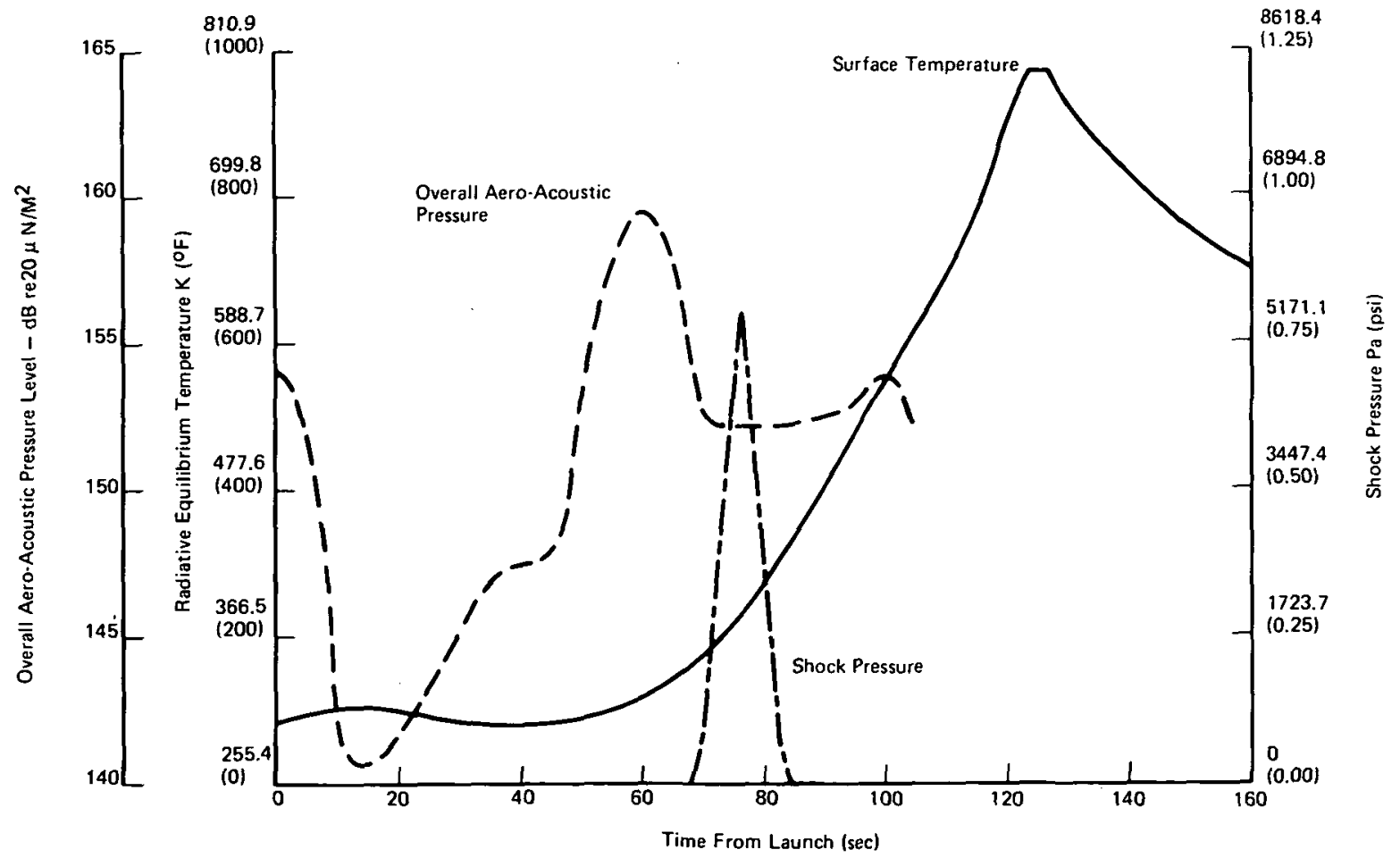

Figure 15. Ascent Environment History - Design Point IV 


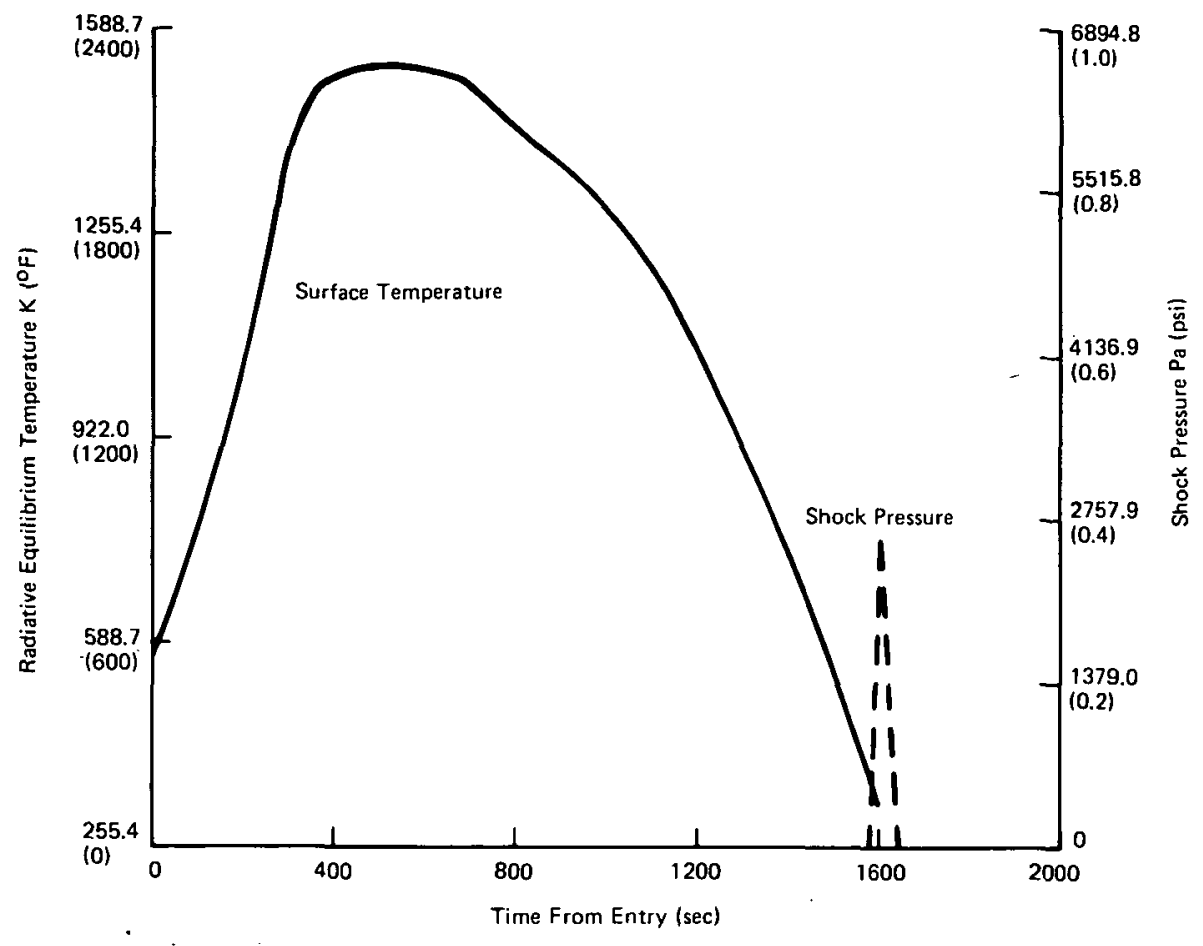

Figure 16. Entry Environment History - Design Point IV

In order to develop "real world" operational and maintainability design guidelines, applicable sections of the specification documents were combined with field site experience through contracts with Shuttle users at NASA/Kennedy Space Center, the USAF Space Division, and Vandenberg Air Force Base. The data were synthesized to establish a set of study guidelines for TPS designers.

\section{DESIGN CRITERIA AND GUIDELINES}

The general objectives of a TPS are:

- Effective insulation

- Light weight

- Low cost in manufacturing and operations

- Durable for long service life and maintenance of a clean, smooth aerodynamic surface.

In order to help meet these objectives, the following design goals/guidelines were established. They are not listed as requirements because a we1l-balanced design, which is inevitably a compromise, will at times emphasize one feature at the expense of another. The best design will be one that balances these goals most acceptably. Basic design criteria, which are established by Shuttle requirements are met through extensive engineering analyses using the design environments. 


\section{Design Guidelines}

Vehicle outer mold line (OML) requirements

- Smoothness

Minimum steps and gaps

Minimum distortion under air loads

Minimum deflection with thermal strains

- Thermal protection

Minimum heat transfer through system

Minimum change in OML (system thickness)

Maintenance of $450 \mathrm{~K}\left(350^{\circ} \mathrm{F}\right)$ maximum on primary structure

Construction and Maintenance Characteristics

- Survivability

Resistance to deterioration in the total operational environment

Acceptance of thermal strains without loss of function

Joining of system(s) suitable for environment

- Fabrication, installation, and operations

Lowest cost materials consistent with requirements

Minimum serial process steps, maximum batch processing

High-rate production of standard hardware

High commonality of panels

Standard tooling

\section{Systems design effectiveness}

- Large panels

Within load and expansion constraints

Compatible with manufacturing processes

- Array geometry

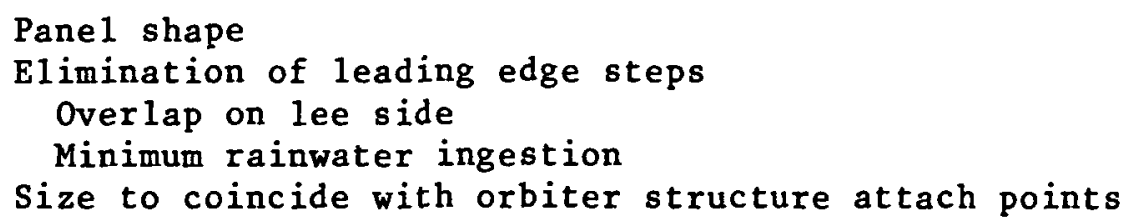

- Mono-panel emphasis

Incorporate insulation into installed package where feasible Minimum loose parts

Attachment effectivity, inspection enhanced 
Design characteristics of attachment concepts

- Easy on--easy off

- Minimum loose parts

- Protection from external environment

- Light weight

- Low cost (in very large quantity production)

- Low heat transfer

- Panel height adjustment (to comply with step criteria)

- Capability of being attached to orbiter structure

- Single panel removal

\section{CANDIDATE DESIGN CONCEPTS}

The concepts considered in this study were identified through the team's industry experience and extensive literature searches. Thus they are concepts that at least have some engineering efforts already performed. Some design modifications were made to some of the concepts to make them more compatible with the orbiter vehicle and its environments.

The concepts investigated fall into three categories: prepackaged, stand-off, and ablators. In prepackaged concepts, the insulation is completely encapsulated to form a single unit which is installed on the vehicle. In stand-off concepts, insulation is secured between the vehicle skin and a heat shield panel (metallic or carbon-carbon). The heat shield is attached to the vehicle via stand-off supports. In ablator concepts, ablative material is attached directly to the vehicle.

Figure 17 depicts the candidate concepts, their descriptions, and use temperatures. Ablator concepts were considered during Task 1 preliminary assessments only. They were deleted from the study when it was determined that there were reusable concepts that could survive the thermal environment.

In addition to normal thermal and structural analyses for each concept design, a series of major trade studies, including panel geometry, OML sensitivity, insulation packaging and attachment, panel-to-panel interface, concept-to-concept interface, and penetration and closeout requirements, was conducted during the detailed engineering investigation. The concept design configurations shown in the following section of this report are the result of modifications made following the trade study analyses.

The following sections present design details and analytical results for each of the candidate prepackaged and stand-off concepts, based on the environments in the appropriate areas of the orbiter. 
$6155 \vee 108475$

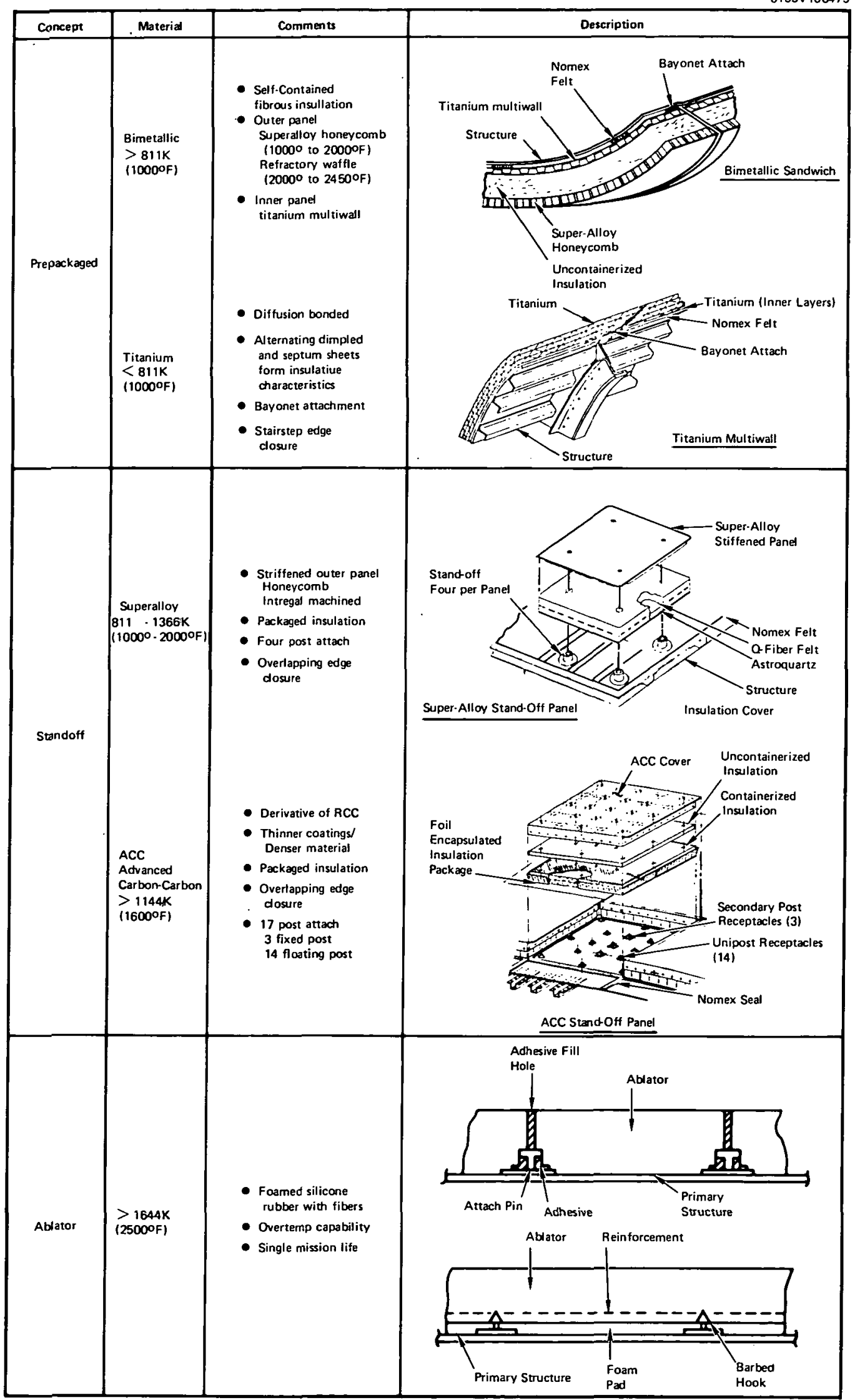

Figure 17. Candidate Concepts 


\section{Prepackaged Concepts}

The prepackaged family of concepts include the titanium multiwall for applications up to $811 \mathrm{~K}\left(1000^{\circ} \mathrm{F}\right.$ ) (Area I), the superalloy/titanium bimetallic sandwich for applications up to $1366 \mathrm{~K}\left(2000^{\circ} \mathrm{F}\right.$ ) (Areas II and III), and the refractory/titanium bimetallic sandwich for applications above $1366 \mathrm{~K}\left(2000^{\circ} \mathrm{F}\right)$ (Area IV). These concepts are similar in terms of panel size, method of attachment, and the fact that they are installed on the vehicle as single units (i.e., the insulation is contained within the unit).

Panel size is $0.3 \mathrm{~m}$ by $0.3 \mathrm{~m}$ (12 in. by $12 \mathrm{in.)}$. Attachment to the vehicle is by means of a bayonet and clip arrangement (Figure 18). The bayonets and clips are diffusion-bonded to the TPS panels, and the clips are mechanically attached to the vehicle. Bayonets from one panel slide through clips mounted on the vehicle and through clips on the back of the panel in front of it. Thus each bayonet secures the forward edge of the panel it is attached to, and the aft edge of the panel in front of it. The panels are installed in a shingle fashion.

Titanium Multiwall Concept. The titanium multiwall panel is constructed of alternating layers of flat sheets of foil-gage titanium and dimpled foil gage sheets, diffusion-bonded to produce an integral prepackaged tile complete with attachments.

Figure 19 shows the design sizing for application in Area I, with adequate thermal performance and structural margin of safety. For structural analysis, the panel was modeled in NASA structural analysis (NASTRAN) 1 as a twodimensional slice through the multiwall.

For thermal analysis, a. one-dimensional thermal math model was developed; and parametric transient runs were made to determine the required thickness. Figure 20 presents the temperature histories for the surface, the titanium inner skin, and the aluminum structure for the TPS design condition.

Bimetallic Sandwich. The bimetallic sandwich consists of fibrous insulation encapsulated by inner and outer panels, which are connected by a foil gage beaded sidewal1. A superalloy (Inconel 617)/titanium sandwich was considered for Areas II and III, and a columbium/titanium combination was considered for Area IV.

The superalloy-titanium design for Area III is shown in Figure 21. The outer panel is an Inconel 617 honeycomb; the inner panel is one layer of titanium multiwall. The beaded Inconel sidewall connecting the inner and outer panels closes out the unit on all four sides, providing complete encapsulation of the fibrous insulation batting. The sidewall is attached to both panels via diffusion bonding.

INASTRAN: Registered trademark of the National Aeronautics and Space Administration. 


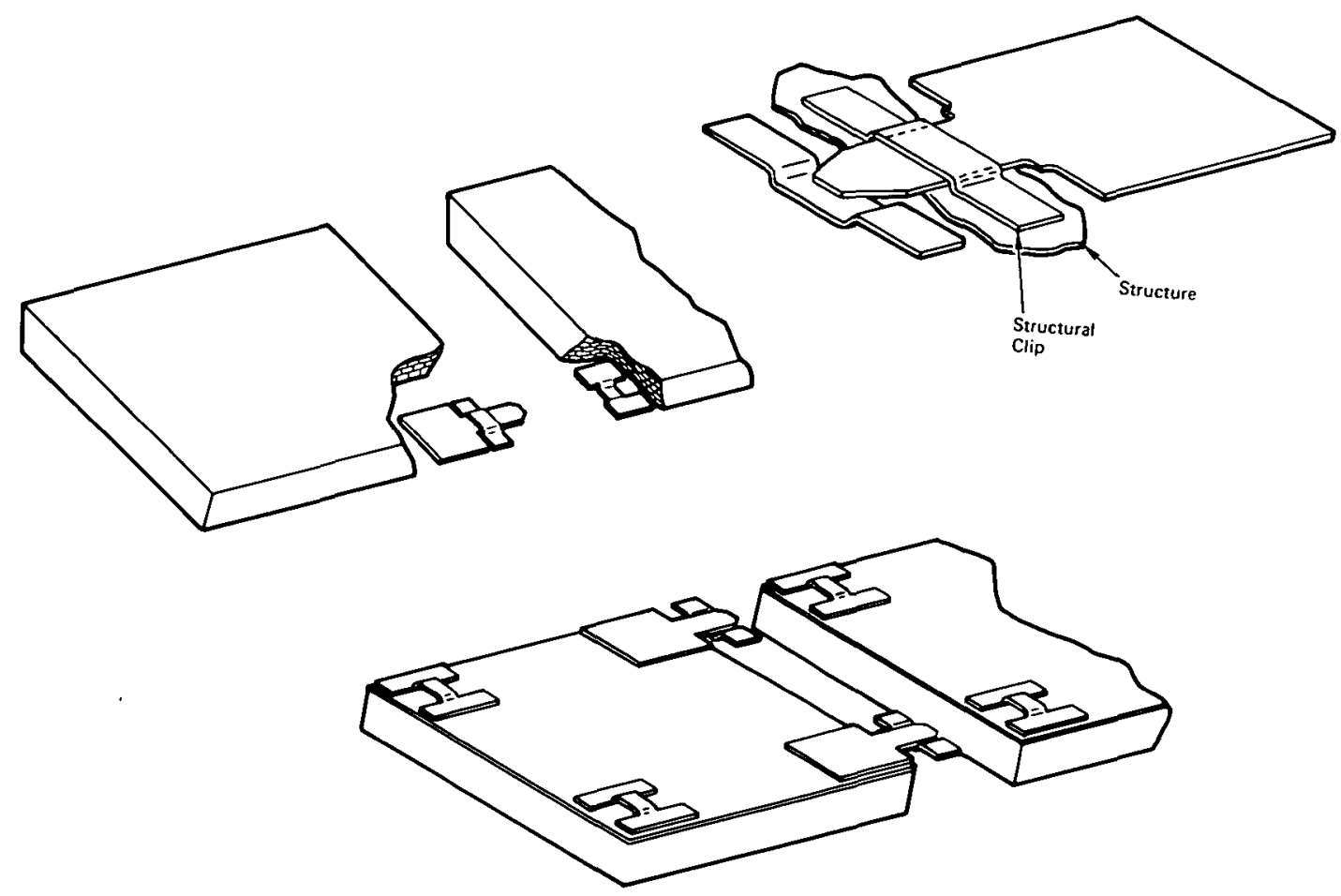

Figure 18. Bayonet Attachment Scheme - Prepackaged Concepts

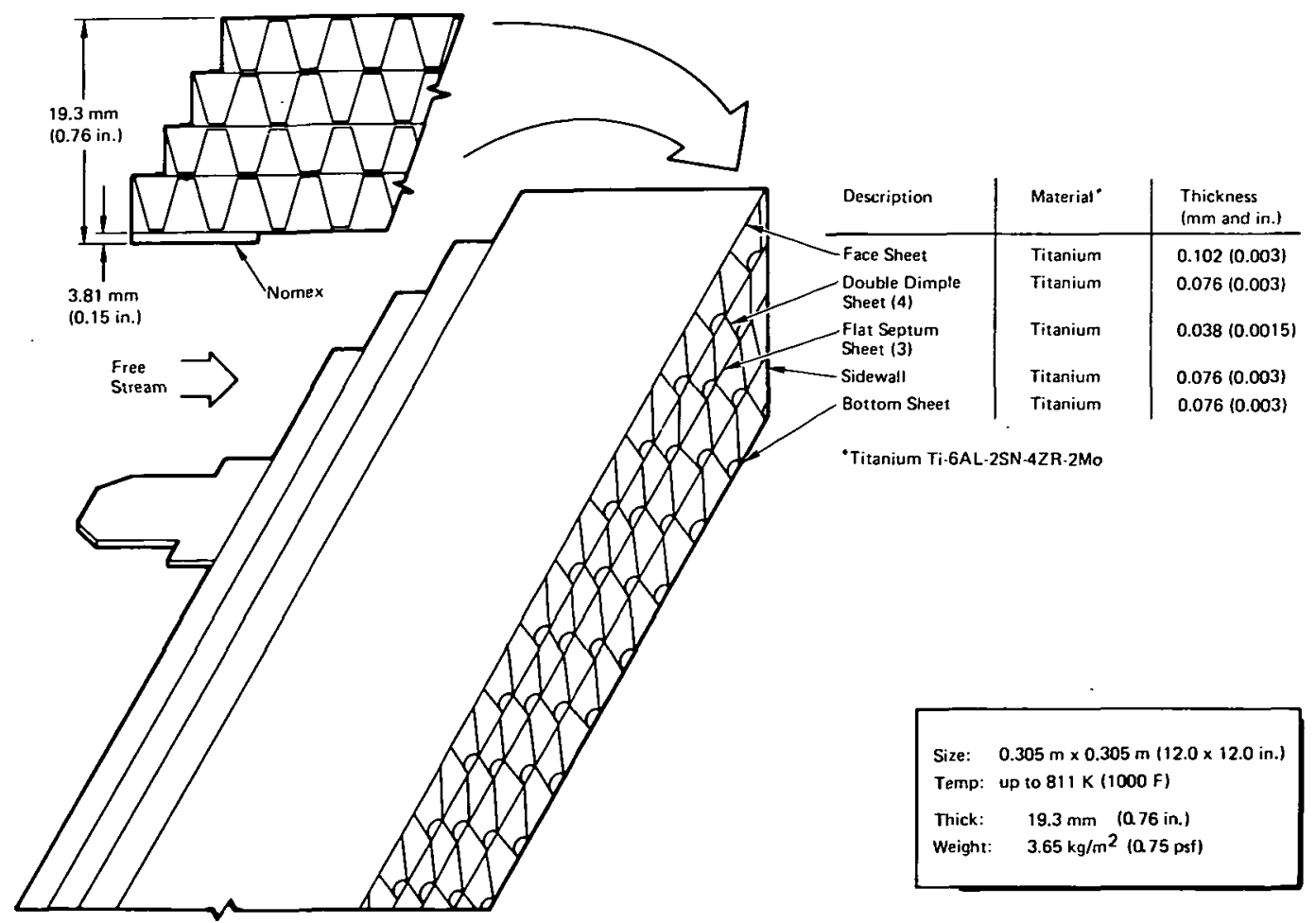

Figure 19. Titanium Multiwal1 


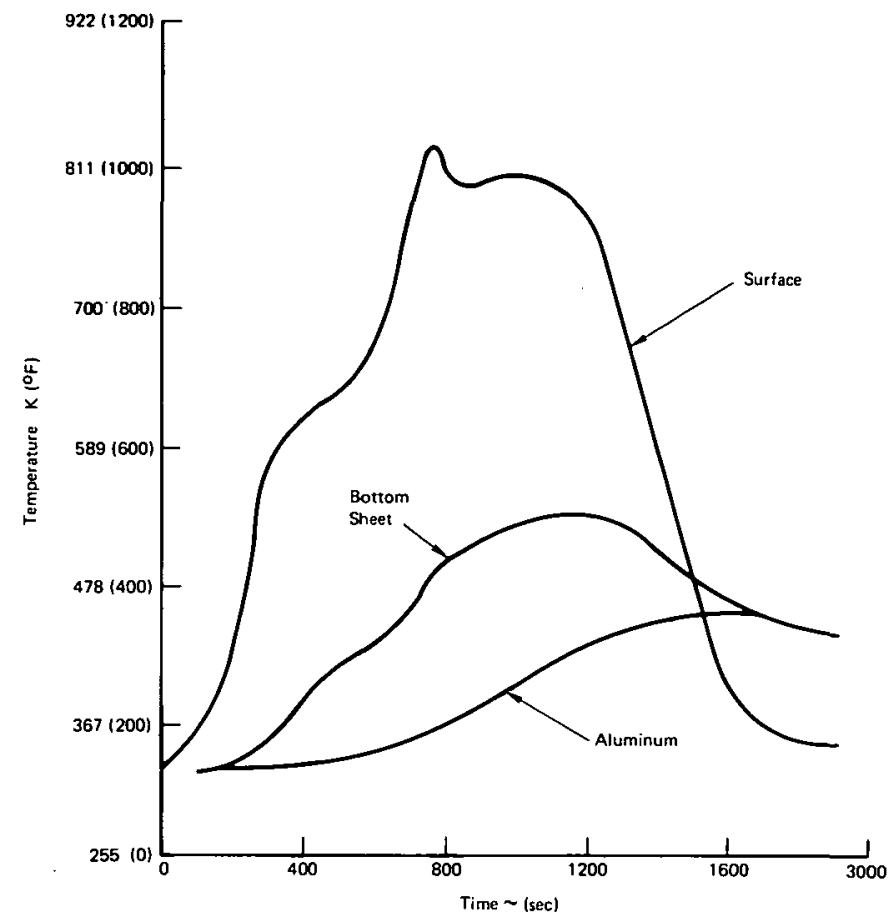

Figure 20. Temperature Histories -

Titanium Multiwall.

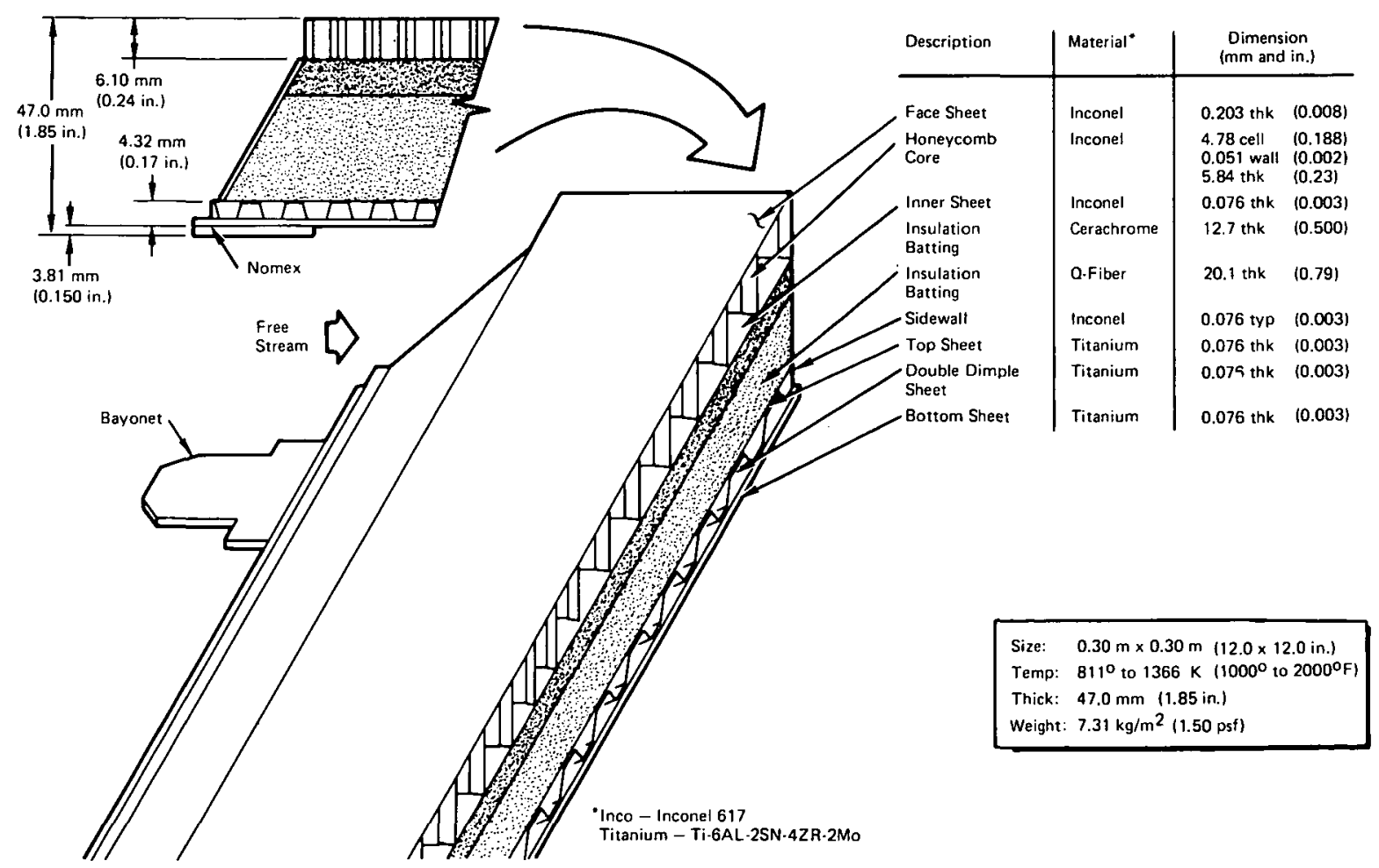

Figure 21. Superalloy Bimetallic Sandwich 
For structural sizing, a NASTRAN three-dimensional model was developed. The material gages shown in Figure 21 were found to be adequate for concept application in both Areas II and III, which increases commonality in fabrication.

Insulation thicknesses for the bimetallic sandwich were established by use of one-dimensional thermal math models. The insulation thickness and composition were selected to provide maximum thermal efficiency (i.e., minimum weight). In Area II, the insulation is composed entirely of Q-Fiber, and in Area III, a composite Cerachrome/Q-Fiber insulation is used (Figure 21). Design results indicate that the concept does not meet the current moldline in Area II, but does in Area III. Impacts due to moldline changes are discussed later under "Orbiter Impacts."

A similar concept, which utilizes a superalloy multiwall outer panel, was also considered. Concept performance was found to be essentially the same, but the honeycomb appears to be more attractive because of the manufacturing complexity of the multiwall.

For applications above $1366 \mathrm{~K}\left(2000^{\circ} \mathrm{F}\right.$ ) (Area IV), a bimetallic sandwich utilizing a coated columbium orthogonally stiffened (waffle) outer panel was considered (Figure 22). The inner panel is one layer of titanium multiwall. The Inconel sidewall is diffusion bonded to the titanium inner pane 1 and mechanically attached to the columbium panel in a manner to accomodate thermal expansion differences in the materials. The design results for this concept are shown in Figure 22.

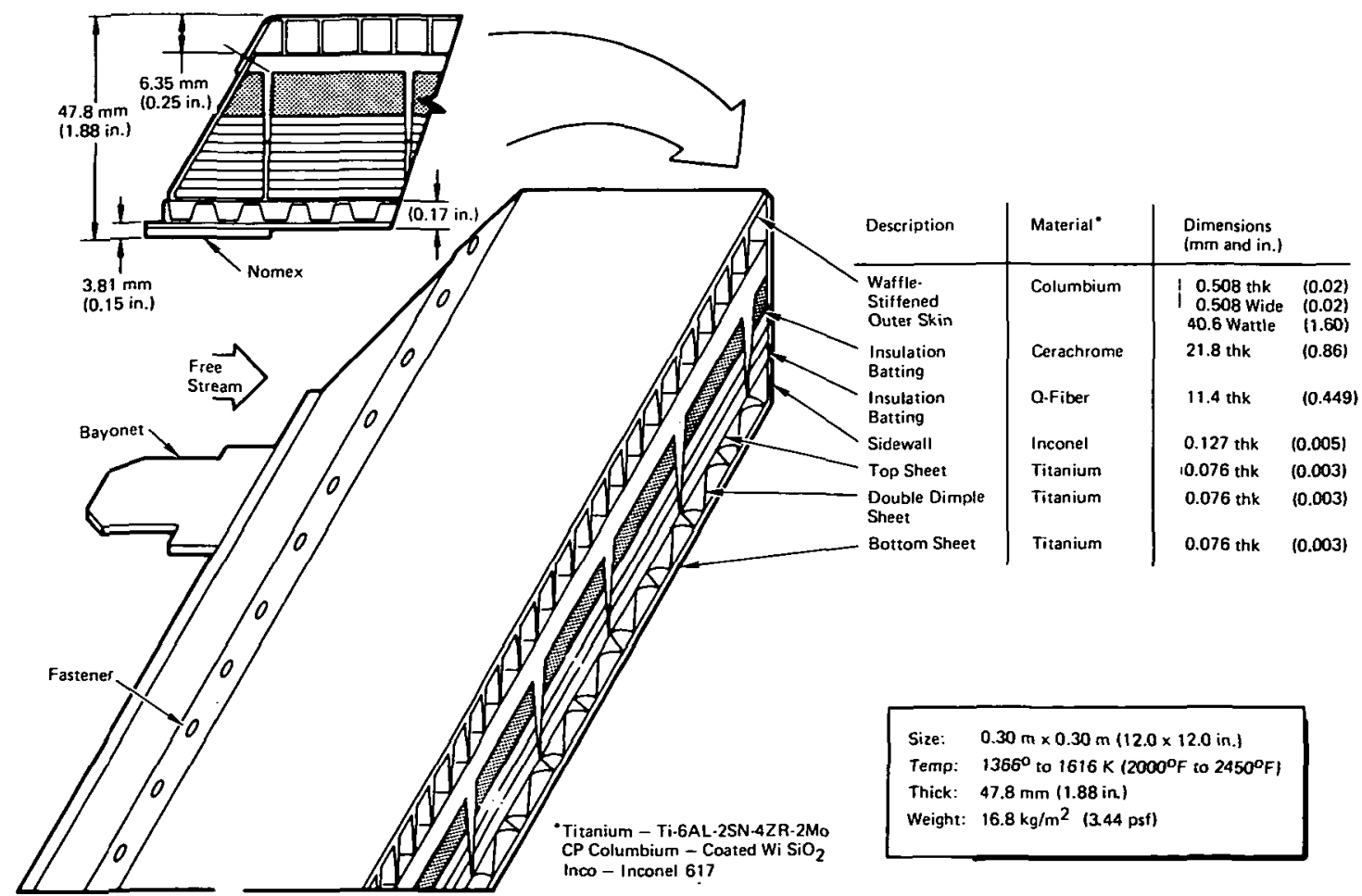

Figure 22. Refractory Waffle Bimetallic Sandwich 


\section{Stand-Off Concepts}

The second generic category of candidate concepts was the stand-off type, where the insulation is secured between the vehicle skin and a heat shield panel.

These stand-off concepts were considered for applications in Areas II, III, and IV (Figure 4). Superalloy panels of various construction were considered for use in Areas II and III, and columbium and carbon-carbon panels were considered in Area IV.

Insulation thickness for all the stand-off concepts was sized by using a one-dimensional thermal math model for each area. Parametric trade studies were performed to define thermally efficient composite insulations for each area. In general, results of the trade studies indicated that through the selection of suitable insulation combinations, the outer mold line constraints can be met. However, in some cases a weight penalty will be incurred.

Analysis results show that the density of the insulation and location with respect to the heated surface affects the structure temperature. Furthermore, the more dense the insulation, the less radiation shine-through (infrared radiation passing through the spaces) is allowed.

Superalloy Stand-off Concepts. Three types of standoff panels were considered for Regions II and III: grid reinforced (isogrid), honeycomb, and corrugated. The isogrid and honeycomb panels use a four-post support scheme with the supports located 20 percent in from the edges so that the pressure induced stresses and displacements are nearly minimized. The posts are designed to permit relatively free thermal expansion and contraction of the panel. The corrugated panel utilizes a bracket-type mount running the length of the panel along the leading and trailing edges. The panel is attached to these brackets between the ribs of the panel, and thermal expansion is taken by rib dimpling and trailing edge bracket bending.

For structural sizing and analysis, a three-dimensional NASTRAN model was constructed of the isogrid and honeycomb panels. The corrugated panels were sized and analyzed according to the procedure and loads outlined in Reference 12. This concept was dropped early in the study due to concern over localized heating uncertainties.

Area II point design dimensions for these concepts are shown in Figures 23 through 25. These dimensions were determined by manufacturing feasibility constraints and represent the material gages which could easily be handled by any manufacturing entity. These material gages are adequate for concept application in Areas II and III, and this results in commonality of fabrication, design, and parts.

High Temperature Stand-off Concepts. Two stand-off concepts were considered for the high-temperature area, Region IV: a refractory metal isogrid panel and an advanced carbon-carbon (ACC) panel. The refractory metal isogrid shingle is supported by four posts located 20 percent in from the edges. The posts are designed to rotate so that relatively free thermal expansion can occur. The ACC panel is orthogonally reinforced with carboncarbon ribbing and stands off the orbiter skin on 17 posts. Fourteen uniposts 


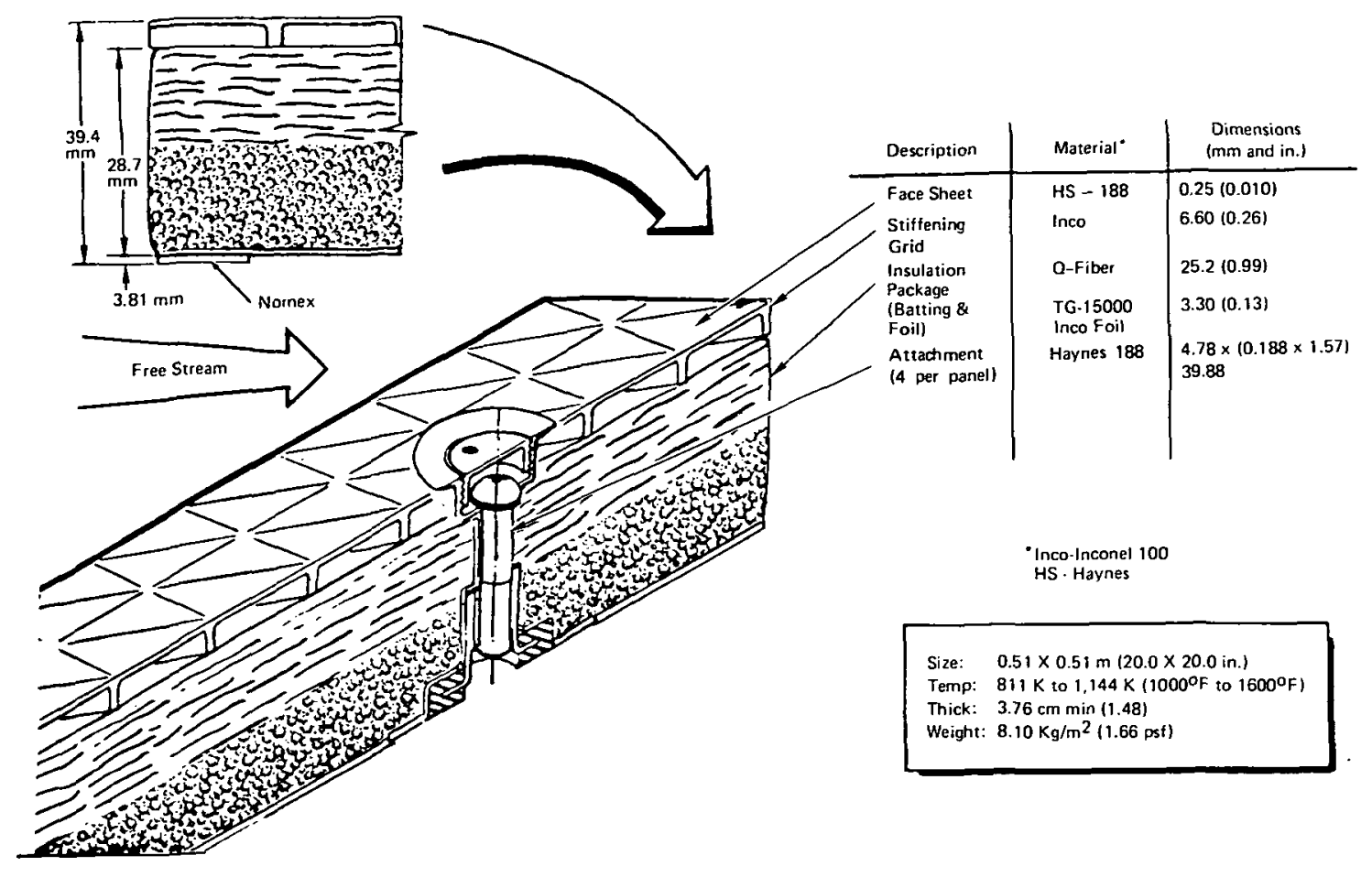

Figure 23. Superalloy Isogrid Stand-off

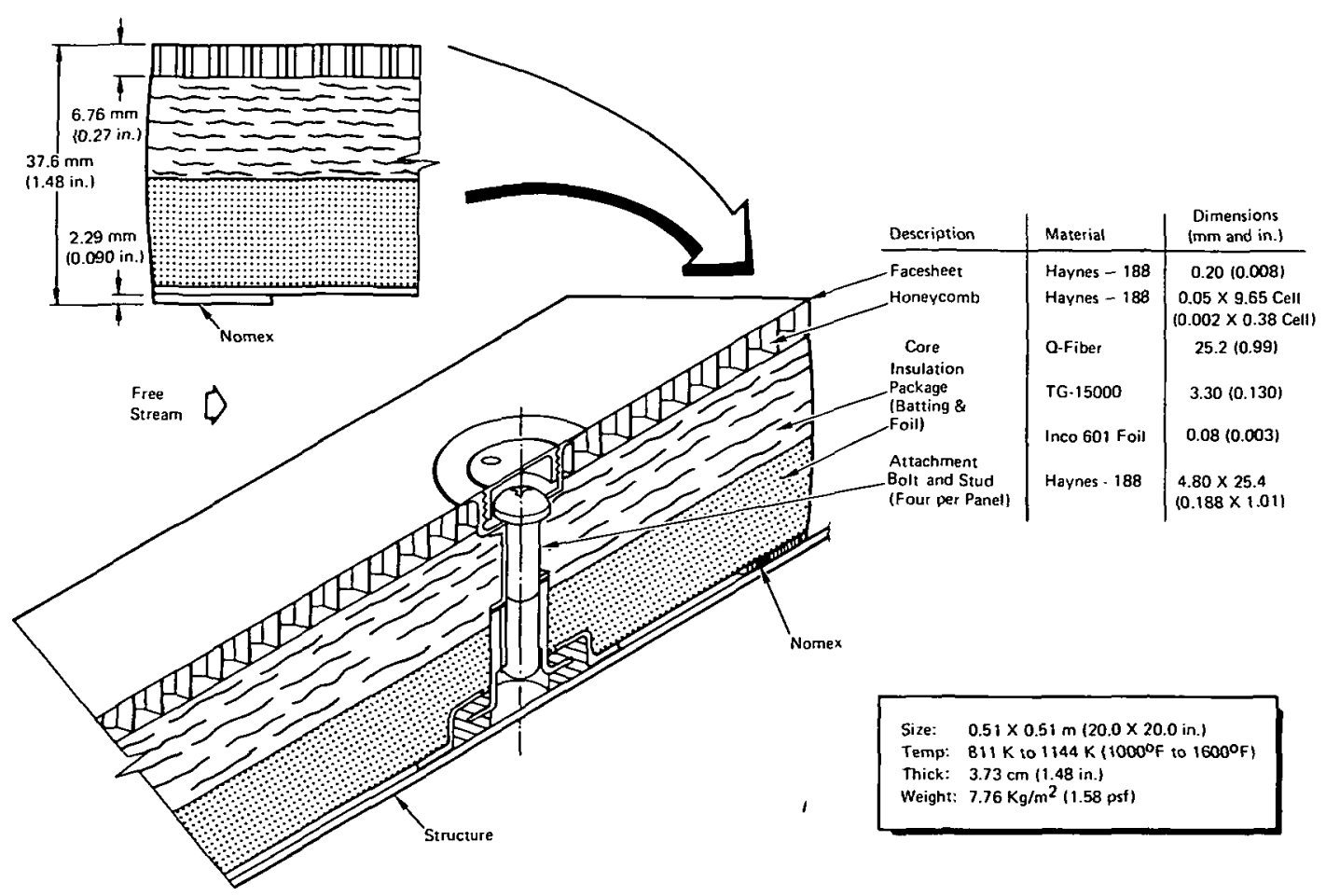

Figure 24. Superalloy Honeycomb Stand-Off 


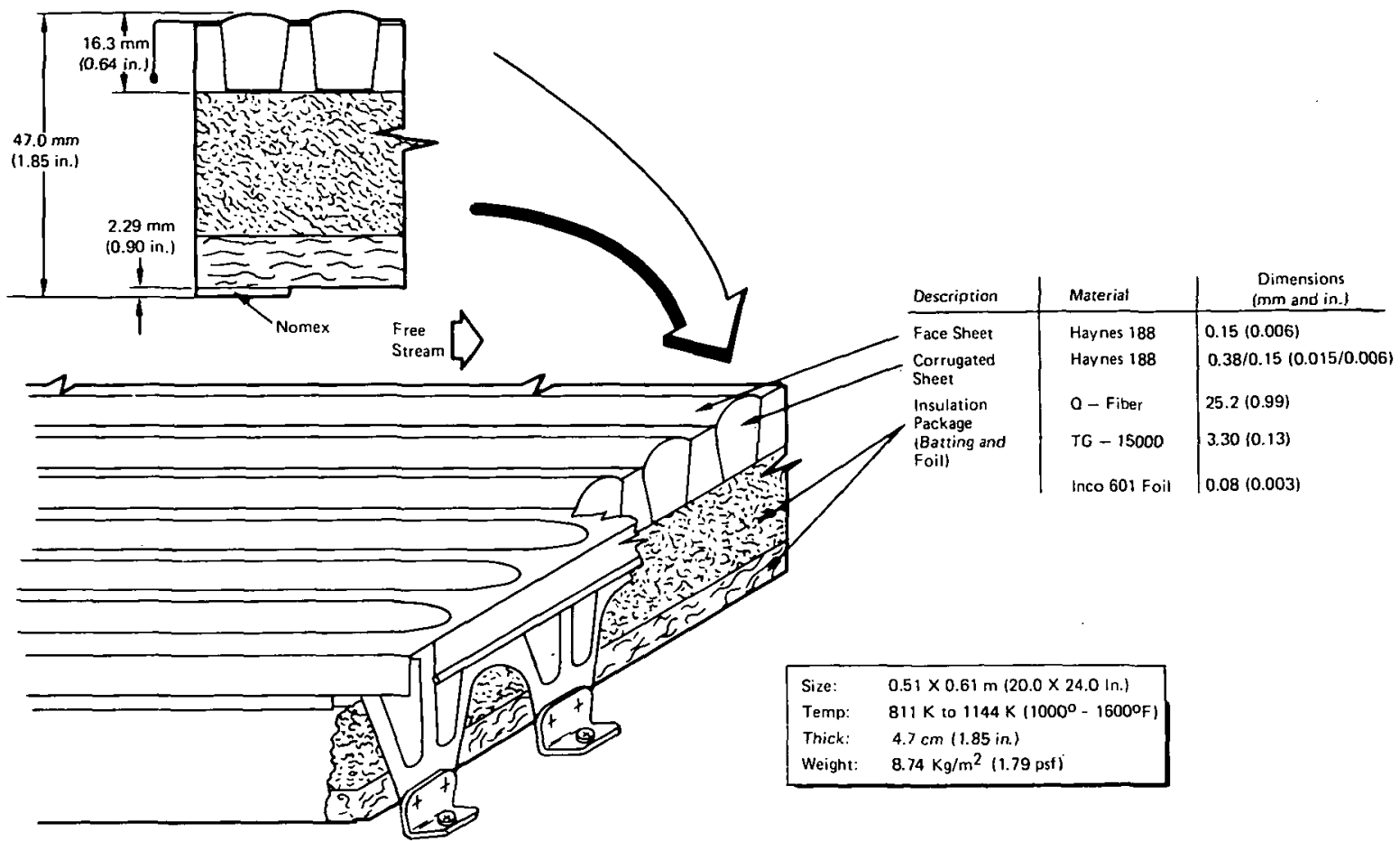

Figure 25. Superalloy Corrugated Stand-off

are free to rotate in all directions, and three secondary posts are rotationally restrained in all but one direction. The panel is attached to these posts by means of spherical mating surfaces. The combined effect is to prevent the build-up of excessive thermal stresses and strains.

Three-dimensional NASTRAN models were used for both the refractory metal and the ACC panels to perform structural analysis and sizing. The final panel dimensions are shown in Figures 26 and 27.

\section{Manufacturing Considerations}

The manufacturing feasibility of all these concepts was assessed by generating detailed manufacturing plans. All steps of the plan were evaluated to assure that the plans are feasible and are understood.

The basic fabrication processes for all the metallic concepts are well known and are commonly used in manufacturing state-of-the-art hardware. These include machining, superplastic forming, diffusion bonding, brazing, and welding. The only process that is not state-of-the-art production for the metallic concepts is bimetallic diffusion bonding, which joins the Inconel sidewall to the titanium inner panel in the bimetallic sandwich concepts. This process has been demonstrated in the laboratory and is being developed into a production process. 


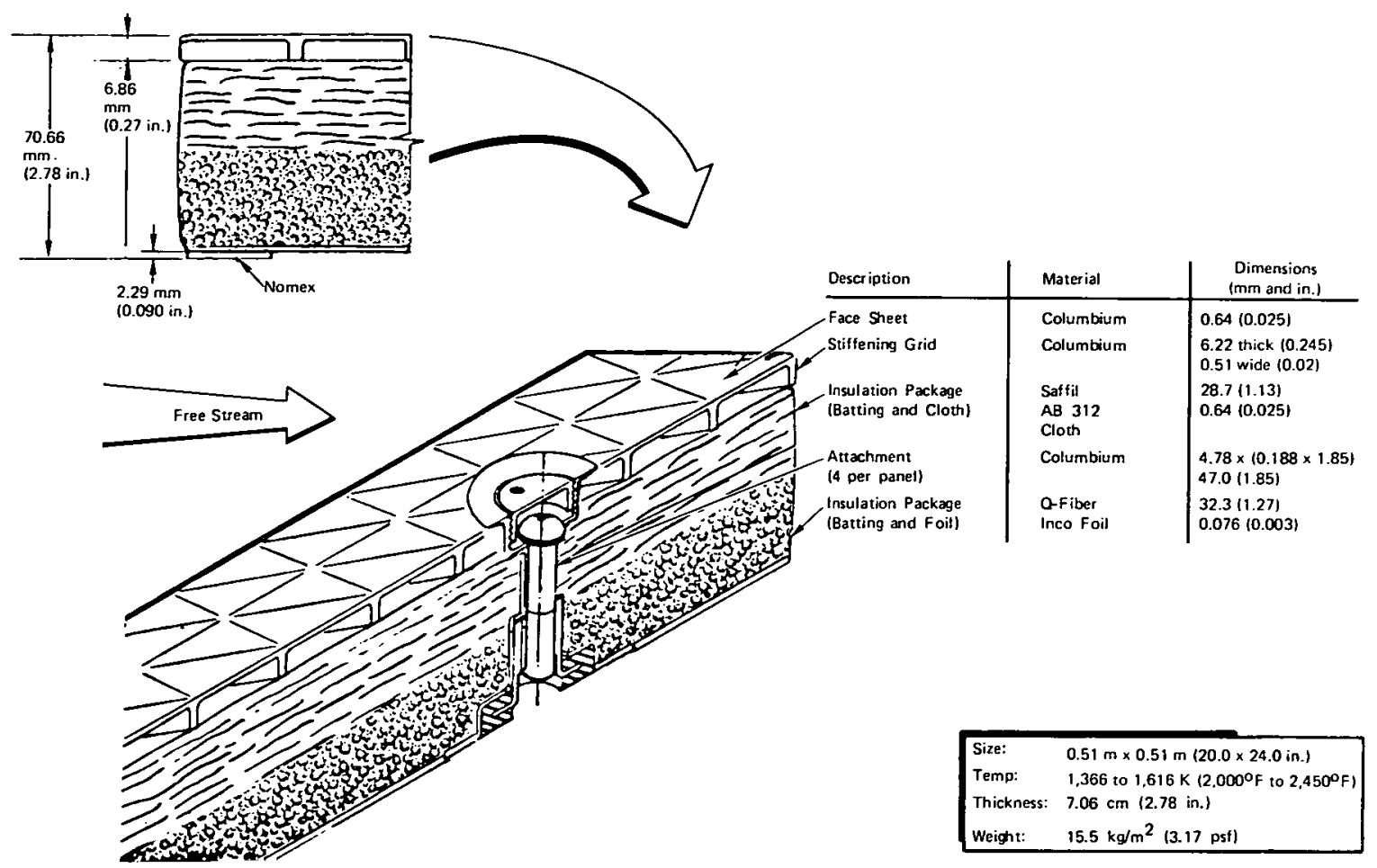

Figure 26. Refractory Stand-off

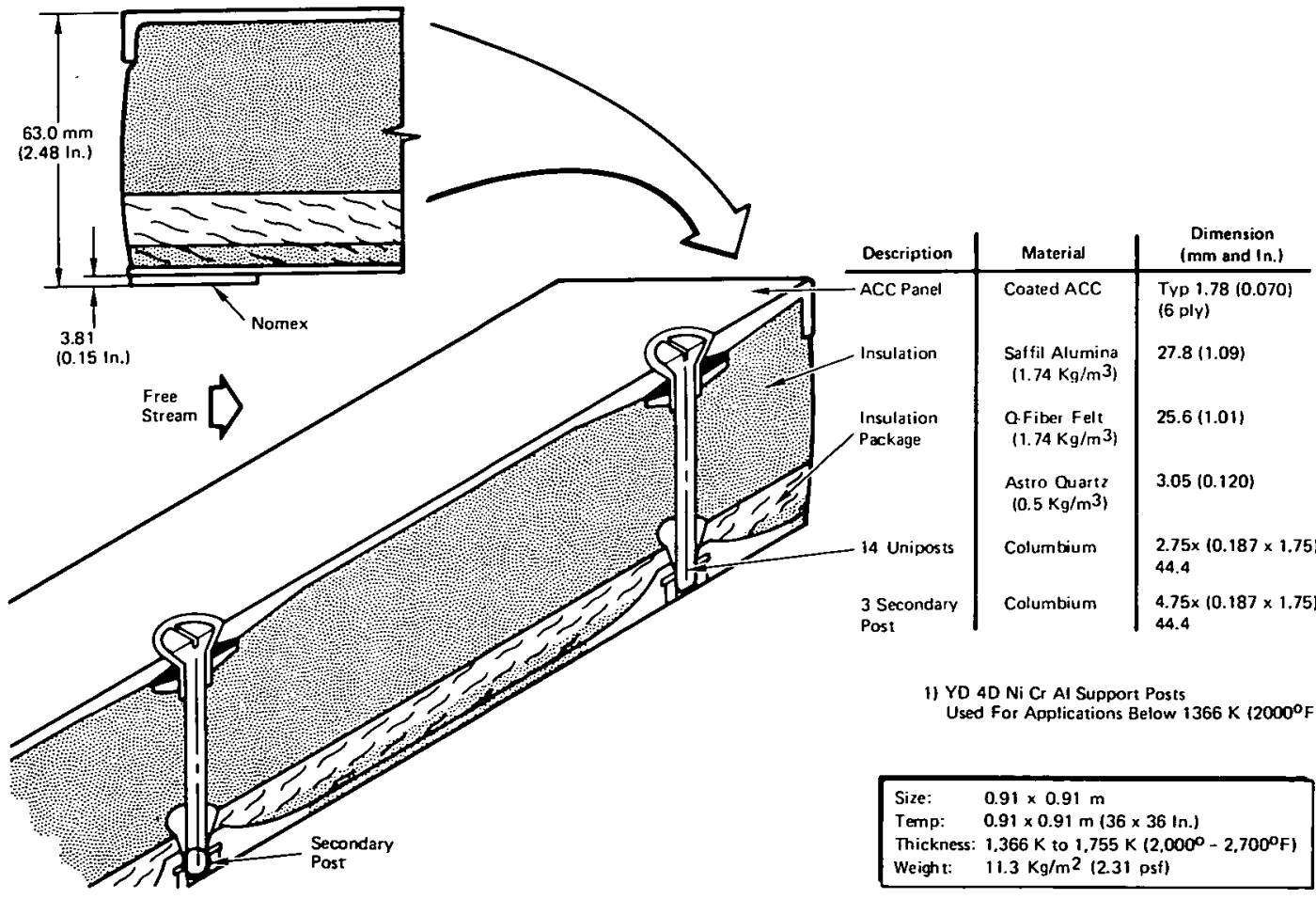

Figure 27. Carbon-Carbon Stand-off 
The ACC proposed for the stand-off concept is slightly different from the reinforced carbon-carbon (RCC) currently used for the orbiter leading edge and nose cap, in that the carbon cloth is produced from an organic base fiber which yields higher strength and modulus properties. Other differences include a change in matrix densifiers, use of fewer plies, and a reduction in coating thickness. However, the production processes for the ACC are very similar to those of the RCC, which are well understood.

\section{CANDIDATE SYSTEMS DEFINITION}

A total of six candidate systems consisting of one concept in each area of the orbiter were developed for systems analysis and comparison. These systems are described in Table 1 . Note that the titanium multiwall is used in Area $I$ for all systems, since it was the only concept considered for low temperature application. The rationale for development of each system is indicated below.

System 1 consists entirely of metallic prepackaged concepts. This provides a great deal of commonality in terms of attachments and interfaces between concepts. Similarly, System 2 utilizes metallic stand-off concepts in all applicable areas, for the same reasons. Systems 3 and 4 are variations of systems 2 and 1 respectively, which provide maximum use of carbon-carbon (Areas III and IV).

Table 1. Candidate Systems Summary

\begin{tabular}{|c|l|l|l|l|}
\hline System & Area I & Area II & Area III & Area IV \\
\hline 1 & $\begin{array}{l}\text { Titanium } \\
\text { multiwal1 }\end{array}$ & $\begin{array}{l}\text { Superalloy } \\
\text { sandwich }\end{array}$ & $\begin{array}{l}\text { Superalloy } \\
\text { sandwich }\end{array}$ & $\begin{array}{l}\text { Refractory } \\
\text { sandwich }\end{array}$ \\
\hline 2 & $\begin{array}{l}\text { Titanium } \\
\text { multiwal1 }\end{array}$ & $\begin{array}{l}\text { Superalloy } \\
\text { stand-off }\end{array}$ & $\begin{array}{l}\text { Superalloy } \\
\text { stand-off }\end{array}$ & $\begin{array}{l}\text { Refractory } \\
\text { stand-off }\end{array}$ \\
\hline 3 & $\begin{array}{l}\text { Titanium } \\
\text { multiwal1 }\end{array}$ & $\begin{array}{l}\text { Superalloy } \\
\text { stand-off }\end{array}$ & $\begin{array}{l}\text { Carbon-carbon } \\
\text { stand-off }\end{array}$ & $\begin{array}{l}\text { Carbon-carbon } \\
\text { stand-off }\end{array}$ \\
\hline 4 & $\begin{array}{l}\text { Titanium } \\
\text { multiwal1 }\end{array}$ & $\begin{array}{l}\text { Superalloy } \\
\text { sandwich }\end{array}$ & $\begin{array}{l}\text { Carbon-carbon } \\
\text { stand-off }\end{array}$ & $\begin{array}{l}\text { Carbon-carbon } \\
\text { stand-off }\end{array}$ \\
\hline 5 & $\begin{array}{l}\text { Titanium } \\
\text { multiwal1 }\end{array}$ & $\begin{array}{l}\text { Superalloy } \\
\text { stand-off }\end{array}$ & $\begin{array}{l}\text { Superalloy } \\
\text { stand-off }\end{array}$ & $\begin{array}{l}\text { Carbon-carbon } \\
\text { stand-off }\end{array}$ \\
\hline 6 & $\begin{array}{l}\text { Titanium } \\
\text { multiwal1 }\end{array}$ & $\begin{array}{l}\text { Superalloy } \\
\text { sandwich }\end{array}$ & $\begin{array}{l}\text { Superalloy } \\
\text { sandwich }\end{array}$ & $\begin{array}{l}\text { Carbon-carbon } \\
\text { stand-off }\end{array}$ \\
\hline
\end{tabular}

The first four systems were developed on the basis of considerations of concept interfaces and commonality of attachments, construction, etc. Finally, Systems 5 and 6 were included on the basis of concept weight comparisons. The carbon-carbon offers a definite weight advantage in Area IV, but a disadvantage 
in Area III. Thus Systems 5 and 6 were created by substituting the appropriate metallic concept for Area III of systems 3 and 4, respectively, thereby providing the lightest weight systems for the two basic concepts.

The weight breakdown for the candidate systems is presented in Table 2. TPS weights were derived by taking the point design unit weights of each concept in the system and spreading them over the applicable area. However, insulation requirements vary over each of the four areas. Therefore, insulation thickness variations over each area were investigated to derive algorithms and weight adjustment factors. On the basis of this study, an OML fairing weight adjustment was computed for each system. Finally, concept closeout designs for interfaces with other concepts and with orbiter penetrations were assessed to determine appropriate weight adjustments. Thus the estimated installed weight for each system is the sum of the TPS weight, the OML fairing adjustment weight, and the interface, penetration, and closeout weight.

Table 2. Candidate Systems Weight Comparisons

\begin{tabular}{|l|c|c|c|c|c|c|}
\hline \multirow{2}{*}{ Category } & \multicolumn{7}{|c|}{ Weight - kg (1b) } \\
\cline { 2 - 7 } & $\begin{array}{c}\text { System } \\
1\end{array}$ & $\begin{array}{c}\text { System } \\
2\end{array}$ & $\begin{array}{c}\text { System } \\
3\end{array}$ & $\begin{array}{c}\text { System } \\
4\end{array}$ & $\begin{array}{c}\text { System } \\
5\end{array}$ & $\begin{array}{c}\text { System } \\
6\end{array}$ \\
\hline - TPS weight & $\begin{array}{c}5,351 \\
(11,796)\end{array}$ & $\begin{array}{c}5,595 \\
(12,335)\end{array}$ & $\begin{array}{c}5,303 \\
(11,690)\end{array}$ & $\begin{array}{c}5,222 \\
(11,513)\end{array}$ & $\begin{array}{c}5,134 \\
(11,318)\end{array}$ & $\begin{array}{c}4,758 \\
(10,489)\end{array}$ \\
\hline $\begin{array}{l}\text { - OMS fairing } \\
\text { weight adjustment }\end{array}$ & $\begin{array}{c}48 \\
(106)\end{array}$ & $\begin{array}{c}73 \\
(162)\end{array}$ & $\begin{array}{c}72 \\
(158)\end{array}$ & $\begin{array}{c}72 \\
(158)\end{array}$ & $\begin{array}{c}73 \\
(162)\end{array}$ & $\begin{array}{c}48 \\
(106)\end{array}$ \\
\hline $\begin{array}{l}\text { - Interface } \\
\text { penetration and } \\
\text { closeout }\end{array}$ & $\begin{array}{c}1,342 \\
(2,958)\end{array}$ & $\begin{array}{c}1,342 \\
(2,958)\end{array}$ & $\begin{array}{c}1,342 \\
(2,958)\end{array}$ & $\begin{array}{c}1,342 \\
(2,958)\end{array}$ & $\begin{array}{c}1,342 \\
(2,958)\end{array}$ & $\begin{array}{c}1,342 \\
(2,958)\end{array}$ \\
\hline - Insta1led weight & $\begin{array}{c}6,740 \\
(14,860)\end{array}$ & $\begin{array}{c}7,010 \\
(15,455)\end{array}$ & $\begin{array}{c}6,716 \\
(14,806)\end{array}$ & $\begin{array}{c}6,636 \\
(14,629)\end{array}$ & $\begin{array}{c}6,549 \\
(14,438)\end{array}$ & $\begin{array}{c}6,148 \\
(13,553)\end{array}$ \\
\hline
\end{tabular}

\section{ORBITER IMPACTS}

Potential operational impacts to the orbiter were assessed throughout the analysis and design efforts in terms of mass, payload capability, changes in the outer mold line (OML), turnaround time, and flight trajectory. No major impacts were identified. Some changes in the OML are inevitable with the application of some of the alternate concepts. The mold line variations appear to be small and will only occur in a limited number of areas on the vehicle. No major problems or impacts are anticipated in refairing these areas.

Potential orbiter performance and schedule impacts were identified and assessed during the study. Since on the basis of alternate system weight estimates, no substantial changes in the overall vehicle mass are expected, payload capability should not be affected. 
One item of major importance is the potential impact of the alternate concepts on orbiter surface roughness. During entry, the thermal gradients in the TPS metallic panels will produce panel bowing ranging up to $6.35 \mathrm{~mm}(0.25$ in.) amplitude in both directions over a span of $587 \mathrm{~mm}(23.1 \mathrm{in.})$. The effect of this panel bowing phenomenon is of major concern since these will strongly influence boundary layer transition from laminar to turbulent flow. Premature boundary layer transition impacts both the maximum surface temperature by increased heating rates and the overall TPS weight (thickness) by increased heat load. Discontinuities due to panel-edge interfaces are of similar concern; however, these concerns have been minimized in the present design. The overlaps between panels eliminate gaps and are oriented to provide rearward facing steps.

The panel bowing shape may be either convex for positive thermal gradients (+ delta $T$ ) or concave for negative thermal gradients ( - delta $T$ ) as shown in Figure 28 . The effective bowing roughness $\left(K_{B} E_{Q}\right)$ is a function of $H / W$, the ratio of the total panel displacement (H) over the length ( $2 w$ ) of the displaced pane1. The magnitude of panel bowing may also be described in terms of the panel edge displacement angle (theta). This is the major parameter in determining whether local flow separation (and reat tachment) occurs. Separation will cause increased localized aeroheating, promote boundary layer transition, and may seriously affect the overall vehicle aerodynamics.

- PANEL BOWING CRITERIA

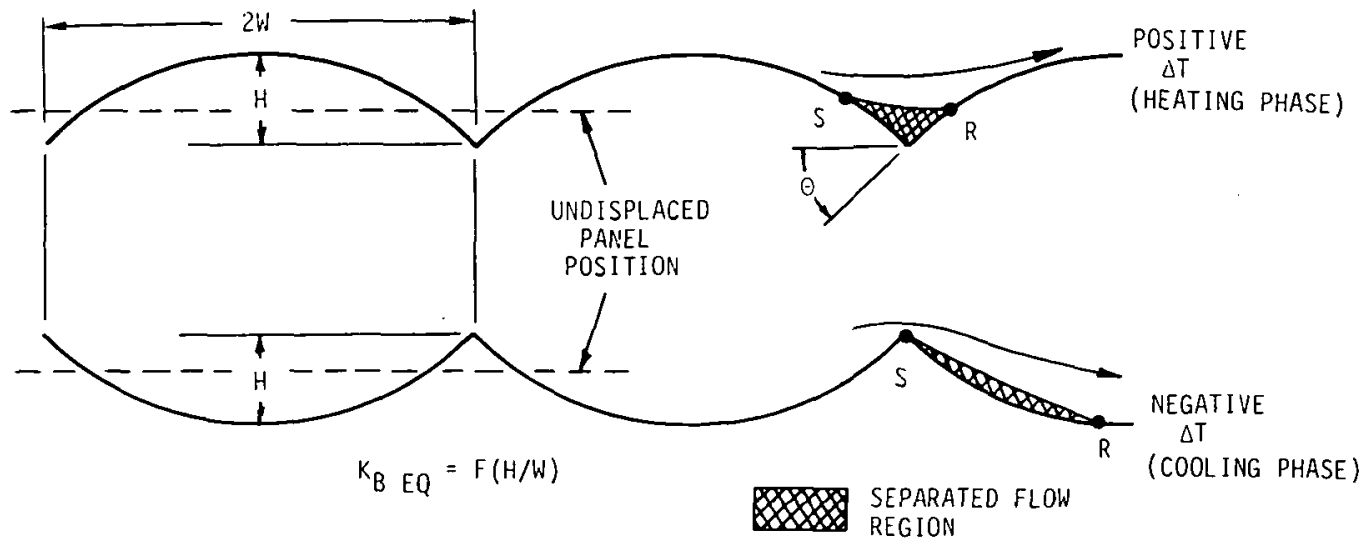

- Step and gap criteria ( $\theta$ SMall)
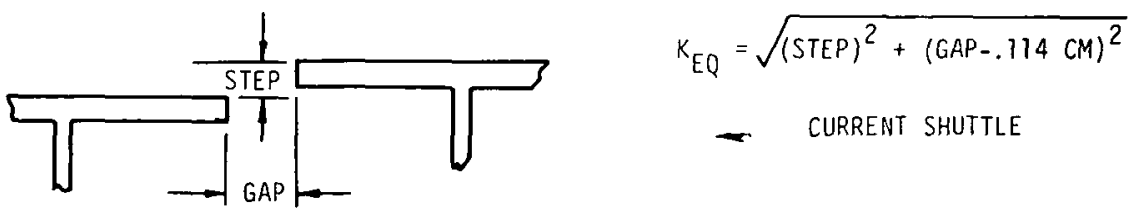

Figure 28. Effect of Roughness 
During times of large thermal gradients (large displacements), the total vehicle roughness is dominated by the effective bowing roughness, $K_{B} E Q$. The actual relationship of bowing on $K_{B} E Q$ is unknown and is an area where detailed testing is needed. However, when the thermal gradients are relatively small (small displacements and hence small theta), the panel edge interface step and gap will dominate the roughness. The Shuttle step and gap criteria are judged to be inappropriate for the current alternate TPS concepts.

Assessment of the overall effects on the aerodynamic and heating environments is beyond the scope of this study, since it requires extensive testing. This problem is not deemed to be a "show stopper" at this time, but should be reassessed after sufficient orbiter flight data are available.

Al1 of the ATPS candidate configurations studied share one positive attribute--each appears to have no adverse impact upon orbiter serial ground turnaround time (GTAT). (See Figure 29.) Reliability/maintainability studies of the concepts/systems indicate an expected inspection and maintenance requirement in the range of 250 to 600 manhours per flight for the TPS, easily compressible to 40 or less turnaround crewhours spent on TPS refurbishment per flight.

On the basis of processing timeline assessments, it was determined that the sequential path of payload bay operations drives Orbiter Processing Facility (OPF) serial flow-through time as long as TPS total refurbishment time remains below 118 crewhours. This is assuming three-shift, 5-day operations on the TPS path. However, it appears feasible to size the TPS inspect/maintain crew for all of the candidate ATPS configurations to allow reduced second and third shift requirements.

Since expected ATPS inspection and maintenance crew costs are small in relation to other TPS-level and STS-level costs (amounting to an indeterminate potential savings in personnel costs) and since it appears that all ATPS refurbishment requirements can be accommodated within the currently assessed opf flowtime without adverse impact, GTAT does not provide a significant basis for discriminating between ATPS configurations in the study's merit function evaluation.

\section{MERIT FUNCTION EVALUATION}

The ultimate objective of the merit function analysis used in the Alternate Thermal Protection System (ATPS) study was selection of the best configuration from among the candidate ATPS concepts. For purposes of the merit function evaluation, the term "best" was defined in terms of improving space Transportation system (STS) operational capability at a minimum total cost within acceptable risk constraints.

Figure 30 indicates the "tier-down" structure used in the ATPS merit function evaluation. At the primary level, three criteria were specified for an efficient acquisition of an operational ATPS for the planned orbiter vehicle (OV) fleet--favorable mission impact, affordable total cost, and acceptable risk. Each of these three primary goals was then subjected to a second-level tier-down in which ten potential discriminators between candidate ATPS 
SERIAL GROUND TURNAROUND TIME (GTAT) IMPACT

(A) TOTAL TPS REFURBISH TIME 0-85 WH NO EFFECT ON GTAT - PLB OPS UMBRELLA POSSIBLE REDUCED TPS CREW COST 46-85 WH, NO 3RD SHIFT 0-45 WH, NO 2ND SHIFT

(B) TOTAL TPS REFURBISH TIME 86-117 WH NO EFFECT ON GTAT - PLB OPS UMBRELLA

(C) TOTAL TPS REFURBISH TIME $\geq 118 \mathrm{WH}$ HOUR-FOR-HOUR INCREASE IN GTAT QUEUE "SERVICE" IMPACTS

FLEET SIZE

FACILITIES

STS CAPACITY

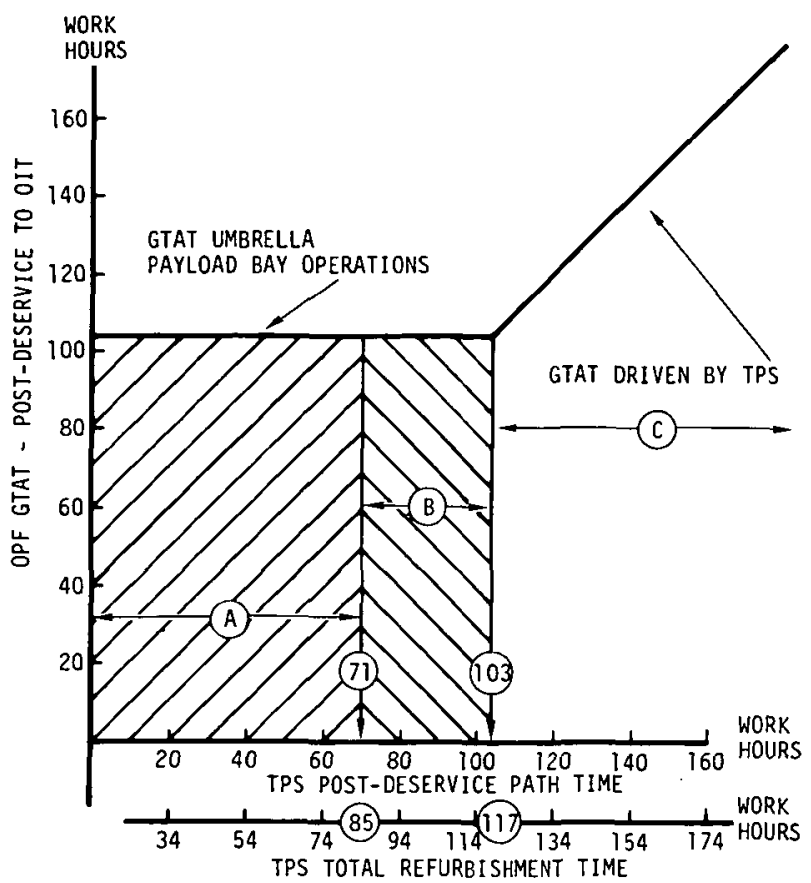

Figure 29: Orbiter Schedule Impacts

- OBJECTIVE - SELECT "BEST" ALTERNAATE

- IDENTIFY DISCRIPIIIATORS

- EVALUATE CONCEPTS, SYSTEMS

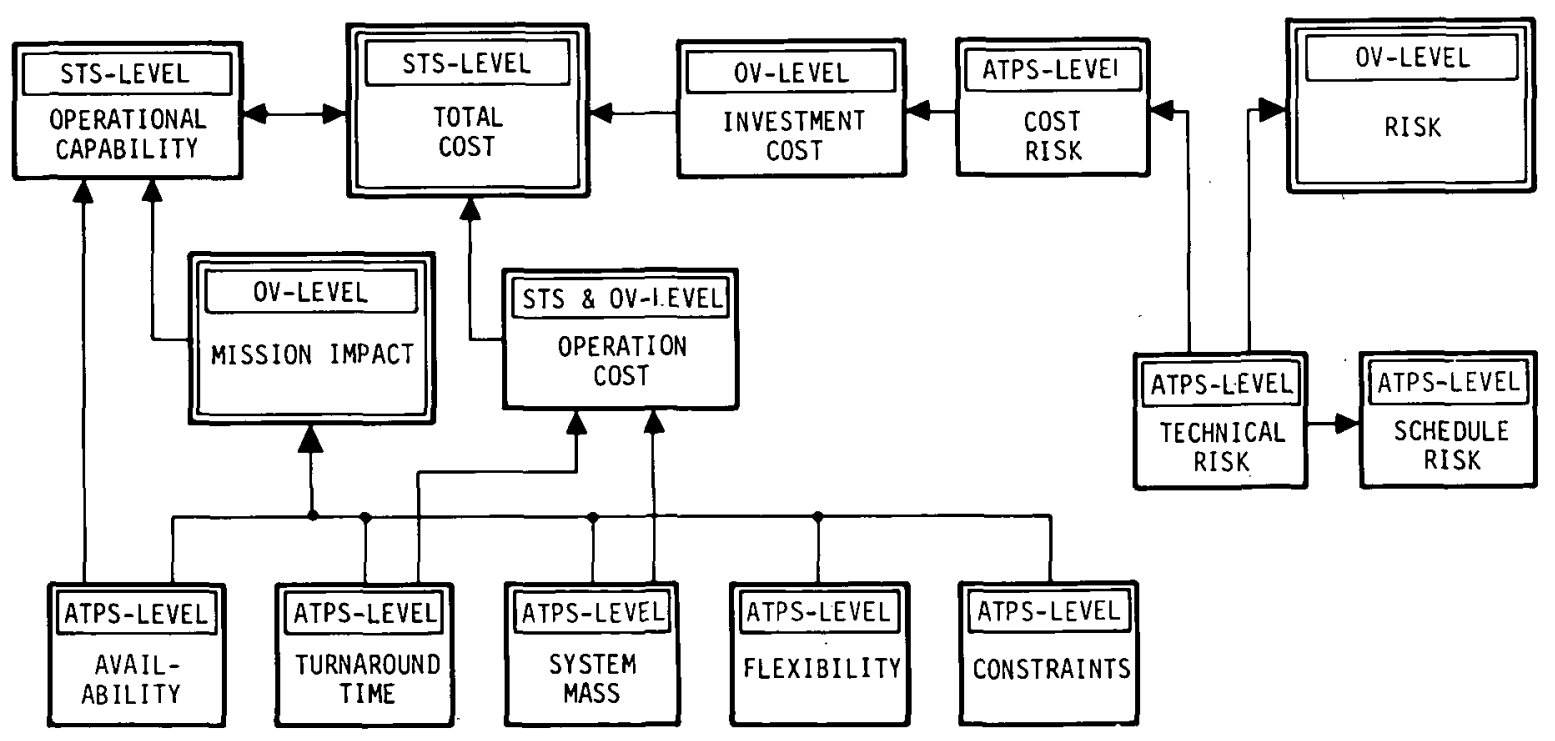

Figure 30. Merit Function Analysis Objective and Structure 
configurations were identified. Each of the ten secondary merit items was subsequently analyzed through a third-level tier-down as shown in Figures 31 and 32 .

Specific secondary merit items examined as part of the study's analysis of ATPS impacts on the OV/STS mission capability, along with a brief description of factors, were:

- Availability--Design, Development, Test and Evaluation (DDT\&E), rough order of magnitude (ROM) schedules for each concept were estimated on the basis of technology status, the level of conceptual design effort remaining to be done, and engineering and advanced development projections. Concept schedules were combined to the ATPS level; estimated time requirements for installation and certification were added; and ATPS/OV initial operating capability (IOC) dates were derived.

- Turnaround Time--ATPS refurbishment processing times were developed from study team analysis of each concept's reliability and maintainability estimates. Direct operations and support costs for inspection, maintenance, and spares support were also evaluated by concept, then summed to ATPS level and used as an input to OV/STS net operation cost evaluation.

- System Mass--Weight estimates for each concept were developed from component mass analysis, spread from point estimates to acreage areas, and adjusted to include installation and orbiter outer moldline (OML) penalties (where appropriate) to derive total system mass. ATPS mass was subsequently used as input to STS-level net operation cost analysis.

- Flexibility--Each concept was examined for existence of significant operational advantages compared to other candidate concepts in the same temperature region.

- Constraints--Each concept was examined for existence of significant operational disadvantages compared to other candidate concepts in the same temperature region.

Specific secondary merit items examined as part of the ATPS study's analysis of STS-level total cost, along with a brief description of factors, were:

- OV-Level Investment Costs--DDT\&E ROM programmatic estimates were made for each concept; system integration efforts were added; and provision was made for installation and certification. Parametric references to RSI, RCC, and relative manufacturing complexities were used to gauge the "reasonability" of concept DDT\&E estimates throughout the work/cost breakdown structure. Learning curves were applied to concept DDT\&E costs to obtain production program ROM costs for three shipset quantities, and concept ROM costs were then summed to ATPS level. 


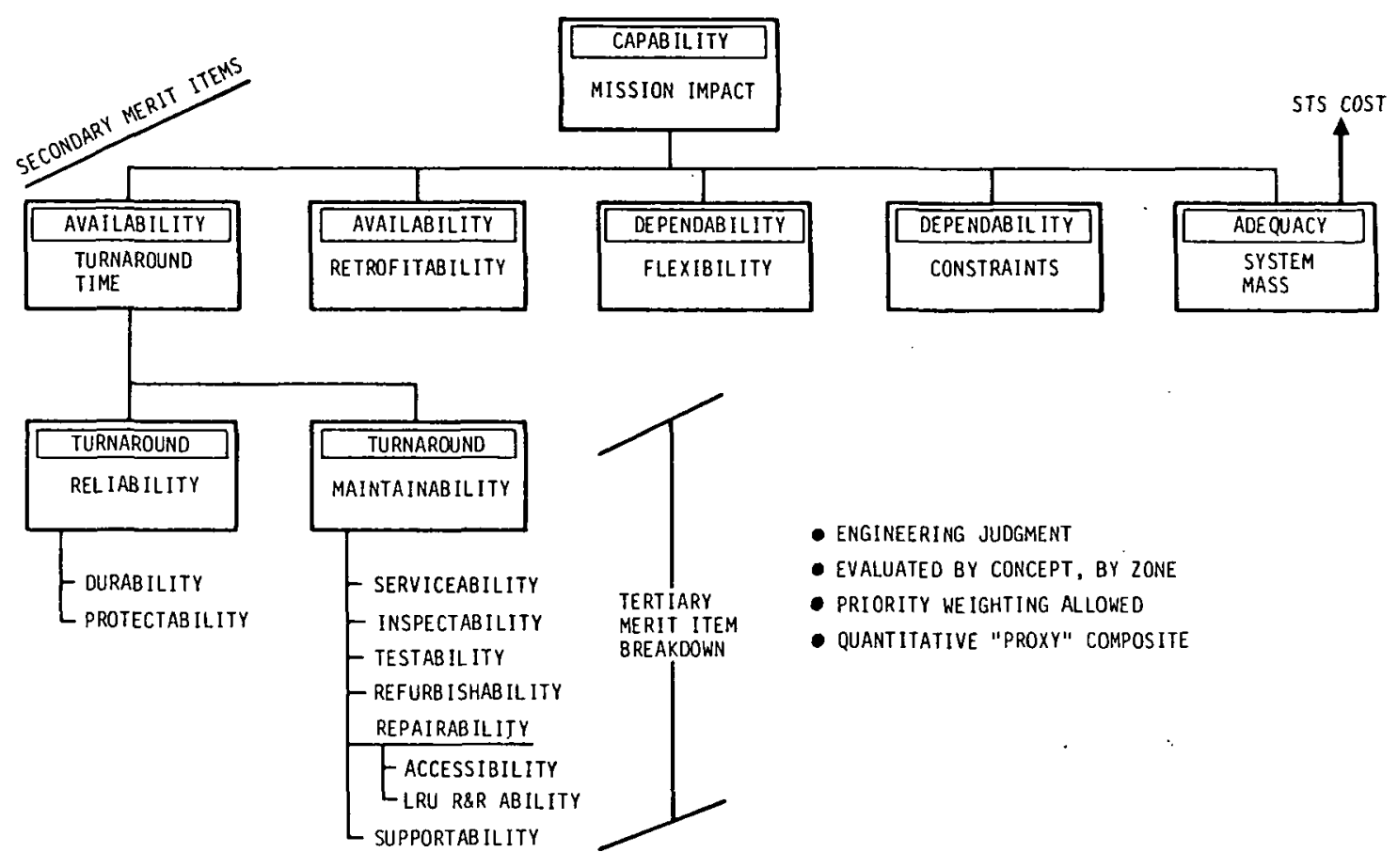

Figure 31. Merit Function Breakdown (Mission Impact, Turnaround Time)

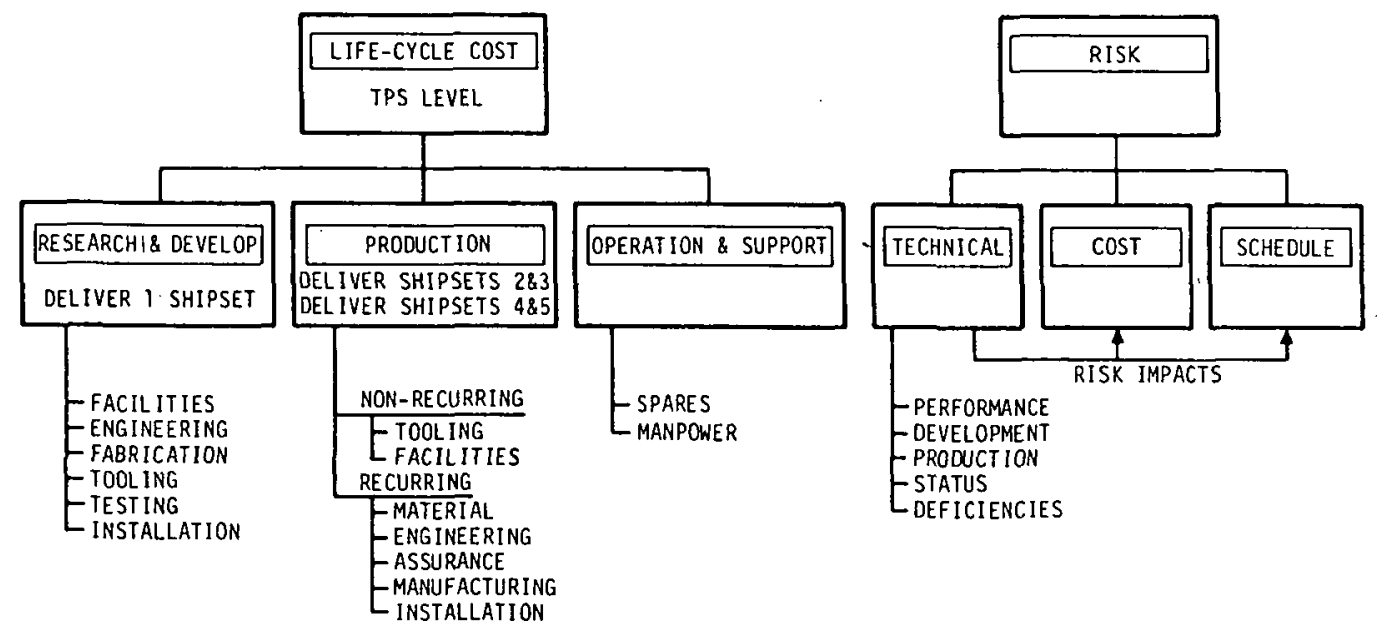

Figure 32. Merit Function Breakdown (Life Cycle Cost and Risk) 
- Net Operations Cost--Concept direct operation and support (O\&S) cost estimates were generated as part of the reliability/maintainability analyses and summed to ATPS level. The ATPS-level net operation cost was computed as the combination of the ATPS O\&S cost per flight plus (or minus) the payload capacity penalty per flight, then projected out to a maximum 300-mission fleet life.

A review of the concepts' critical technologies led to identification of technical risks associated with each concept and potential impacts of those identified concept risks on ATPS-level ROM cost and ROM schedule. Risk analysis was limited to subjective statements based on engineering judgment and, for each concept, began with a consensus assessment of technology status, proceeded through specification of technology deficiencies expected to be encountered in engineering development and advanced development DDT\&E phases, and culminated with enumeration of probable risk impacts on concept cost and schedule estimates. After the risk identification and risk impact assessment for each concept were completed, results were arrayed in an ATPS-level risk summary matrix (Figure 33). From a programmatic standpoint, all concepts, except the refractory metallic, high-temperature zone designs, appear to have acceptable development risks. Thus, while development risk assessments provide a basis for discriminating against the refractory metal concepts, all configurations of Area II and Area III concepts are roughly equivalent in terms of overall risk.

\begin{tabular}{|c|c|c|c|c|c|c|c|c|c|c|c|c|c|c|c|c|c|c|}
\hline SYSTEM & & 1 & & & 2 & & & 3 & & & 4 & & & 5 & & & 6 & \\
\hline AREA & TECH & $\cos T$ & $\mathrm{SCH}$ & $\mathrm{TECH}$ & $\cos T$ & $\mathrm{SCH}$ & TECH & COST & $\mathrm{SCH}$ & TECH & COST & $\mathrm{SCH}$ & TECH & $\operatorname{COST}$ & $\mathrm{SCH}$ & TECH & COST & SCH \\
\hline I & LOW & MOD & $\begin{array}{l}\text { LOW- } \\
\text { MOD }\end{array}$ & LOW & MOD & $\begin{array}{l}\text { LOW- } \\
\text { MOD }\end{array}$ & LOW & MOD & $\begin{array}{l}\text { LOW- } \\
\text { MOD }\end{array}$ & LOW & MOD & LOW- & LOW & MOD & $\begin{array}{l}\text { LOW- } \\
\text { MOD }\end{array}$ & LOW & MOD & $\begin{array}{l}\text { LOW- } \\
\text { MOD }\end{array}$ \\
\hline II & $\begin{array}{l}\text { LOW- } \\
\text { MOD }\end{array}$ & MOD & $\begin{array}{l}\text { LOW- } \\
\text { MOD }\end{array}$ & LOW & LOW & LOW & LOW & LOW & LOW & $\begin{array}{l}\text { LOW- } \\
\text { MOD }\end{array}$ & MOD & $\begin{array}{l}\text { LOW- } \\
\text { MOD }\end{array}$ & LOW & LOW & LOW & $\begin{array}{l}\text { LOW- } \\
\text { MOD }\end{array}$ & MOD & $\begin{array}{l}\text { LOW- } \\
\text { MOD }\end{array}$ \\
\hline III & $\begin{array}{l}\text { LOW- } \\
\text { MOD }\end{array}$ & MOD & $\begin{array}{l}\text { LOW- } \\
\text { MOD }\end{array}$ & Low & LOW & LOW & $\begin{array}{l}\text { LOW- } \\
\text { MOD }\end{array}$ & $\begin{array}{l}\text { LOW- } \\
\text { MOD }\end{array}$ & $\begin{array}{l}\text { LOW- } \\
\text { MOD }\end{array}$ & $\begin{array}{l}\text { LOW- } \\
\text { MOD }\end{array}$ & $\begin{array}{l}\text { LOW- } \\
\text { MOD }\end{array}$ & $\begin{array}{l}\text { LOW- } \\
\text { MOD }\end{array}$ & LOW & LOW & LOW & $\begin{array}{l}\text { LOW- } \\
\text { MOD }\end{array}$ & MOD & $\begin{array}{l}\text { LOW- } \\
\text { MOD }\end{array}$ \\
\hline IV & $\mathrm{HIGH}$ & $\mathrm{HIGH}$ & HIGH & $\begin{array}{l}\text { MOD- } \\
\text { HIGH }\end{array}$ & $\begin{array}{l}\text { MOD- } \\
\text { HIGH }\end{array}$ & LOW & $\begin{array}{l}\text { LOW- } \\
\text { MOD }\end{array}$ & $\begin{array}{l}\text { LOW- } \\
\text { MOD }\end{array}$ & $\begin{array}{l}\text { LOW- } \\
\text { MOD }\end{array}$ & $\begin{array}{l}\mathrm{LON}- \\
\mathrm{MOD}-\end{array}$ & $\begin{array}{l}\text { LOW- } \\
\text { MOD }\end{array}$ & $\begin{array}{l}\text { LOW- } \\
\text { MOD }\end{array}$ & $\begin{array}{l}\text { LOW- } \\
\text { MOD }\end{array}$ & $\begin{array}{l}\text { LOW- } \\
\text { MOD }\end{array}$ & $\begin{array}{l}\text { LOW- } \\
\text { MOD }\end{array}$ & $\begin{array}{l}\text { LOW- } \\
\text { MOD }\end{array}$ & $\begin{array}{l}\text { LOW- } \\
\text { MOD }\end{array}$ & $\begin{array}{l}\text { LOW- } \\
\text { MOD }\end{array}$ \\
\hline
\end{tabular}

Figure 33. ATPS System Risk Summary 
Application of the merit function evaluation methodology proceeded from the concept level for each of the concepts to the ATPS level on the six candidate systems. As shown in merit function process summary (Table 3 ), seven of the ten previously established secondary evaluation criteria emerged as discriminators between ATPS candidates. Of these, ATPS "system mass" and its associated impact on ov payload capacity proved to be the most significant discriminator between ATPS because of its economic valuation at the STS level.

Table 3. Merit Function Process Summary

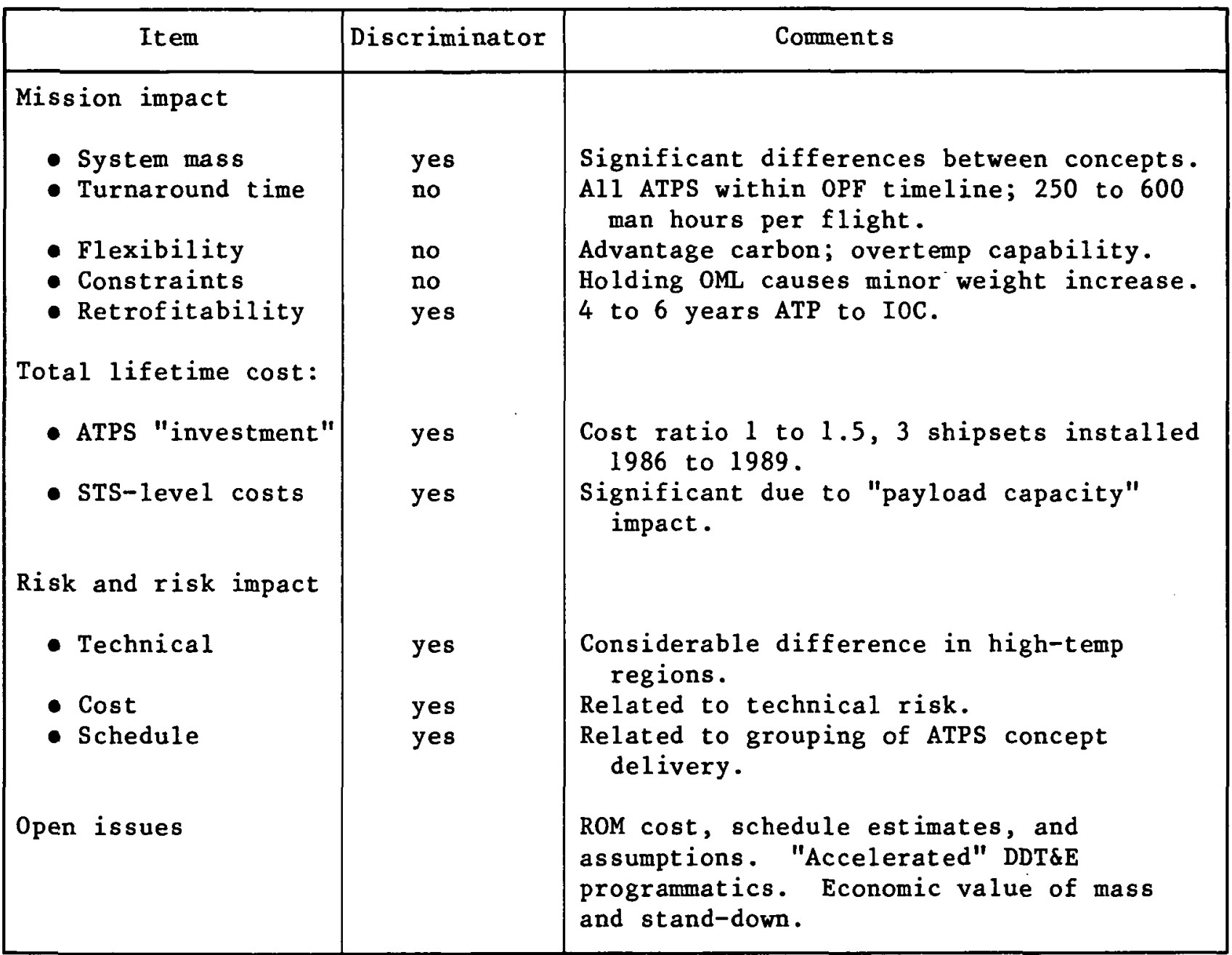

Although the spread in ATPS ROM investment outlay is small and direct O\&S costs across candidate configurations are nearly equal, significant differences in delta mass valuations create clear-cut decision preferences on an ROM STS-level total cost basis. Figure 34 indicates the spread in ATPS STS-1evel ROM total economic cost for a three shipset program at various flight activity levels and the emergence of a preferred ATPS configuration. The 1ightest weight ATPS studied, System 6, has a low (within "noise" of lowest) front-end investment outlay, nominal direct operation and support cost, a payload (capacity increase) cost savings. 


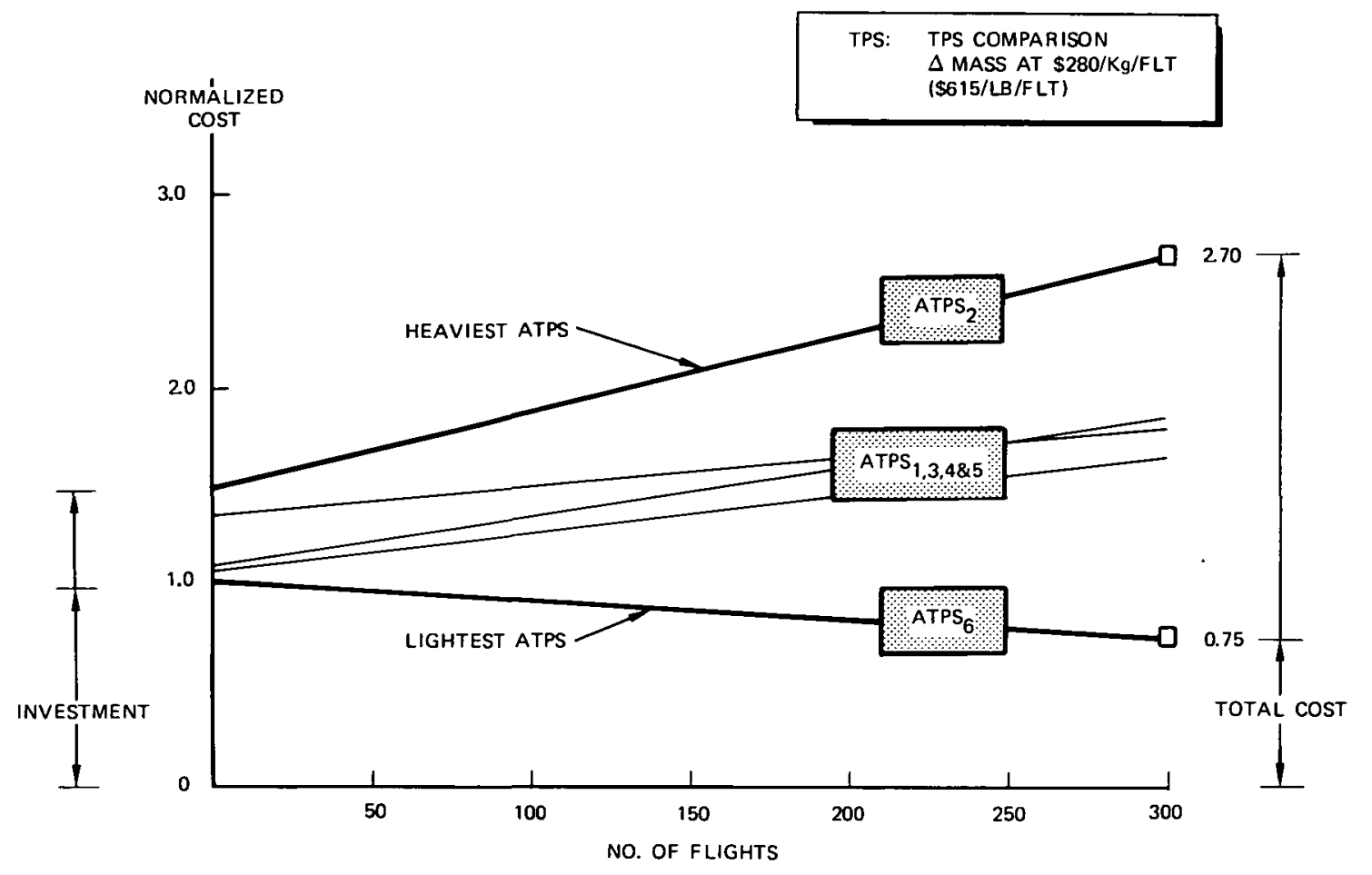

Figure 34. STS-Level ROM Total Economic Cost, Three Shipsets Installed

Figure 35 shows the merit function evaluation matrix completed for decisionmaking purposes. An examination of the overall evaluation matrix indicates that, in terms of mission impact, cost and risk criteria, system 6 or a derivative thereof is the "best compromise" solution. System selection, however, is highly contingent upon the accuracy of the concept mass and cost estimates, the selection of a baseline reference weight for existing TPS system, and the preflight evaluation of orbiter mass changes.

\section{SYSTEM SELECTION}

Selection of the "best" alternate TPS was made through a process of evaluating the results of the merit function analysis, concept designs and analysis, and systems considerations. Final selection involved the best engineering judgment by NASA LaRC and the ATPS industry study teams.

On the basis of results of the merit function analysis, System 6 emerged as the apparent best system. These results were further synthesized, considering the concepts in each area and the relationships of the concepts at a systems level.

In the low-temperature area, up to $811 \mathrm{~K}\left(1000^{\circ} \mathrm{F}\right)$ (Area I), the titanium multiwall was the only concept considered in this study. Another concept, advanced fibrous reusable surface insulation (AFRSI), is currently under development and is planned to be implemented on the orbiter, ultimately replacing all LRSI tiles; however, the AFRSI concept is generically beyond the scope of this study. Within the scope of this study, the titanium multiwall appears to be an attractive alternate to LRSI in the low temperature area. 


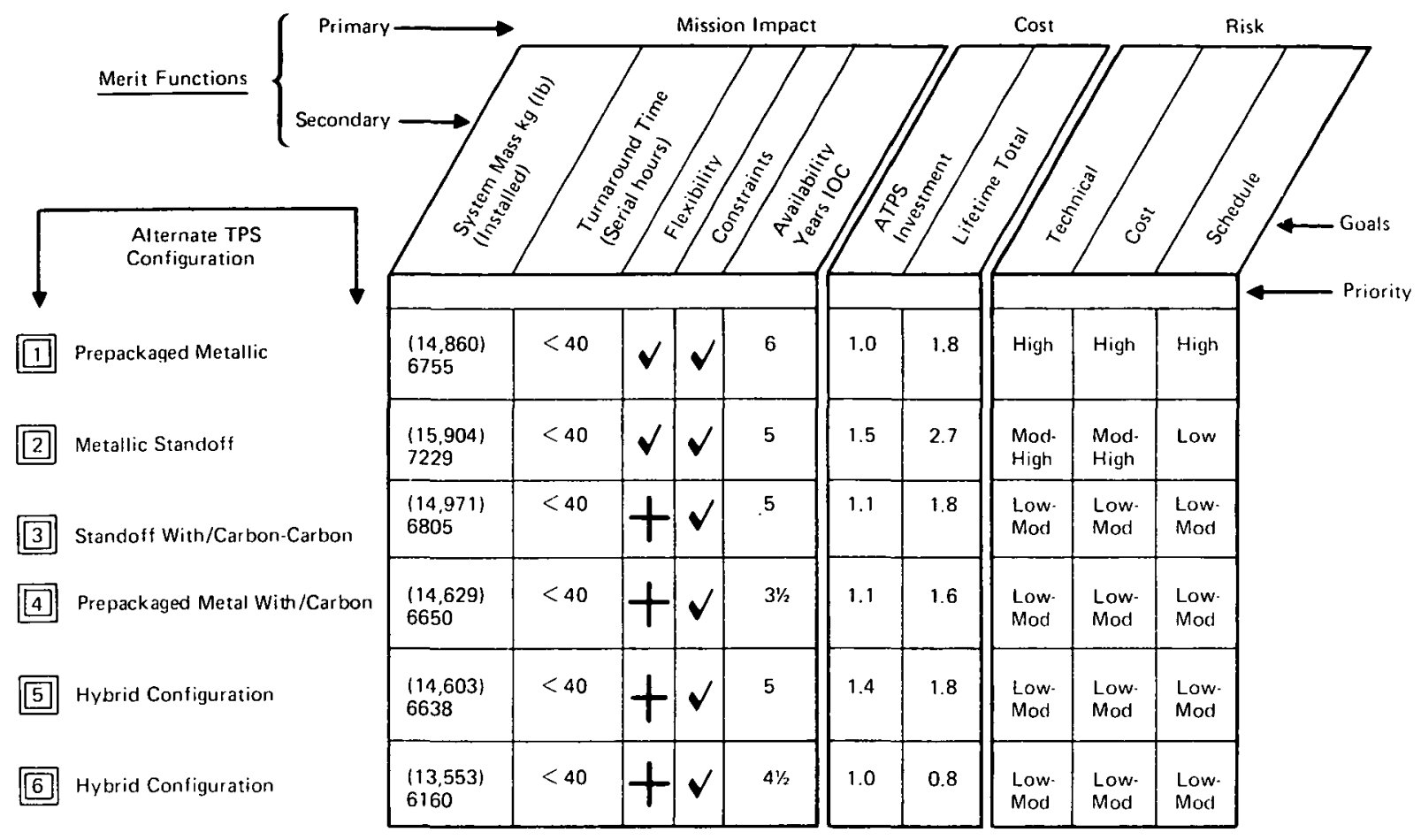

Figure 35. Merit Function Evaluation

In the mid-temperature areas, $811 \mathrm{~K}$ to $1366 \mathrm{~K}\left(1000^{\circ} \mathrm{F}\right.$ to $\left.2000^{\circ} \mathrm{F}\right)$, the superalloy bimetallic sandwich and the superalloy stand-off are basically the same, within the accuracy of the analyses. No significant discriminators based on cost or engineering analysis were found. However, programmatic assessments revealed that current on-going programs for the bimetallic sandwich concept will alleviate several identified technology deficiencies. No significant development programs are currently underway for the stand-off concepts. As a purely practical decision, in view of on-going efforts to develop the prepackaged bimetallic sandwich for mid-temperature acreage application, it was included in the selected ATPS.

The superalloy material for the bimetallic sandwich has a maximum use temperature of $1366 \mathrm{~K}\left(2000^{\circ} \mathrm{F}\right)$. Application of the concept throughout Area III (up to $1366 \mathrm{~K}$ ) provides little if any overtemperature capability. On the basis of the engineering judgment of the team, application of the bimetallic sandwich was 1 imited to $1255 \mathrm{~K}\left(1800^{\circ} \mathrm{F}\right)$, thus providing increased overtemperature capability. While this results in a weight increase by substituting carboncarbon in its place, it reduces technical performance risk.

In the high-temperature region, the carbon-carbon stand-off concept offers a definite weight advantage over all the metallic concepts considered. Some developmental risks associated with this concept are moderate, but none are considered to be "show stoppers." Thus the carbon-carbon stand-off concept was selected for areas above $1255 \mathrm{~K}\left(1800^{\circ} \mathrm{F}\right)$. 
Figure 36 presents the selected concepts, and the areas of the orbiter where they apply. The areas shown are based on 1 imiting the use of the bimetallic sandwich to $1255 \mathrm{~K}\left(1800^{\circ} \mathrm{F}\right)$ and extending the use of the carbon-carbon stand-off. Thus a modified version of System 6 was selected as the "best" alternate. While none of the concepts are completely developed or validated, the concepts do appear to be viable.

The revised weight summary for the selected system is presented in Table 4 and accounts for the area revisions. In order to assess the potential weight impact to the orbiter, a 20-percent growth factor was applied to this "paper" weight estimate, and is included in Table 4. On the basis of these assumptions, the selected system appears to be weight competitive with the RSI system.

Table 4. Selected System Weight Summary - Kg (1b)

\begin{tabular}{|c|c|c|c|c|}
\hline & $\begin{array}{l}\text { Titanium } \\
\text { Multiwall }\end{array}$ & $\begin{array}{c}\text { Bimetallic } \\
\text { Sandwich }\end{array}$ & $\begin{array}{c}\text { Carbon-Carbon } \\
\text { Stand-off }\end{array}$ & Total \\
\hline TPS weight & $\begin{array}{c}1,103 \\
(2,432)\end{array}$ & $\begin{array}{l}1,470 \\
(3,240)\end{array}$ & $\begin{array}{c}2,622 \\
(5,780)\end{array}$ & $\begin{array}{r}6,234^{*} \\
(13,742)\end{array}$ \\
\hline \multirow{3}{*}{$\begin{array}{l}\text { OML fairing weight } \\
\text { adjustment } \\
\text { Interface, penetrations } \\
\text { and closeouts }\end{array}$} & -- & $\begin{array}{c}19 \\
(43)\end{array}$ & $\begin{array}{c}57 \\
(125)\end{array}$ & $\begin{array}{r}91 * \\
(202)\end{array}$ \\
\hline & & & & $\begin{array}{c}1,331 \\
(2,935)\end{array}$ \\
\hline & & Inst & Lled weight & $\begin{array}{c}7,656 \\
(16.879)\end{array}$ \\
\hline \multicolumn{5}{|c|}{$\begin{array}{l}\text { *Includes } 20 \% \text { growth factor. } \\
\text { Baseline RSI weight used for comparison is } 7,321 \mathrm{Kg}(16,139 \mathrm{lb}) \text { (From Space } \\
\text { Shuttle Orbiter Mass Properties Status Report, Rockwell International ST\&SG, } \\
\text { SD 72-SH-0120-102, May 1981.) }\end{array}$} \\
\hline
\end{tabular}




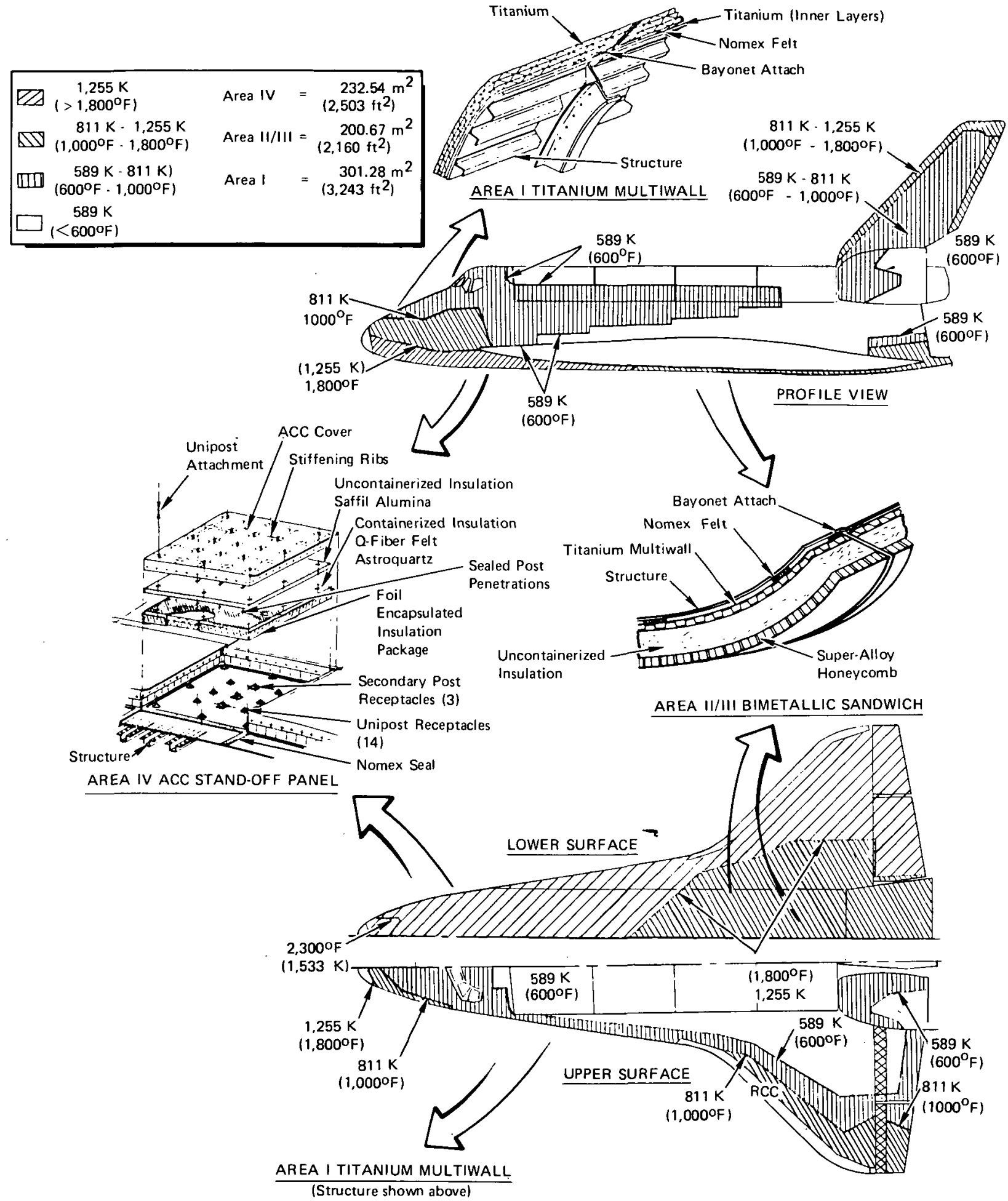

Figure 36. Application of Selected Concepts 


\section{Page intentionally left blank}

\section{Page intentionally left blank}




\section{OBJECTIVE 2: TECHNOLOGY REQUIREMENTS}

The second major objective in the Alternate Thermal Protection system (ATPS) study was to identify voids and deficiencies in the concept and system technology, along with recommended activities to eliminate the voids and deficiencies and bring the system to operational readiness.

A two-day technology review was conducted during the latter stages of the design and analysis activities at Langley Research Center (LaRC). The objectives of the review were to (1) define the technology status for each concept, (2) assess the technical risks of each concept, and (3) provide a relative ranking of the concepts. Representatives from each of the team members, as well as the LaRC study team, participated.

Figure 37 presents the event network that was established as the flow of events required to qualify an alternate TPS for the orbiter. Blocks 1 through 6 of the flow are considered to be R\&D efforts; blocks 7 through 10 relate to DDT\&E efforts.

The review used a three-point index to grade activity toward milestone achievement within each concept's program flow--an "0" grade was assigned where no work had been completed; a "1" rating was assigned where some work had been done, but additional work would be required to complete the event milestone; or a " 2 " rating was assigned where sufficient work had been completed to permit progressing to the next event milestone. All grading was eventually assigned by consensus engineering judgment among the technologists after allowing extended periods for an exchange of opinion.

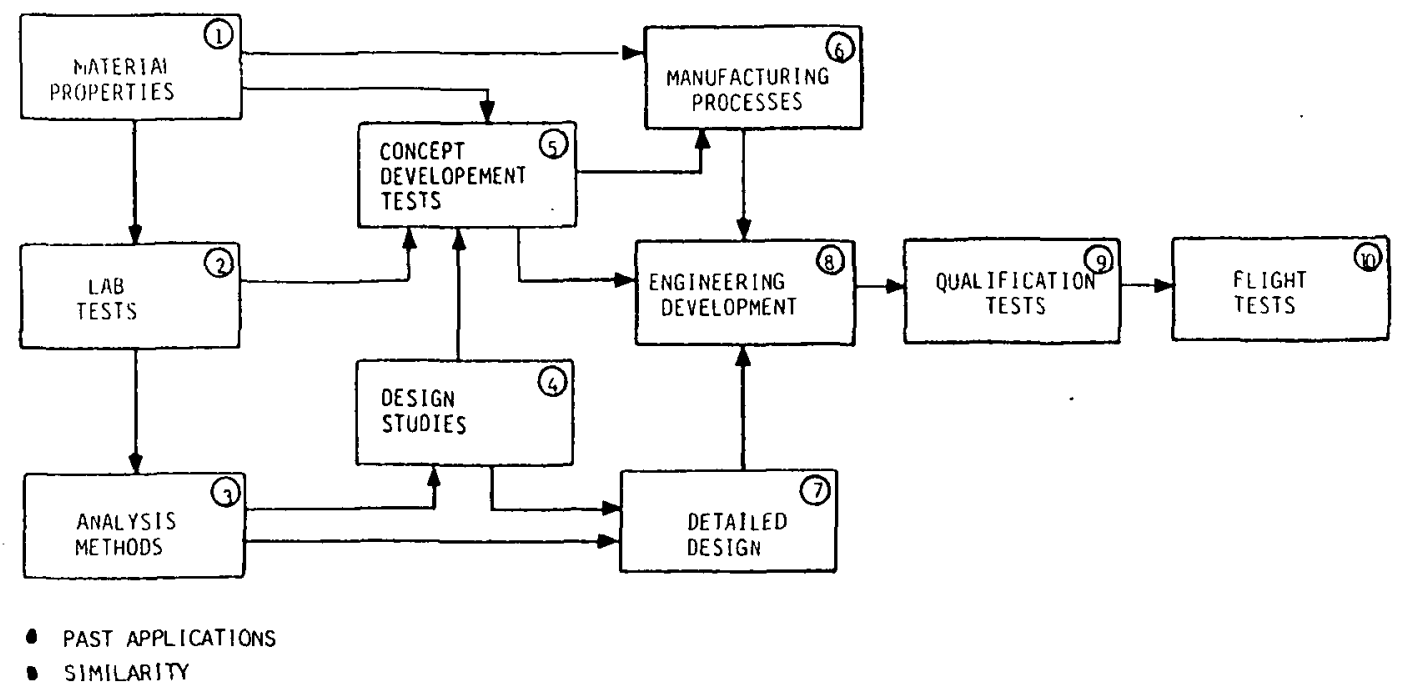

Figure 37. Flow of Events Required to Qua1ify an Alternate TPS for the Orbiter 
Table 5 shows the technology status of five promising concepts for each of the events in the network. Each of the five concepts shown had, during Task 2, been considered as components of equivalent "best" alternate configurations. The prepackaged titanium multiwall for potential application on acreages at less than $811 \mathrm{~K}\left(1,000^{\circ} \mathrm{F}\right)$ and the standoff advanced carbon-carbon concept for potential acreage application in the highest temperature regime are common to a 11 derivatives of the best ATPS. In mid-temperature $(811 \mathrm{~K}$ to $1,366 \mathrm{~K})$ acreages, however, the final selection between a prepackaged bimetallic sandwich concept, a stand-off superalloy isogrid concept, and a superalloy honeycomb concept was still under consideration (the decision later reduced to pragmatic "on-going efforts" criteria favoring bitallic sandwich).

Table 5. Concept Technology Status Selected Concepts

0 - None available 1 - Some available 2 - Adequate available

\begin{tabular}{|c|c|c|c|c|c|c|}
\hline \multirow{2}{*}{\multicolumn{2}{|c|}{ Item }} & \multicolumn{5}{|c|}{ Status by Concept* } \\
\hline & & $\frac{\text { IAA }}{2}$ & $\frac{I I / I I I A D}{2}$ & $\frac{I I / I I I B C}{2}$ & $\frac{I I / I I I B D}{2}$ & $\frac{\text { I VBH }}{1}$ \\
\hline $\begin{array}{r}1 \\
2 \\
3 \\
4 \\
5 \\
6 \\
7 \\
8 \\
9 \\
10\end{array}$ & $\begin{array}{l}\text { Material properties } \\
\text { Lab tests } \\
\text { Analysis methods } \\
\text { Design studies } \\
\text { Concept development tests } \\
\text { Manufacturing process } \\
\text { Detailed design } \\
\text { Engineering development } \\
\text { Qualification tests } \\
\text { Flight test }\end{array}$ & $\begin{array}{l}2 \\
1 \\
1 \\
2 \\
1 \\
2 \\
0 \\
0 \\
0 \\
0\end{array}$ & $\begin{array}{l}2 \\
1 \\
2 \\
1 \\
0 \\
1 \\
0 \\
0 \\
0 \\
0\end{array}$ & $\begin{array}{l}2 \\
1 \\
2 \\
1 \\
0 \\
1 \\
0 \\
0 \\
0 \\
0\end{array}$ & $\begin{array}{l}2 \\
2 \\
2 \\
1 \\
1 \\
1 \\
0 \\
0 \\
0 \\
0\end{array}$ & $\begin{array}{l}1 \\
1 \\
2 \\
2 \\
0 \\
1 \\
0 \\
0 \\
0 \\
0\end{array}$ \\
\hline & $\begin{array}{l}\text { *Concept Legend: } \\
\text { IAA: Titanium Multiwal } \\
\text { II/IIAD: Superalloy Bin } \\
\text { II/IIIBC: Superalloy I } \\
\text { II/IIIBD: Superalloy Hc } \\
\text { IVBH: Carbon-Carbon St }\end{array}$ & $\begin{array}{l}\text { allic } \\
\text { rid St } \\
\text { ycomb } \\
\text {-off }\end{array}$ & $\begin{array}{l}\text { Sandwich } \\
\text { and-off } \\
\text { Stand-off }\end{array}$ & & & \\
\hline
\end{tabular}

Comparison of the flow of events required to qualify an ATPS with the concept technology status reveals that all of these concepts are still in the early development stage and that considerable efforts remain to bring any concept to a matured, flight-worthy status. This comparison of event milestones required with current technology status highlighted the detailed tasks remaining to be accomplished to bring each concept through the first five or six steps of its program (Phase A, Concept Design, and Phase B, Advanced Development) and served as the basis for developing the R\&D recommendations for each concept. 
As an added information bonus, the technology review involved extensive discussions of the technical development risks associated with each concept, and the potential impacts of those development risks on each concept's DDT\&E cost and schedule. These data were summarized earlier in this report as factors involved in selection of the best ATPS configuration.

\section{RESEARCH AND DEVELOPMENT RECOMMENDATIONS}

The objective of this section is to identify programs that would eliminate voids and deficiencies in the technology. All activities are Phase A (R\&D) type studies, related to Blocks 1 through 5 of the Technology Status Flow (Figure 37).

There are recommendations that are common to all concepts in the systems, as well as recommended programs specifically addressed to individual concepts. Priorities are assigned to the recommended programs. Potential orbiter experiments (OEX) applications are discussed utilizing the selected system.

\section{Systems R\&D Recommendations}

Ensuing sections are pertinent to all selected concepts, except where noted. Most items pertain to information enhancement. The status of existing data is presented with identification of the required information.

Insulation Materials. This study is proposed to satisfy requirements for al1 concepts utilizing fibrous batt insulation. While a vast amount of data exist on fibrous insulation materials, the bulk of pertinent data was generated by McDonne 11 Douglas in the 1970 to 71 time period under Contract NAS8-26115. The effects of thermal exposure followed by induced vibration were a major evaluation test in the study. Although other thermal performance data were generated, not all of the materials of current interest were included and the effect of reduced pressures on conductivity is incomplete.

A supplemental study is proposed wherein the data base would be completed for candidate materials, including: TG 15000, Astro-quartz, Micro-quartz (Q-Fiber Felt), Dynaflex (Cerrachrome), Fiber Frax H, Saffil Alumina, Durablanket, and zirconia felt. Testing is to encompass measurement of conductivity as a function of temperature, pressure, and insulation density. Additional data on the effect of acoustic loading following thermal exposure would be generated. Additionally, the effectivity of radiation barriers interspersed in very low-density insulations would be investigated.

Surface Roughness Effects. The status of ATPS is that current Shuttle orbiter smoothness criteria are exceeded either: (1) as installed or (2) due to the distortions of panels under the influence of thermal and pressure loads. These conditions could result in localized heating or a more serious circumstance, early transition to turbulent flow. 
Data from the orbiter flight would be assessed in order to refine the analytical methods for predicting surface roughness effects on aeroheating in one of the efforts. A program to quantify, at the prototype leve1, panel displacement effects on aeroheating should be conducted along with analysis. Analytical investigation of the benefits of trajectory variation on minimizing thermal gradients (and thereby panel distortion) is a third program to be considered.

Materials Properties. Basic materials properties are well established for the metallic materials. However, expansion of data in several areas is desirable. One is the information on the potential degradation of thin foil stock during processing and service. Another is expansion of the creep resistance data base, particularly under the low stresses encountered at maximum temperatures during re-entry. A third area requiring expansion of available data is the performance of high emissivity coatings at temperatures above $1144 \mathrm{~K}\left(1,600^{\circ} \mathrm{F}\right)$.

Materials properties for advanced carbon-carbon (ACC) have been identified as a gap in the technology. A program is needed to establish a preliminary design data base, particularly for thin composites ( 5 to 8 plies). Variables should include determination of the effects of different carbon fibers, matrix builder materials, number of plies, and different coating materials. Evaluation of ACC after thermal exposure is a necessary adjunct to these investigations.

A necessary corollary program is generation of materials properties for high temperature fastener stock. Dispersion strengthened alloys are proposed for fasteners where service temperatures are $1533 \mathrm{~K}\left(2,300^{\circ} \mathrm{F}\right)$ or less and coated colombium fasteners are expected to be used above $1533 \mathrm{~K}\left(2300^{\circ} \mathrm{F}\right)$. Testing should include determination of properties at service temperatures before and after simulated service exposure. An investigation of special thread forms for coated small diameter columbium fasteners is desired.

Inspection, Test, and Repair of Systems. A wide range of non-destructive evaluation (NDE) techniques is available for structural shapes and configurations. However, an investigation of the applicability of the NDE methods to alternate thermal protection systems is required. As an example, such NDE methods as radiography, holography, thermographics, and ultrasonics should be applied to: the detection of detached bonds, the condition of insulation and insulation packages, the integrity of the attachments, and subsurface defects and/or mass loss in carbon-carbon.

Circumstances often dictate systems functional testing in lieu of inspection. The pertinence of systems functional simulation tests to the end requirement has been proven for a variety of structural configurations. Examples include pressure proof testing of high efficiency pressure vessels and pull proof testing of tiles on the orbiter. A pressure proof test of prepackaged ATPS could assure the existence of sufficient bond integrity to accomplish its function. Testing is required for determination of the specific levels of pressure to be used; however, the nominal requirement would be on the order of 1.25 times the maximum internal (burst) pressure encountered in flight. 
Tracer tests are different in that pieces of the same material as the structure of interest are positioned so that the test pieces see the same environment as the structure. After a suitable period of time, i.e., flights, these test pieces are removed and subjected to evaluative procedures, including destructive testing. The results indicate the rate of degradation of the test piece and, therefore, the structure. Advanced carbon-carbon (ACC) is subject to subsurface degradation (mass loss) in the intermediate temperature range with a resultant loss of mechanical strength. A proposal has been made to use detachable flanges (seals) on ACC panels. With used sampling methods, flanges would be removed selectively after a pre-determined number of flights and sent to the laboratory for evaluation. Test results would give the rate of mass loss for the panel/body point. A similar system, using test buttons, is utilized on baseline orbiter for monitoring reinforced carbon-carbon (RCC) leading edge components, particularly on flanges operating at moderate (most damaging) temperatures. Testing is required to obtain degradation rates.

ATPS system repair is a necessary adjunct to successful accomplishment of operational goals. The applicability of available repair techniques to the selected concepts should be demonstrated. Such techniques as indirect resistance welding, plasma sprayed doublers (all metallics), and coating repair (ACC and coated columbium fasteners) need to be investigated.

Moisture Intrusion. Operational circumstances require the consideration of the presence of moisture, in the form of rain water or as moist air, and the need for encapsulation of the fiberous insulation. The configuration of the individual concepts dictates the manner in which water intrusion occurs; however, the fibrous insulation constitutes the major retention feature. It is proposed that laboratory-scale arrays ( 2 to 3 panels) of each concept be subjected to: (1) deluge rain water tests, and (2) venting ingestion tests in moist air environments. Each test will include such factors as water-proofing (including heating effects on the water proofing agent) and drying rates after exposure.

\section{Concept Specific R\&D Recommendations}

Programs for the individual concepts should include the fabrication and inspection of sufficient panels in the concept of interest to achieve prototype scale arrays. Testing for the arrays should include simulated service environmental exposure using radiant heat and wind tunnel facilities. These evaluations will permit the early identification of interaction mechanistic effects in order to resolve systems design integration considerations.

\section{Priority Assignment of R\&D Recommendations}

An order of priorities has been established for the recommendations. The 1 ist is as follows:

1. Develop detailed test plans, designs, and analyses of concept development test specimens. 
2. Perform required laboratory tests to complete preliminary materials and processes data base for: (a) advanced carbon-carbon properties, (b) thermal conductivity values for fibrous insulation, and (c) bimetallic diffusion bonded joints.

3. Fabricate panel arrays and conduct concept developmental tests to: (a) demonstrate manufacturing procedures, (b) obtain performance characteristics, and (c) verify analytical predictions.

4. Assess applicable inspection, test, and repair techniques.

5. Enhance the materials data base and initiate investigations toward optimized materials.

\section{Orbiter Experiments (OEX) Applications}

As the ATPS concepts and systems mature through the R\&D cycle, it becomes increasingly important to contemplate the actual demonstration of applicability by Shuttle orbiter flight testing. Conceptually, an array would be fabricated and installed, preferably on components that could be interchanged during Shuttle orbiter turnaround. These components might be doors, such as the nose landing gear and main landing gear doors. The benefits of an oEx program are as follows:

1. The concept matures through an actual fabrication and certification cycle.

2. Design requirements for production are defined.

3. Interfacing with baseline TPS demonstrate retrofitability.

In summary, the voids and deficiencies in the technology that were defined in the technology review can be eliminated by the research and development (R\&D) activities identified. The activities appear to be feasible and no "show stoppers" were identified. 


\section{OBJBCTIVE 3: PROGRAM PlaNS, COSTS, AND SChEDULBS}

The third objective of the ATPS study is to prepare plans, schedules, and cost estimates for the required $R \& D$ and design, certification, fabrication, installation, and maintenance of the selected system.

Concept development plans and programmatics were synthesized by the Alternate Thermal Protection System (ATPS) study team in conjunction with NASA/LaRC from the results of earlier detailed analyses. Specific plans for each concept's fabrication, quality assurance, installation, certification, and maintenance, along with its technology status and remaining R\&D requirements, were considered in estimating the DDT\&E program schedule and ROM cost for the best ATPS identified.

The primary comparative advantages of the selected ATPS over the other five configurations examined within the study's constraints are its lower investment cost and lower weight. This alternate, a hybrid consisting of prepackaged metallic and standoff carbon-carbon, as shown in Figure 36 , offers a significant potential improvement in durability relative to the baseline RSI tiles and appears to be weight competitive with the existing $T P S$ as shown in Table 4 even with an allowance for possible weight growth as the transition from "paper" to hardware is made.

The detailed concept technology status review (Table 6) conducted in Study Task 2, which led to identification of each concept's technology requirements and to recommendation of $R \& D$ programs to resolve those deficiencies as outlined earlier in this report, also formed one basis for estimating the front-end programmatic schedule and ROM cost for the selected ATPS.

DDT\&E ROM schedules for each of the three concepts encompassed by the hybrid best ATPS are shown in Figure 38. Both prepackaged metallic concepts (titanium multiwall and bimetallic sandwich) are funded as on-going R\&T programs under NASA/LaRC contract with Rohr Industries at the present time. Therefore, a Phase B (advanced development) go-ahead appears feasible for a Calendar 1983 start if sufficient funding were provided in the FY 1983 appropriation. On-going R\&T efforts on the stand-off advanced carbon-carbon concept for high temperature zone usage are currently limited to Vought's continuing, internally funded, development and would probably require one appropriation cycle under normal circumstances to fund and start up the requisite Phase $A$ (approximately $\$ 5$ million, 1980 constant) activities.

ROM DDT\&E program schedules for both metallic concepts were originally estimated by Rohr in a programmatic "network" cost/schedule structure, and were refined by the results of technology status review; by the enabling research requirements remaining to be done; by the specific development plans for manufacturing, quality assurance, certification, and installation; and by 
FY 1982 funding levels provided for the R\&T effort. Long-lead-time procurement of titanium material is a concern in Phase B and Phase $C$ of the DDT\&E programmatics for both metallic concepts. However, no other capacity or technology development 1 imitations were identified.

Table 6. Technology Status

\begin{tabular}{|c|}
\hline TITANIUM MULTIWALL \\
\hline $\begin{array}{l}\text { LaRC/Rohr development program } \\
\text { - Design studies } \\
\text { - } 9 \text { pane } 1 \text { array tested (concept development) } \\
\text { - } 12 \text { panel array planned (concept development) } \\
\text { - OEX flight test planned }\end{array}$ \\
\hline SUPERALLOY SANDWICH \\
\hline $\begin{array}{l}\text { LaRC/Rohr Development Program } \\
\text { - Design studies } \\
\text { - Manufacturing process (bimetallic diffusion bonding process) } \\
\text { - Panel fabrication and testing (concept development) }\end{array}$ \\
\hline ACC MULTIPOST \\
\hline $\begin{array}{l}\text { - Design studies (Vought, LaRC, JSC) } \\
\text { - Manufacturing process (similar to RCC) } \\
\text { - Panel fabrication }\end{array}$ \\
\hline
\end{tabular}

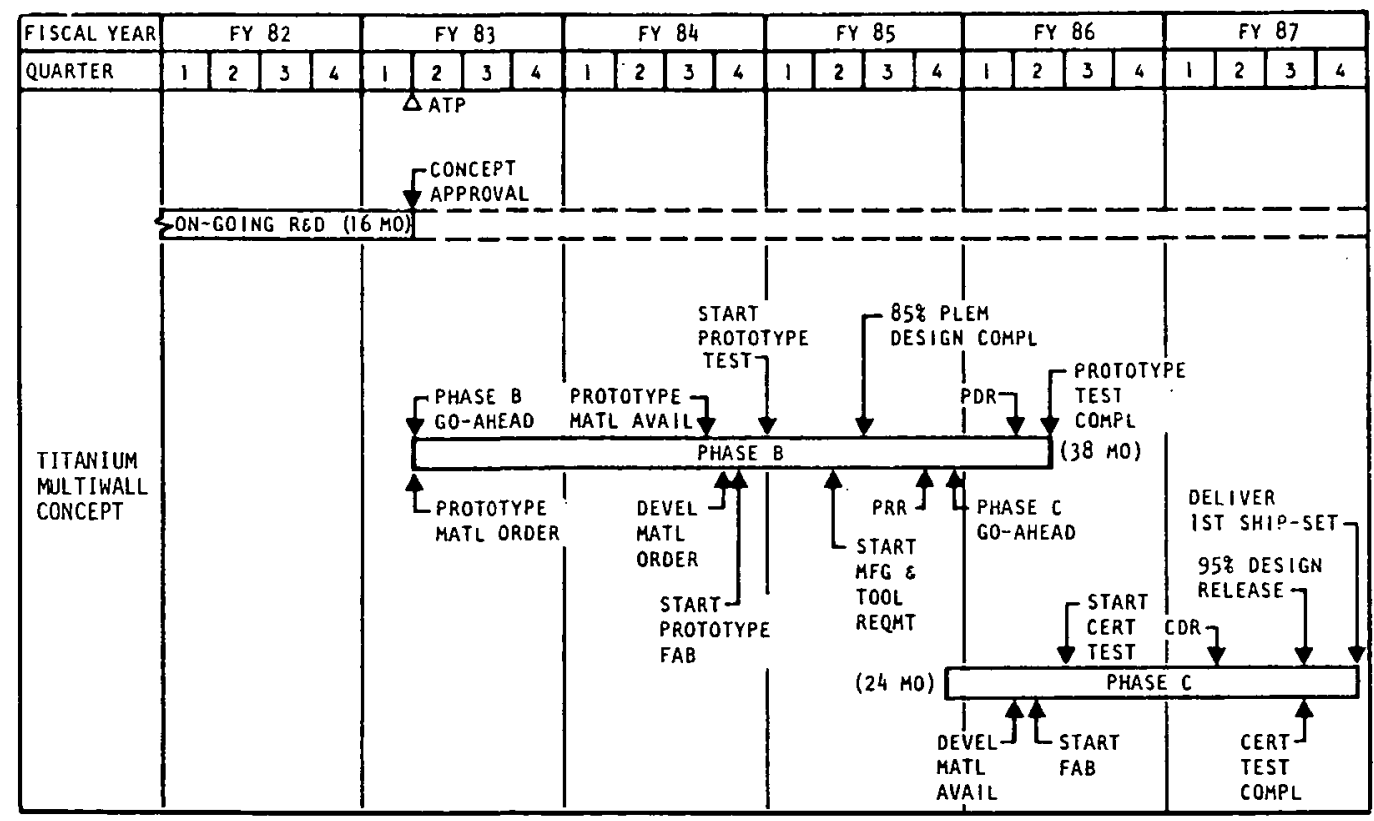

Figure 38. Advanced TPS ROM Master Schedule (Sheet 1 of 3) 


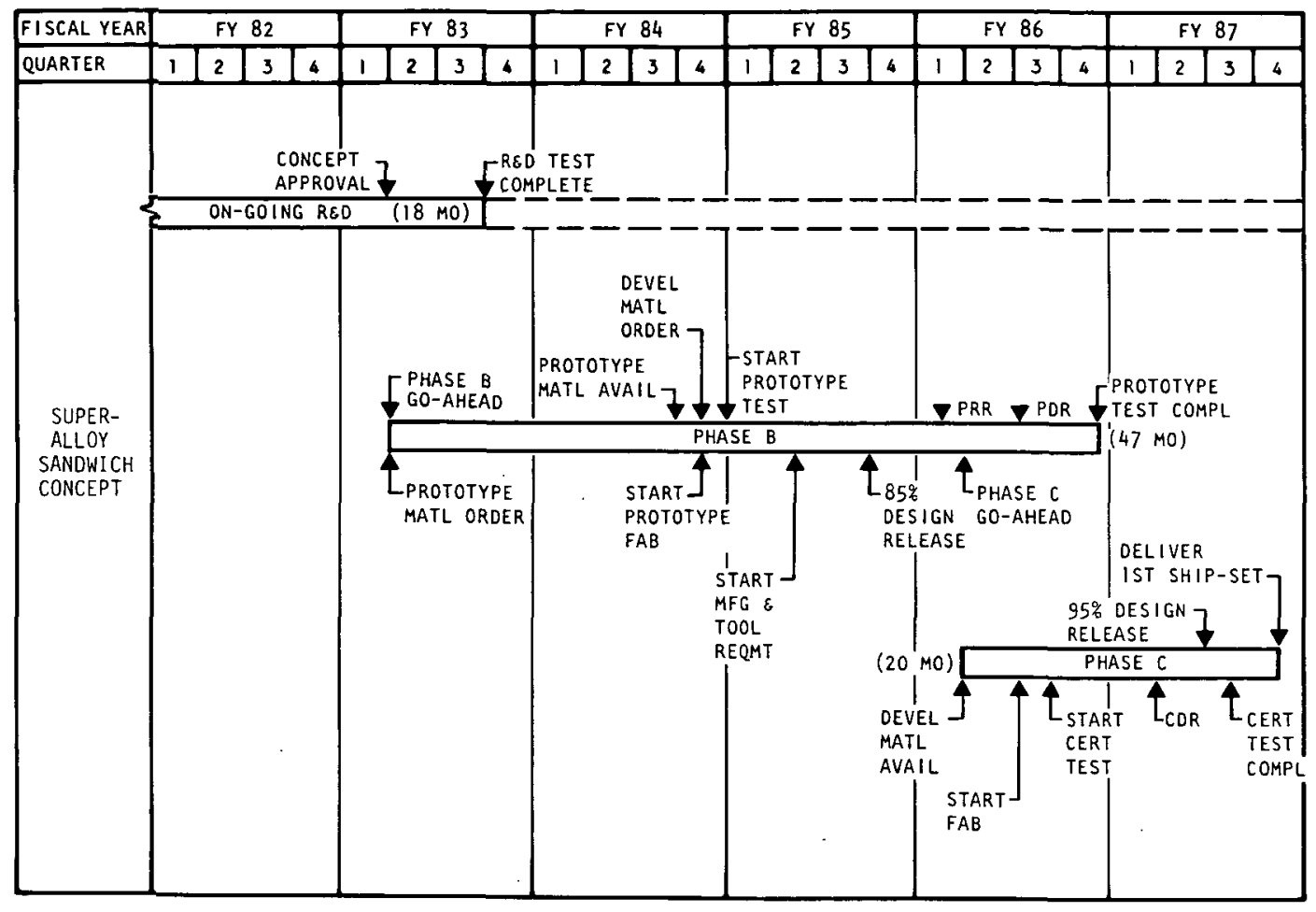

Figure 38. Advanced TPS ROM Master Schedule (Sheet 2 of 3)

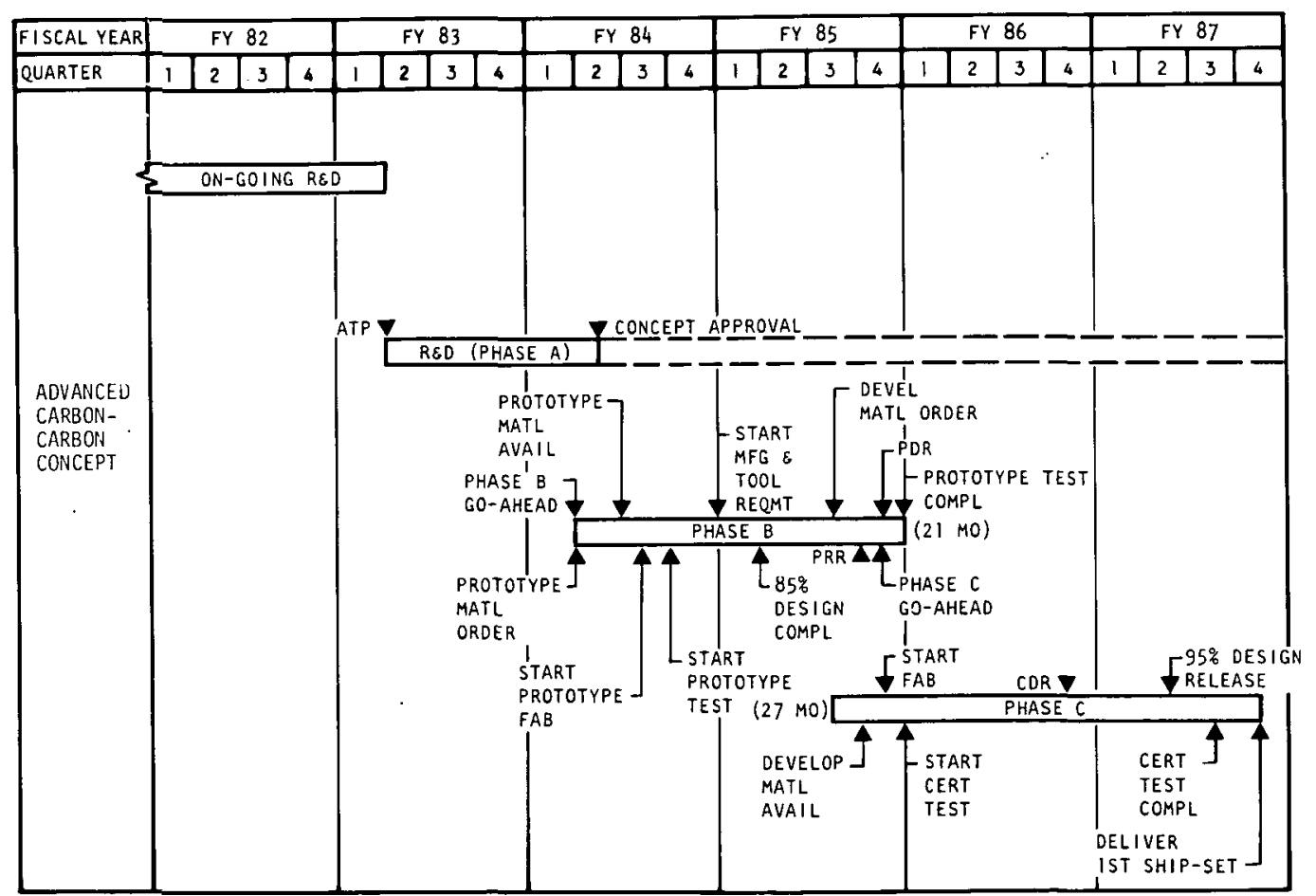

Figure 38. Advanced TPS ROM Master Schedule (Sheet 3 of 3) 
ROM DDT\&E program schedules for the advanced carbon-carbon concept were originated by Vought and were materially revised to reflect funding realities (contracted Phase A slipped to FY 1983 start) and for developmental risk reduction (Phase $A, B$, and $C$ overlaps were reduced). Contractual R\&T appropriation lead times are a major consideration, but no other capacity or technology impediments were identified.

The cost breakdown structure (CBS) used for ROM cost estimation in the ATPS study is essentially identical to the CBS used for cost accumulation on the RSI and RCC components of the thermal protection system for 0V-102. This CBS similarity allowed estimates of ROM costs and schedules for each concept to be directly compared to realized cost experience on the existing TPS and provided one of several bases for "reasonability" checks built into the study's ROM estimating procedure.

The bases of ROM cost estimates used in the ATPS study were the "subcontract material" manufacturing cost estimates provided by Rohr Industries for the prepackaged metallic concepts and by Vought for the advanced carbon-carbon concept. For each concept studied, two different estimating structures were used. An "acreage" estimate--DDT\&E manufacturing cost for $46.45 \mathrm{sq}$ $(500 \mathrm{sq} f t), 232.26 \mathrm{sqm}(2500 \mathrm{sq} f t)$, and $464.52 \mathrm{sq} \mathrm{m}(5000 \mathrm{sq} f t)$ of panelized material--allowed costs to be segregated into "fixed" and "variable" components. A network estimate--DDT\&E manufacturing cost for the same events characterized in the technology status flow--allowed costs to be identified with subcontractor progress milestones. One major adjustment to the team-member-generated manufacturing cost estimates--provision for prototype fabrication and test--was made to ensure comparability between estimates.

After adjustment of each concept's subcontract material manufacturing cost estimate for prototypes and solution of the manufacturing cost equation for appropriate acreage application, upward expansion through the cost breakdown structure to the concept DDT\&E investment cost level was accomplished by use of parametric relations established from the RSI and RCC program experiences. These parametric cost estimating relations (CER's) generated ROM costs for prime contractor manufacturing involvement, for subcontractor and prime contractor engineering effort, and for overall concept contribution to ATPS installation and certification costs.

Following the parametric expansion from concept manufacturing cost to concept DDT\&E investment cost, ATPS ROM DDT\&E investment cost was derived by summation across the three concepts. A series of "sanity" checks was built into the ROM cost estimating procedure, including: (1) actual cost experience on similar materials, (2) analyses of relative manufacturing complexities, and (3) breakdown of engineering costs to the headcount, functional discipline, and program year levels.

ROM direct operating and support costs were estimated as an integral portion of the study's reliability/maintainability analyses of concept expected failure modes and expected failure rates.

ROM investment cost and ROM direct $0 \& S$ cost for both 3 shipset and 5 shipset ATPS programs were estimated by cost reduction (learning) curves applied to first unit costs. 
Ground rules and assumptions underlying the ROM cost analysis are as follows:

- Estimates are rough order of magnitude (ROM).

Developed from three acreage estimates for each concept

Concept estimates refined by DDT\&E "network"

DDT\&E estimates adjusted for comparability and completeness

Assume "normal" DDT\&E program schedule

- Estimates adjusted to, or expressed in, undiscounted 1980 million dollars unless otherwise noted.

Escalation factors, where used, supplied by NASA

Inflated ATPS DDT\&E ROM costs assume 1982 start

- Manufacturing costs (Rohr and Vought) are basis of ROM costs.

Adjusted to obtain consistency with manufacturing complexity

- Engineering, integration, and installation estimates are parametric.

- Investment and O\&S spares estimated by cost reduction curves for

3 and 5 ov shipset programs.

- Prototype fabrication and test - DDT\&E network adjustment.

Assumed at 20 percent of first shipset procurement, fabrication, and assembly for all concepts

- Engineering - cost breakdown structure adjustment.

Assumed equivalent with manufacturing complexity on all metallic concepts; equivalent to actual experience on carbon-carbon concept

- Provision for installation/certification included.

- Economic valuation of ground turnaround time, ov "stand-down", and mass change is not included.

Table 7 summarizes the ATPS and concept DDT\&E ROM investment costs for each of the three concepts composing the selected ATPS. R\&T cost estimates for both the titanium multiwall and bimetallic sandwich concepts were provided by NASA/LaRC, and represent additional funding required to be added to the current ongoing activity; and subcontract material manufacturing costs for both concepts were estimated by Rohr Industries. R\&T cost and subcontract material manufacturing cost estimates for the advanced carbon-carbon concept were provided by Vought. Prime contractor manufacturing, total engineering, and total other costs were estimated by parametric relations from the Rockwell RSI (Lockheed subcontract) and RCC (Vought subcontract) data base with differences in manufacturing, engineering, and DDT\&E other proportions due to differences in subcontract structures. 
Table 7. Selected ATPS ROM Investment Cost, DDT\&E Summary

( $\$ 1980$ million constant)

\begin{tabular}{|l|c|c|c|c|c|}
\hline \multicolumn{1}{|c|}{ Concept } & R\&T & Manufacturing & Engineering & $\begin{array}{c}\text { DDT\&E } \\
\text { Other }\end{array}$ & $\begin{array}{c}\text { DDT\&E Total } \\
\text { ROM Cost }\end{array}$ \\
\hline $\begin{array}{l}\text { Titanium } \\
\text { multiwa1l } \\
\text { (Area I) }\end{array}$ & 0.7 & 11.8 & 14.6 & 2.5 & 29.5 \\
\hline $\begin{array}{l}\text { Bimetallic } \\
\text { sandwich } \\
\text { (Area II/III) }\end{array}$ & 0.6 & 13.7 & 17.0 & 2.8 & 34.1 \\
\hline $\begin{array}{l}\text { Carbon-carbon } \\
\text { stand-off } \\
\text { (Area IV) }\end{array}$ & 5.5 & 21.6 & 18.7 & 0.2 & 45.9 \\
\hline System & 6.8 & 47.0 & 50.2 & 5.5 & 109.5 \\
\hline
\end{tabular}

Figure 39 shows the total cumulative DDT\&E program cost profile in both constant $\$ 1980$ million and "then-year" $\$$ million, the latter escalated at NASA-supplied rates. Each of the individual concept ROM cost estimates was spread across its own DDT\&E schedule with an even distribution of 40 percent engineering and 60 percent manufacturing during Phase A, a $60: 40$ ogive distribution of remaining engineering costs during Phases $B$ and $C$, and a 20:80 ogive distribution of remaining manufacturing costs across Phases $B$ and $C$. Total other costs, primarily associated with installation and checkout activities, were spread evenly across the nine-month ATPS installation period.

The study's analysis of direct operation and support cost per flight, as shown in Table 8 , was based on failure mode and failure rate data provided by Rohr Industries for the prepackaged metallic concepts and by Vought for the advanced carbon-carbon concept as part of the merit function questionnaire response. Minor clarifications and modifications to the original responses resulted from Rockwell's in-house ATPS reliability/maintainability analysis, especially as regards inspection requirements for each concept.

By design, the selected ATPS configuration requires relatively low levels of labor for inspection and repair between flights. Therefore, labor costs per flight constitute only about 2 percent of direct $0 \& S$ cost per flight, with spares costs composing the remainder. Since repair of any advanced carbon-carbon concept panel is expected to require factory repair with a lengthy spares pipeline delay and since no commonality of advanced carbon-carbon panels has been assumed, it appears probable that sparing policy would require one complete shipset on-site. This cost component, which is likely to be front-end rather than recurring, has been amortized as a recurring cost over 300 flights for analytic purposes. 


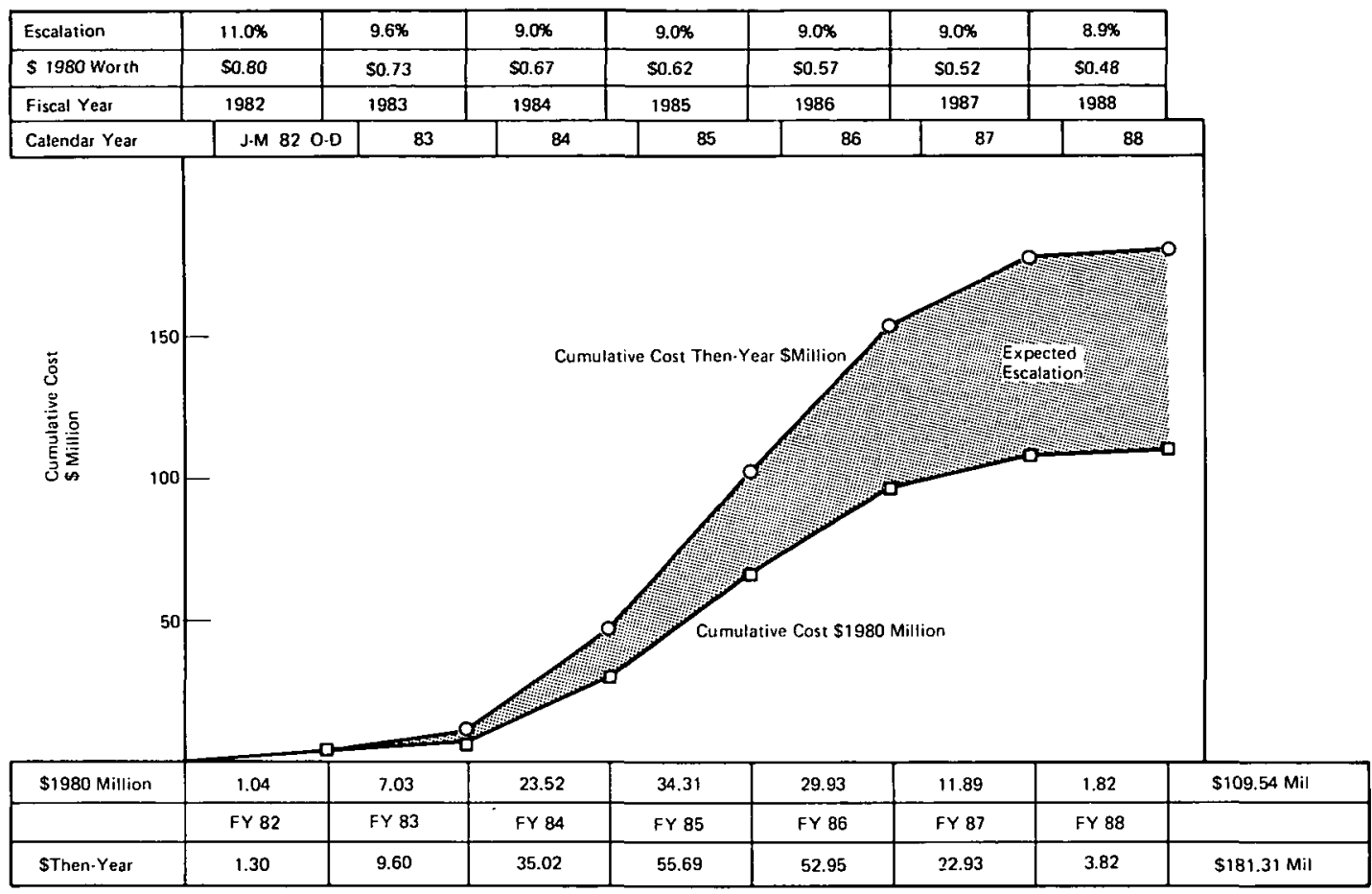

Figure 39. Program Funding Requirements - Best ATPS

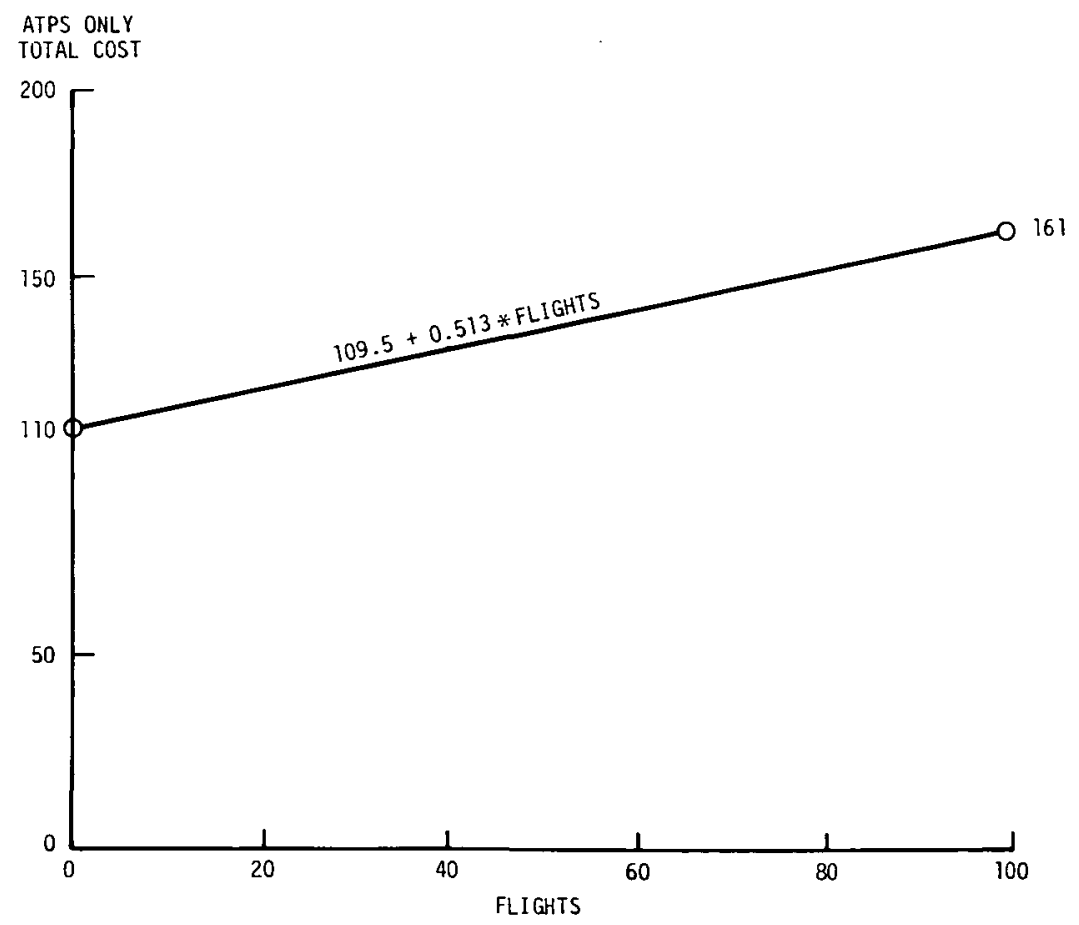

Figure 40. ATPS Only (No STS Valuation) ROM

Total Cost, DDT\&E 
Table 8. Direct Operation and Support Cost Per Flight

\begin{tabular}{|c|c|c|c|c|c|c|c|c|}
\hline Concept & $\begin{array}{l}\text { Inspect } \\
\text { MH/F1t }\end{array}$ & $\begin{array}{l}\text { Maintain } \\
\text { MH/Flt }\end{array}$ & $\begin{array}{l}\text { Labor } \\
\text { Cost } / F 1 t\end{array}$ & $\begin{array}{l}\text { Condemn } \\
\text { Rate/F1t }\end{array}$ & $\begin{array}{l}\text { No. Panels } \\
\text { Condemn }\end{array}$ & $\begin{array}{l}\text { Average } \\
\text { Cost/Panel }\end{array}$ & $\begin{array}{l}\text { Spares } \\
\text { Cost/Fit }\end{array}$ & $\begin{array}{l}\text { Total Direct } \\
\text { OdS Cost/Flt }\end{array}$ \\
\hline $\begin{array}{l}\text { Titanium } \\
\text { multiwall }\end{array}$ & 178.4 & 36.8 & 6,456 & 0.005 & 17.8 & 9,102 & 162,355 & $\begin{array}{l}(\$ \text { million }) \\
0.169\end{array}$ \\
\hline $\begin{array}{l}\text { Bimetallic } \\
\text { sandwich }\end{array}$ & 59.4 & 12.5 & 2,156 & 0.005 & 11.9 & 15,800 & 187,704 & 0.190 \\
\hline $\begin{array}{l}\text { Carbon-carbon } \\
\text { standoff }\end{array}$ & 16.1 & 43.8 & 1,797 & \multicolumn{3}{|c|}{$\begin{array}{l}\text { Full shipset spares } \\
\text { amortized over } 300 \text { flights. }\end{array}$} & 152,993 & 0.155 \\
\hline ATPS & 254 & 93 & 10,409 & & & & 503,052 & 0.513 \\
\hline
\end{tabular}

Figure 40 combines the ATPS ROM investment cost (intercept) and direct operation and support cost per flight (slope) to derive ATPS ROM total cost for the DDT\&E shipset extended to its probable maximum useful life of 100 missions. At the 100-mission mark, however, one full shipset of usable advanced carbon-carbon would remain in spares inventory for subsequent or concurrent use on any greater program quantity.

ROM investment costs for ATPS shipset quantities up to a total of 5 are shown in Table 9. R\&T activities for all three concepts are assumed to be complete before the end of DDT\&E and include approximately half the total provision for prototype manufacture and test. Prototype activity is expected to continue beyond the DDT\&E shipset, though at diminishing levels. Production costs follow a low-slope 98 percent cost-reduction (learning) curve because of the highly automated nature of the overall manufacturing process. Both engineering and other (including installation) costs reflect somewhat higher learning impacts; however, both the uniqueness of each ov configuration and the heavy requirement for sustaining engineering (man-rated system) mitigate against the assumption of a steeper cost reduction effect than the 90 percent slope used.

Table 9. Selected ATPS ROM Investment Cost, Program Quantity ( $\$ 1980$ Million Constant)

\begin{tabular}{|c|c|c|c|c|c|c|c|}
\hline \multirow[b]{2}{*}{ Shipset } & \multirow[b]{2}{*}{ R\&T } & \multicolumn{2}{|c|}{ Manufacturing } & \multirow[b]{2}{*}{ Eng ineering } & \multirow[b]{2}{*}{ Other } & \multirow{2}{*}{$\begin{array}{c}\text { Shipset } \\
\text { Cost }\end{array}$} & \multirow{2}{*}{$\begin{array}{l}\text { Cumulative } \\
\text { Investment }\end{array}$} \\
\hline & & Prototypes & Production & & & & \\
\hline DDT\&E 1 & 6.8 & 1.6 & 45.4 & 50.2 & 5.5 & 109.5 & 109.5 \\
\hline 2 & 0 & 1.1 & 44.5 & 41.4 & 5.0 & 92.0 & 201.5 \\
\hline 3 & 0 & 0.5 & 43.6 & 37.8 & 4.5 & 86.4 & 287.9 \\
\hline 4 & 0 & 0 & 42.7 & 36.2 & 4.0 & 82.9 & 370.8 \\
\hline 5 & 0 & 0 & 41.9 & 34.9 & 3.6 & 80.4 & 451.3 \\
\hline
\end{tabular}




\section{CONCLUDING REMARRS}

Design results indicate that a weight-competitive, more durable, metallic/carbon-carbon TPS for the space shuttle orbiter is viable. The metaliic and carbon-carbon concepts are not completely developed or validated. R\&D programs to mature the concepts have been defined and are recommended to provide back-up/potential improvements for the Space Shuttle orbiter and other future space transportation systems.

The "best" alternate thermal protection system considering metallics, ablators, and carbon-carbon concepts is a hybrid configuration consisting of prepackaged metallic concepts for application in the $589 \mathrm{~K}\left(700^{\circ} \mathrm{F}\right)$ to $1255^{\mathrm{K}}\left(1800^{\circ} \mathrm{F}\right)$ surface temperature areas, and a carbon-carbon stand-off concept for areas where temperatures are above $1255 \mathrm{~K}\left(1800^{\circ} \mathrm{F}\right)$. The estimated total installed investment cost for a fleet. of five vehicles is approximately 425 million dollars. Detailed programmatic analyses reveal that the availability of this system is approximately five years from authority to proceed (ATP). 
Page intentionally left blank

Page intentionally left blank 


\section{REFERERCES}

1. Varisco, Angelo; Bell, Paul; and Wolter, Willy. Design and Fabrication of Metallic Thermal Protection Systems for Aerospace Vehicles. NASA CR-145313, February 1979.

2. Greenshields, David H.: Orbiter Thermal Protection System Development. Proceedings Fourteenth Space Congress, Space Technology for Better Living, Cocoa Beach, FLA., April 27-29, 1977.

3. Stein, Bland A.; Bohon, Herman L.; and Rummler, Donald R.: An Assessment of Radiative Metaliic Thermal Protection Systems for Space Shuttle. NASA TM X-2570, 1972 .

4. Bohon, Herman L.; Shideler, John L.; and Rummler, Donald R.: Radiative Metallic Thermal Protection Systems: A Status Report. J. Spacecraft and Rockets, Vol. 14, No. 10, pp 626-631, 0ct. 1977. AIAA paper No. 77-391.

5. Kelly, H. Neale; Rummler, Donald R.; and Jackson, L. Robert: Research in Structures and Materials for Future Space Transportation Systems - An Overview. AIAA/NASA Conference on Advanced Technology for Future Space Systems. May 8-10, 1979, Hampton, VA, pp 12-23. AIAA Paper No. 79-0859.

6. Seiferth, R.W.: Ablative Heat Shield Design for Space Shuttle. NASA CR132282 , [1973].

7. Forcht, B.A.; While, D.; et.a1.: Development of a Fail Safe Design Oxidation Resistant Reinforced Carbon System for the Wing Leading Edge of a Space Shuttle Vehicle. Vought Systems Division, LTV Aerospace Corp. Phase III final report of NASA Contract NAS9-12763. Five volumes NASA CR-134139 to CR-134143, 1973 .

8. Rummler, Donald R.; and Black, William E.: Evaluation of Coated Columbium for Thermal Protection Systems Application. ASME/AIAA SAE 16 th Structures, Structural Dynamics and Materials Conference, Denver, Co., May 27-29, 1975, AIAA Paper No. 75-187.

9. Jackson, L. Robert: Mu1tiwa 11 TPS. Recent Advances in Structures for Hypersonic Flight. NASA CP-2065, pp.671-706, September 1978 .

10. Taylor, Allan H.; and Jackson, L. Robert: Thermostructural Analysis of Structural Concepts for Hypersonic Cruise Vehicles. Presented at AIAA 18 th Aerospace Sciences Meeting, Pasadena, CA, January 14-16, 1980 . AIAA Paper No. 80-0407.

11. Blair, W.; Meaney, J.E., Jr.; and Rosentha1, H.A.: Design and Fabrication of Titanium Multi-Wall Thermal Protection System (TPS) Test Panels. NASA CR-159241, February 1980 . 
12. Dow, M.B.; Tompkins, S.S.; Coe, F.: Materials and Design for Ablative Heat Shie1ds. NASA TM X-1570, 1972.

13. Haas, D.W.: Refurbishment Cost Study of the Thermal Protection System of a Space Shuttle Vehicle - Phase II. NASA CR-112034-1, 1972.

14. Thompson, R.L.; Rummel, W.D.; and Driver, W.E.: Study of Critical Defects in Ablative Heat Shield Systems for Space Shuttle. NASA CR-2010, 1972.

15. Medford, J.E.: Prediction of In-Depth Oxidation Distribution of Reinforced Carbon-Carbon Material for Space Shuttle Leading Edges. AIAA Paper 77-783, June 1977 .

16. Curry, D.M.; Johansen, K.J.; and Stephens, E.W.: Reinforced Carbon-Carbon Oxidation Behavior in Convective and Radiative Environments. NASA TP1284 , August 1978 .

17. Strouhal, George; and Tillian, Donald J.: Testing the Shuttle Heat-Protection Armor. Astronautics \& Aeronautics, Jan. 1976, pp. 57-65. 


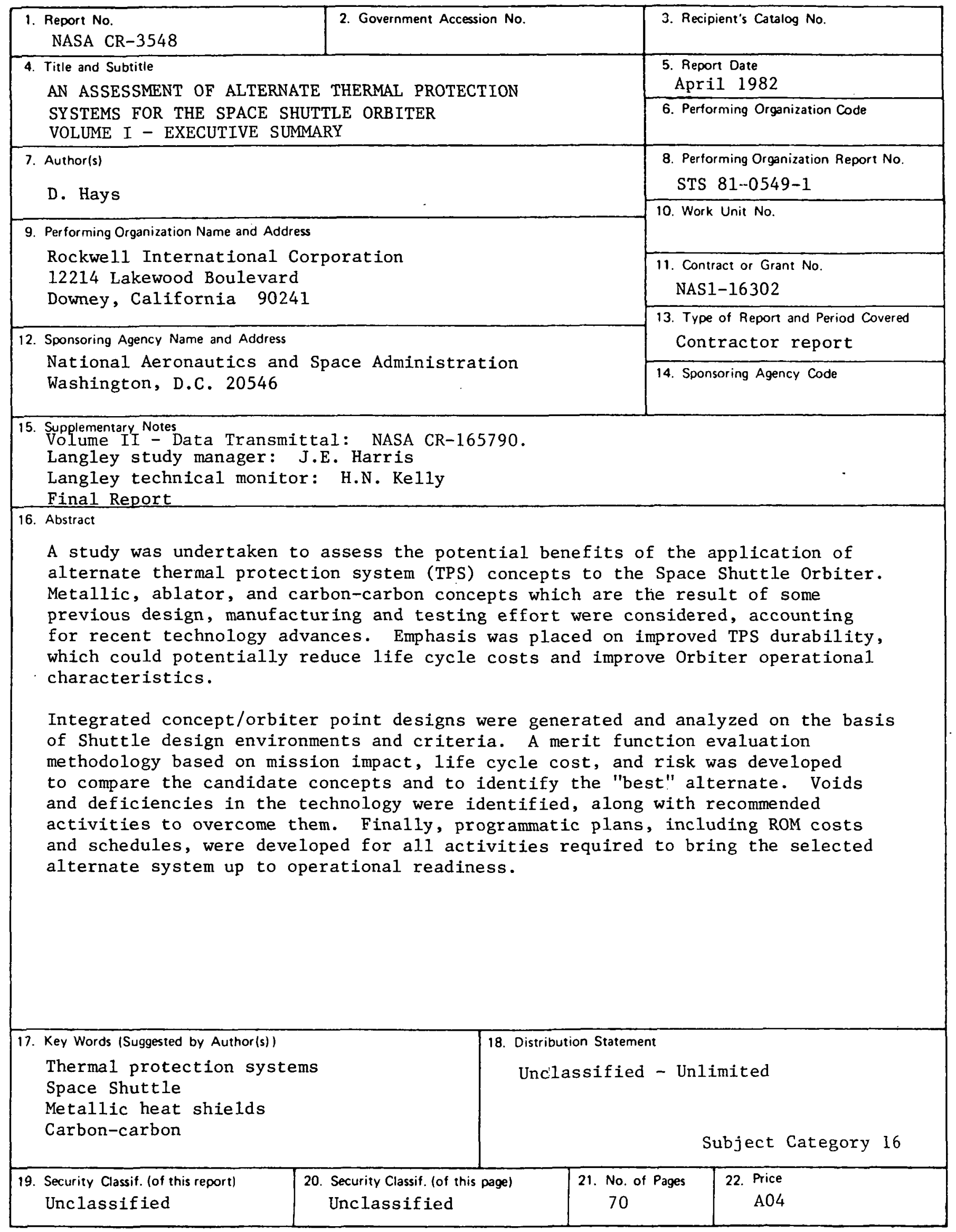

